\title{
Europa IM MitTElalter
}

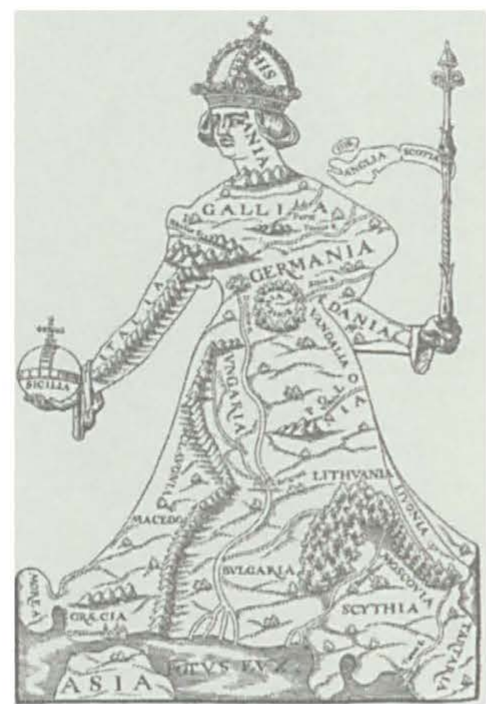

BAND 15

Abhandlungen und

Beiträge zur historischen

Komparatistik

Herausgegeben von

Michael Borgolte

\section{sppII73}

"Integration und

Desintegration der Kulturen im

europäischen Mittelalter"

Dieser Band ist aus dem Schwerpunktprogramm 1173 der Deutschen Forschungsgemeinschaft hervorgegangen. 


\section{Lateinisch-griechisch-arabische Begegnungen}

Kulturelle Diversität

im Mittelmeerraum des Spätmittelalters

Herausgegeben von

Margit Mersch und Ulrike Ritzerfeld

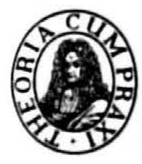

Akademie Verlag 
Gedruckt mit Unterstützung der Deutschen Forschungsgemeinschaft.

Bibliografische Information der Deutschen Nationalbibliothek

Die Deutsche Nationalbibliothek verzeichnet diese Publikation in der Deutschen Nationalbibliografie; detaillierte bibliografische Daten sind im Internet über http://dnb.d-nb.de abrufbar

ISBN 978-3-05-004664-8

(C) Akademie Verlag GmbH, Berlin 2009

Das eingesetzte Papier ist alterungsbeständig nach DIN/ISO 9706.

Alle Rechte, insbesondere die der Übersetzung in andere Sprachen, vorbehalten. Kein Teil dieses Buches darf ohne schriftliche Genehmigung des Verlages in irgendeiner Form - durch Photokopie, Mikroverfilmung oder irgendein anderes Verfahren - reproduziert oder in eine von Maschinen, insbesondere von Datenverarbeitungsmaschinen, verwendbare Sprache übertragen oder übersetzt werden.

Einbandgestaltung: Jochen Baltzer, Berlin Druck und Bindung: Druckhaus „Thomas Müntzer“, Bad Langensalza

Printed in the Federal Republic of Germany 


\section{Inhalt}

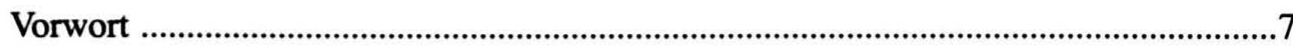

Kulturelle Diversität im Mittelmeerraum des Spätmittelalters

Von Margit Mersch (Erlangen)

Zu Problematik und Erkenntnispotential der Untersuchung materieller bzw. visueller Kulturen im Mittelmeerraum

Von Ulrike Ritzerfeld (Berlin) .19

Alexandria aus Athen zurückerobern? Perspektiven einer mediterranen Kunstgeschichte mit einem Seitenblick auf das mittelalterliche Sizilien

Von Gerhard Wolf (Florenz)

Fine Commodities in the Thirteenth-century Mediterranean. The Genesis of a Common Aesthetic

Von Maria Georgopoulou (Athen)

Symbole der Macht. Mittelalterliche Heraldik zwischen Ost und West

Von Robert Ousterhout (Philadelphia)

Feuerprobe, Portraits in Stein. Mittelalterliche Propaganda für Venedigs Reliquien aus Konstantinopel und die Frage nach ihrem Erfolg

Von Karin Krause (Basel) 
Leibesfülle zwischen Ost und West. Beobachtungen zur Byzanz- und Antikenrezeption in der Bibel von Gerona

Von Annette Hoffmann (Heidelberg) .163

I musulmani nel sud Italia. Scontri, incontri, reciprocità

Von Vito Bianchi (Bari) 181

Indizien kultureller Differenz in den mittelalterlichen Bau-, Bild- und Schriftdenkmalen aus Bari und Matera. Ein Schichtenmodell

Von Dietrich Heißenbüttel (Stuttgart)

,Lateinisch-griechische“ Begegnungen in Apulien. Zur Kunstpraxis der Mendikanten im Kontaktbereich zum orthodoxem Christentum

Von Margit Mersch (Erlangen) und Ulrike Ritzerfeld (Berlin)

Bettelmönche und Islam. Beobachtungen zur symbolischen Darstellung von Missionsprinzipien der Mendikanten in Text, Handlung und Bildkunst des 13. Jahrhunderts

Von Anne Müller (Eichstätt) .285

Die Autorinnen und Autoren .309

Personen- und Ortsregister 311

Tafeln 


\section{,Lateinisch-griechische“ Begegnungen in Apulien. Zur Kunstpraxis der Mendikanten im Kontaktbereich zum orthodoxen Christentum}

\section{Margit Mersch \& Ulrike Ritzerfeld}

\section{Orthodoxe Kirchen und Mendikanten in Apulien}

Am 25. März 1385 bestätigte Papst Urban VI. Gründung und Bau der Franziskanerkirche S. Caterina in Galatina im südlichen Apulien. Diese sei von dem lokalen Feudalherren Raimondo del Balzo Orsini errichtet worden, da in qua quidem Terra homines Graeci et Latini Christiani cohabitant, divina officia dumtaxat in Graeca lingua, quam Latini minime intelligunt, celebrantur, ${ }^{1}$ weil also in dieser Gegend griechische und lateinische Christen zusammen lebten, die Liturgie jedoch allein in Griechisch gefeiert werde, was die lateinischen Christen nicht verstünden. Deshalb sollten die Franziskanerbrüder in S. Caterina für letztere, für ipsos Latinos, die Hl. Messe in lateinischer Sprache, in lingua Latina, zelebrieren. Der Text stellt den griechischsprachigen Einwohnern der Region die des Griechischen nicht mächtige Bevölkerungsgruppe der Latini gegenüber. Die jeweils angegebene Sprache impliziert vermutlich zugleich den jeweiligen Kirchenritus. Deutlich wird in den Unterscheidungen von Lateinern und Griechen die Abgrenzung von religiösen und sprachlichen Traditionen - der , griechischen' Kultur wird eine ,lateinische' gegenübergestellt. ${ }^{2}$ Der zitierte Urkundentext und das Bauprojekt von S. Caterina sind als Reaktion der römisch-katholischen Kirche auf das religiöse Nebeneinander von Gläubigen der Ostkirchen und der römischen Kirche im spätmittelalterlichen Apulien gewertet worden und sollen das gezielte Vorgehen im „Krieg“" ${ }^{3}$ gegen den griechischen Ritus belegen, bei dem den Mendikanten eine aus-

1 Michele Montinari, Galatina antica. L'Ospedale di Santa Caterina. Galatina 1941, ND o. O. 1988, IV-VI, Documento 9 u. 10. Der Papst stellte zum selben Datum zwei Bullen mit sehr ähnlichem Wortlaut aus, eine für den franziskanischen Provinzialminister und eine für Raimondo del Balzo Orsini.

2 Vgl. dazu Mario D'Elia, Vicende storiche del bilinguismo greco-romanzo, in: Luigi Orlando (Hrsg.), Grecìa Salentina. Arte, cultura e territorio. Galatina 1996, 13-30, bes. 14-18.

3 Diesen Ausdruck gebraucht Cosimo De Giorgi, La provincia di Lecce. Bozzetti di viaggio. 2 Bde. (Biblioteca di cultura pugliese, Bd. 8.) Lecce 1882, ND Galatina 1975, Bd. 2, 414. Valentina Vissicchio/Enrico Spedicato/Elisabetta De Giorgi (Hrsg.), Iscrizioni latine del Salento. Trepuzzi, 
schlaggebende Funktion zugewiesen wird. ${ }^{4}$ Tatsächlich sahen sich die orthodoxen Gemeinden Süditaliens vom Vierten Lateranischen Konzil an, als Konditionen für das Miteinander der Kirchen festgelegt wurden, zunehmendem Druck ausgesetzt. ${ }^{5}$ War der seit der normannischen Eroberung sukzessive wachsende römisch-katholische Einfluss zunächst mithilfe der Benediktiner ausgeübt worden, ${ }^{6}$ so wirkte die römische Kirche zur Zeit der Anjou mit Hilfe der Bettelorden. Besondere Bedeutung für Apulien gewannen die Franziskaner, welche das religiöse Leben vom 13. Jahrhundert an maßgeblich mitgestalteten? Bereits der Ordensgründer soll laut Thomas von Celano und diverser regionaler Legenden mehrfach in der Region verweilt haben. ${ }^{8}$ Die Verbreitung der Minderbrüder im Süden begann bald nach der Konsolidierung der ersten Niederlassungen in Mittel- und Norditalien. In den größeren Städten Apuliens wie Bari, Brindisi, Taranto, Matera und in einigen Zentren der Peripherie wie Nardò und wohl auch Oria, Ostuni und Alessano wurden im Laufe des 13. Jahrhunderts Konvente gegründet. Zu Beginn des 14. Jahrhunderts häufen sich die Quellennachrichten über bestehende und neu gestiftete Niederlassungen der Franziskaner. ${ }^{9}$ Einen weiteren Wachstumsschub ver-

Squinzano, Cavallino, Galatina. Galatina 2004, 164, sprechen von dem S. Caterina vom Papst zugewiesenen „compito di ,latinizzare“ il Salento, in quanto la curia romana aveva interesse a far prevalere la lingua latina come segno tangibile della sua autorità, in opposizione al rito greco-bizantino, diffuso allora, insieme alla lingua greca, su buona parte del Salento."

4 Von einem religiös-politischen Programm der Santa Sede mit Hilfe der Franziskaner spricht z. B. Maria Stella Calò Mariani, Note sulla pittura salentina del Quattrocento, in: Archivio Storico Pugliese 32, 1979, 139-164, bes. 140.

5 Peter Herde, Il papato e la chiesa greca nell'Italia meridionale dall'XI al XIII secolo, in: La chiesa greca in Italia dall'VII al XVI secolo. Atti del convegno storico interecclesiale, Bari, 30.4.4.5.1969. 3 Bde. Padua 1972-73. Bd. 1. Padua 1973, 223-232.

6 Hubert Houben, I benedettini e la latinizzazione della Terra d'Otranto, in: Tra Roma e Palermo. Aspetti e momenti del Mezzogiorno medioevale. Galatina 1989, 159-176.

7 Noch immer basieren die meisten Darstellungen zur Geschichte der Franziskaner im Salento auf der Arbeit von Primaldo Coco, I Francescani nel Salento. Bd. 1: Dalle origini sino al 1517. Lecce 1921. Seine Angaben, die sich u. a. auch auf legendäre Überlieferungen stützen, sind im Einzelnen jeweils anhand jüngerer Regionalstudien zu überprüfen und ergänzen; siehe etwa korrigierend zu Lecce: Hubert Houben, Istituzioni ecclesiastiche e vita religiosa, in: Benedetto Vetere (Hrsg.), Storia di Lecce. Dai bizantini agli aragonesi. (Storia di Lecce, Bd. 1.) Rom/Bari 1993, 395-417, hier 411. Aktuelle, kritische Denkanstöße zu den Anfängen der Franziskaner in Apulien sind zu finden bei Giovanni Vitolo, Ordini mendicanti e dinamiche politico-sociali nel Mezzogiorno angionino-aragonese, in: Rassegna storica salernitana 30, 1998, 67-101. Kritisch zu rezipieren sind: Gennaro Bove, Il francescanesimo in Puglia. Città di Castello 1987; Stefano Adiuto Putignani, Il francescanesimo salentino. Le origini. Bari 1970.

8 Thomas de Celano, Vita secunda S. Francisci. Ed. Collegium s. Bonaventurae, in: Legendae S. Francisci Assisiensis, saeculis XIII et XIV conscriptae, Analecta Franciscana 10, 1926/1941, 129-268, hier Cap. 38, 171f. Zu den Legenden vgl. Domenico Bacci, San Francesco d'Assisi nelle leggende pugliesi. Brindisi 1925.

9 Luigi Pellegrini ist der Auffassung, dass die Franziskaner noch zu Beginn der 1230er Jahre nicht südlich einer Linie auf der Höhe von Salerno-Bari gesiedelt hätten; Luigi Pellegrini, Insediamenti 
zeichnete der Orden im 15. Jahrhundert, als u. a. unter dem Anstoß der Observanzbewegung im gesamten Süden neue Konvente in den kleineren Städten und ländlichen Regionen gegründet wurden. ${ }^{10}$ Die Hauptaufgabe der Konvente bestand in der Sicherstellung der lateinischen Seelsorge und in der Bereitstellung von Begräbnis- und Memorialleistungen für die Oberschichten. Von Bischöfen und Päpsten wurden die Minoriten Apuliens aber ebenfalls mit inquisitorischen Aufgaben betraut, die sich zunächst auf Juden, dualistische Häretiker und die so genannten schismatischen Christen der Ostkirchen bezogen und im späten 14. und frühen 15. Jahrhundert mit der Verfolgung von Fratizellen zu einem großen Teil auch die eigenen Reihen betrafen. ${ }^{11}$ Einigen Quellen zufolge zeigten die apulischen Franziskaner jedoch ein besonders ausgeprägtes Interesse an der Kontrastierung der Ostkirchen. Beispielsweise berief sich der Konvent der Minderbrüder von Oria auf den $\mathrm{Hl}$. Franziskus, der die Niederlassung gegründet haben soll, um der byzantinisch-griechischen Mehrheit vor Ort standzuhalten. ${ }^{12}$ Der Widerstand musste sich in erster Linie gegen die in direkter Konkurrenz zu den Minoriteneinrichtungen stehenden orthodoxen Klöster als Zentren byzantinischer Tradition, als „ultimo baluardo della civiltà bizantina" ${ }^{13}$ richten, ${ }^{14}$ die ihrerseits auf die zunehmende Einflussnahme reagiert zu haben scheinen. Bereits Nikolaos (Nektarios) von Otranto (1155/60-1235), Igumenos des orthodoxen Klosters S. Nicola di Casole, verfasste Schriften ,gegen die Lateiner“.15 In seinen Syntagmata diskutiert er die strittigen

francescani nell'Italia del Duecento. Rom 1984; ders., Territorio e città nell'organizzazione insediativa degli ordini mendicanti in Campania, in: Rassegna storica salernitana 5, 1986, 9-41.

10 Vitolo, Ordini mendicanti (wie Anm. 7), 75f.

11 Felice Moretti, Eretici ed eresie in Puglia in età sveva e angioina, in: Felice Moretti (Hrsg.), Cultura e società in Puglia in età sveva e angioina. Atti del convegno di studi, Bitonto, 11.13.12.1987. Bitonto 1989, 105-122, hier 117-119; Slavko Slišković, Inquisizioni e frati minori in Bosnia, Frati minori e inquisizione. (Atti dei convegni della società internazionale di studi francescani e del centro interuniversitario di studi francescani, n. s., Bd. 16.) Spoleto (Perugia) 2006, 383-408, hier 407; vgl. auch John Moorman, A History of the Franciscan Order from its Origins to the Year 1517. Oxford 1968, 302f., 424f.

12 Bove, Francescanesimo (wie Anm. 7), 22. Freilich ist die Überlieferung legendarisch. Belegt ist aber päpstliches Interesse an einer solchen Rolle der Franziskaner. So verbriefte Urban V. 1363 dem Provinzial der Minoriten von Kalabrien die Erlaubnis, drei neue Konvente zu gründen, um der Verbreitung von Fratizellen und der Resistenz des griechischen Ritus, der noch immer in vielen Gebieten der Region verwurzelt sei, zu begegnen; Bullarium Franciscanum, Romanorum Pontificum. Bd. 6. Ed. Konrad Eubel/Giovanni Giacinto Sbaraglia. Rom 1902, Nr. 886.

13 Pasquale Corsi, Presenza e influssi bizantini nella cultura pugliese medievale: lo status quaestionis e le nuove ipotesi di ricerca, in: Silvio Fioriello (Hrsg.), Bitonto e la Puglia tra tardoantico e regno normanno. Atti del Convegno, Bitonto, 15.-17.10.1998. (Il Grifo, Bd. 3.) Bari 1999, 257264 , bes. 263.

14 Vgl. dazu Pasquale Corsi, Bisanzio e la Puglia: linee di ricerca per la storia del Mezzogiorno nel Medioevo. Bari 1994, 75-110.

15 Johannes Maria Hoeck/Raimund Josef Loenertz, Nikolaos-Nektarios von Otranto, Abt von Casole. Beiträge zur Geschichte der ost-westlichen Beziehungen unter Innozenz III. und Friedrich II. 
Punkte wie das filioque, die Azymen und die Priesterehe. Entsprechend sind Glaubensdispute zwischen Minoriten und griechischen Mönchen überliefert. ${ }^{16}$ Bekannt sind auch aus späterer Zeit Beschwerden über die Mendikanten, die ,perseguitavano i Greci e costringevanli a formarsi il sacramento di pane azimo, e non fermentato." 17

Die religiöse Praxis scheint jedoch nicht so sehr von krassen Gegensätzen geprägt gewesen zu sein, wie dies die Semantik der Urkunden und der teils offen parteinehmenden historiographischen Berichte nahe legen. ${ }^{18}$ Den vor der jeweiligen kirchenpolitischen Situation zu bewertenden offiziellen Auseinandersetzungen um Unterschiede in der Lehre und Anerkennung des Primats steht der modus vivendi im religiösen Leben Apuliens gegenüber. Die Komplexität der Situation wird gerade in der Person des Nikolaos von Otranto und der Geschichte seines Klosters sichtbar. Der Igumenos war zwar einerseits in einem in byzantinischer Tradition wurzelnden Umfeld beheimatet und vertrat dieses mit seinen Schriften und bei Konzilien als Dolmetscher, bewegte sich jedoch vor allem in höfischen Zirkeln und trat in diplomatischen Missionen für Friedrich II. in Erscheinung. Bezeichnend sind seine Bemühungen, die Grundlagen seines Glaubens einer lateinischen Allgemeinheit zu erklären; ${ }^{19}$ er trat als Vermittler zwischen den Kulturwelten ${ }^{20}$ auf. S. Nicola di Casole wiederum, reichstes Kloster Unteritaliens, ,ponte fra Occidente e Oriente“ 21 und ,più importante nucleo di concentramento e irradiazione di opere in lingua greca nell'intero Occidente" 22 , unterstand bereits zur Zeit seiner Gründung jurisdiktionell dem lateinisch besetzten Erzbistum Otranto. Friedrich II. gliederte alle lateinischen und griechischen Kirchen und Klöster

(Studia patristica et Byzantina, Bd. 11.) Ettal 1965, 88-105, 180.

16 Pietro Pompilio Rodotà, Dell'origine, progresso e stato presente del rito greco in Italia. 3 Bde. Rom 1758-1763. Bd. 2: Dei monaci basiliani. Rom 1760, 118; Grazio Gianfreda, Il monachesimo italo-greco in Otranto. Galatina 1977, 96-99.

17 Der Streit wurde nach Rom getragen und dort zur Zeit Martins V. (1417-1431) zugunsten der Griechen entschieden. Antonio De Ferrariis, Del sito della Iapigia. Epistola di Antonio Galateo diretta al Chiarissimo Gio. Battista Spinelli Conte di Cariati. Voltata dal latino all'idioma italiano da Vincenzo Dolce. Stamperia di Gaetano Rusconi. Neapel 1853, 84f.

18 Ein Beispiel für die öffentliche Parteinahme ist der aus dem griechischen Galatone stammende Humanist Antonio de Ferraris, der gerade das Vorgehen der Mendikanten als respektlos den lokalen Traditionen gegenüber beschreibt. Vgl. dazu die vorhergehende Anmerkung.

19 Vgl. dazu André Jacob, Testimonianze bizantine nel Basso Salento, in: Salvatore Palese (Hrsg.), Il Basso Salento. Ricerche di storia sociale e religiosa. Galatina 1982, 49-69, bes. 61f.

20 So bezeichnet von Michael Chronz, Der Beitrag des Nikolaos von Otranto (Nektarios von Casole) zur Vermittlung zwischen den Kulturwelten des 13. Jahrhunderts, in: Jan Aertsen (Hrsg.), Geistesleben im 13. Jahrhundert. (Miscellanea Mediaevalia, Bd. 27.) Berlin/New York 2000, 555-573.

21 Cesare Daquino, Bizantini di Terra d'Otranto. San Nicola di Casole. Lecce 2000, 5.

22 Rosario Coluccia, Lingua e religione. Il ruole della chiesa e l'affermazione del Volgare in Puglia, in: Fabrizio Frasnedi/Riccardo Tesi (Hrsg.), Lingue, stili, traduzioni. Studi di lunguistica e stilistica italiana offerti a Maria Luisa Altieri Biagi. Florenz o. J. (2004), 71-95, bes. 73; Chronz, Beitrag (wie Anm. 20), 557, Anm. 18. 
der Region in den Sprengel des Erzbischofs ein. ${ }^{23}$ Auch das Innenleben der orthodoxen und römisch-katholischen Klöster scheint sich nicht fundamental unterschieden zu haben. Bereits vor dem Eintreffen der Bettelorden ähnelte das klösterliche Leben der Benediktiner demjenigen der Basilianermönche. ${ }^{24}$

Außerhalb der Klostermauern musste diese Tendenz noch stärker zu fühlen sein. Im 14. und 15. Jahrhundert gehörten zwar noch große Teile der apulischen Bevölkerung, vor allem in der Terra d'Otranto, den Ostkirchen an, die Gemeinden hatten sich jedoch beträchtlich von deren Traditionen entfernt. So sind auch in den liturgischen Codizes der Region Differenzen zu den östlichen Festkalendern zu bemerken.25 Andererseits konnten sich die Gemeinden aber dennoch durch die Ablehnung des filioque, die Verwendung gesäuerten Brotes sowie die Priesterehe von der römischen Kirche unterscheiden. ${ }^{26}$ Sie standen demnach im inhaltlichen wie geographischen Sinne zwischen den Kirchen ${ }^{27}$ Deutlich wird, dass sich der religiöse Alltag in Apulien nicht mit einer simplen Kategorie der Bipolarität beschreiben lässt, auch wenn dies die Urkunden häufig vorgaukeln. Dabei bleibt ebenfalls zu berücksichtigen, dass die religiöse Situation der Region extrem bunt und vielschichtig war und somit über eine Dichotomie von West- und Ostkirche hinausging. Zwar war die Bevölkerung durch die jahrhundertelange byzantinische Herrschaft über einen langen Zeitraum dem Einfluss der griechisch-orthodoxen Kirche unterworfen, vorhanden waren jedoch nicht nur unterschiedliche Zweige der orthodoxen Kirche, sondern ebenfalls zahlreiche jüdische Gemeinschaften, vereinzelte Muslime sowie Angehörige weiterer Glaubensrichtungen wie Bogumilen, Albigenser, Waldenser und Fratizellen. ${ }^{28}$ Eine ähnliche Bandbreite gilt

23 Chronz, Beitrag (wie Anm. 20), 557.

24 Vgl. dazu Dietrich Heißenbüttel, Italienische Malerei vor Giotto. Wandmalerei und Geschichte des Gebiets um Matera (Apulien/Basilicata) bis zur Mitte des 14. Jahrhunderts: Matera, Laterza, Ginosa, Gravina. Diss. phil. Halle-Wittenberg 2000, 55. Online im Internet: URL:http://sundoc. bibliothek.uni-halle.de/diss-online/00/03H067/index.htm (Stand 20.05.2007).

25 Vgl. dazu Francesco Danieli, Il rito greco a Galatone. S. Francesco d'Assisi in un codice bizantino del sec. XV. Galatina 2005, 99.

26 Vgl. dazu Herde, Il Papato (wie Anm. 5), 224, 235; Zacharias Tsirpanlis, Comunità e chiese greche in Terra d'Otranto, in: La chiesa greca in Italia dall'VII al XVI secolo. Atti del convegno storico interecclesiale, Bari, 30.4.-4.5.1969, 3 Bde. Padua 1972-1973, Bd. 2. Padua 1972, 845877.

27 Bereits aus dem 12. Jahrhundert sind Mischformen überkommen, die beweisen, dass keineswegs eine strenge sprachliche Trennung die Regel war. Vgl. dazu Christine Ungruh, Das Bodenmosaik der Kathedrale von Otranto. Diss. phil. Göttingen 2009. Eine Annäherung zwischen römisch-katholischen und orthodoxen Gläubigen konnte durch die gemeinsame Nutzung von Kirchengebäuden sowie die Einsetzung eines Vorstehers für beide Gemeinden gefördert werden. In Galatone feierten im 15. Jahrhundert wohl aus Platzgründen beide Gemeinden ihre Gottesdienste in der Collegiata Assunta. Darüber hinaus wurde ein Mitglied des katholischen Klerus zum Protopapa ernannt, von da an blieb über einen langen Zeitraum hinweg das Amt des katholischen Arcipriesters mit dem des Protopapas in einer Person vereint. Danieli, Rito greco (wie Anm. 25), 24f. 
auch für Herkunft und Sprachen der Bewohner. Die mehrfache Kolonisation durch Griechen, die Besetzung durch die Byzantiner, durch Normannen und im späten Mittelalter wiederum durch französische Fürsten, der Kontakt mit arabischen Eroberern sowie der intensive Handel mit dem Orient hatten in der Region die unterschiedlichsten Ethnien und Sprachen aufeinander treffen lassen. Zwar war auch im 14. Jahrhundert das Griechische im Süden Apuliens noch großflächig verbreitet, zu differenzieren ist jedoch, abgesehen von Sprachminoritäten und Relikten vergangener Zeiten, zum Beispiel aus dem Arabischen, ${ }^{29}$ nicht nur zwischen Griechisch und Latein, sondern zwischen unterschiedlichen gesprochenen Dialekten und dem jeweiligen liturgischen Sprachgebrauch..$^{30}$ Heute noch zeugen Orts- wie Nachnamen und dialektale Ausdrücke von der Existenz verschiedener Sprachtraditionen, exemplarisch vertreten in dem in der Grecìa Salentina gesprochenen „Griko“31

\section{Die Kunstlandschaft Apuliens}

Der ethnischen, religiösen und linguistischen Vielfalt und den unterschiedlichen geographischen Gegebenheiten, politischen und religiösen Entwicklungen entsprechend zeichnet sich auch die Kunstlandschaft Apuliens durch Vielseitigkeit aus. Bereits im Hohen Mittelalter kamen mit Reisenden, Pilgern, den Kreuzfahrern und Orden wie den Templern und Johannitern Impulse aus dem nahen Osten ins Land. Als grundlegender Einschnitt wirkte jedoch der Herrschaftswechsel von den Byzantinern zu den Normannen, änderten sich doch in dem Gebiet, das seine wesentliche religiöse, linguistische und künstlerische Prägung unter byzantinischer Führung erhalten hatte, mit Ankunft des fremden Feudaladels und mit ihm der Benediktiner sowie später der Mendikanten grundsätzlich die Voraussetzungen für die Kunstentwicklung. Entsprechend wird vom Zeitpunkt der normannischen Eroberung an eine Spannung zwischen Orient und Okzident in der apulischen Gesellschaft konstatiert, als deren Ausdruck sich eine ,byzantinische“ und eine ,westliche“ Kunst gegenüberstehen sollen. ${ }^{32}$ Diese Etikettierung birgt die Gefahr, die unterschiedlichen Strömungen zu übersehen, die in der apulischen Kunst nur zu deutlich an den Tag treten. Ihr buntes Erscheinungsbild wird im Bereich der Architektur besonders deutlich. Während normannische Herrscher in Süditalien im 11. und 12. Jahrhundert unter anderem auf Architekturformen rekurrierten, die sie von arabischen Bauten Siziliens oder vom Kreuzzug kannten (wie etwa das Grabmal des

29 Vgl. auch die Ausführungen von Vito Bianchi in diesem Band.

30 D'Elia, Vicende storiche (wie Anm. 2), bes. 14f.

31 Coluccia, Lingua e religione (wie Anm. 22), 72. Zur Grecìa Salentina vgl. Mario Cazzato/Antonio Constantini, Grecìa Salentina. Arte, cultura e territorio. Hrsg. v. Luigi Orlando. Galatina 1996.

32 So beispielsweise Cosimo Damiano Fonseca im Vorwort zu: Marina Falla Castelfranchi, Pittura monumentale bizantina in Puglia. Mailand 1991, 9-11, hier 11. 
Bohemund in Canosa von ca. 1111) $3^{33}$ brachten normannische Bischöfe, Äbte und Stifter ab der Mitte des 11. Jahrhunderts (etwa in Aversa, Venosa oder Mileto) ${ }^{34}$ Umgangschöre aus französischen und englischen Landen oder den Grundriss von ,Cluny II“ in die Kirchenarchitektur ein. Daneben aber entstanden traditionelle basilikale Bauten mit spätantiken und byzantinischen Anklängen wie die Kathedrale von Otranto ${ }^{35}$ (vor 1163) und Kompositionen wie die Kathedrale von Gerace (Ende 11./Anf. 12. Jahrhundert), ${ }^{36}$ die lokale byzantinische (Vierungskuppel) und lateinische Traditionen (frühchristl. Säulenbasilika nach dem Vorbild von Montecassino) mit dem Grundriss des Chores von Cluny verband. San Nicola in Bari (ca. 1105) wurde in seiner innovativen und charakteristischen Verbindung normannisch-nordeuropäischer, südeuropäisch-italienischer, spätantik-römischer sowie rheinischer (und eventuell auch islamischer) Architekturelemente zum einflussreichsten Architekturmodell des so genannten apulisch-romanischen Stils für zahlreiche eindrucksvolle Kathedralen und Kirchen in Süditalien. ${ }^{37}$ So ist die in sich sehr variantenreiche apulische Romanik des 11. und 12. Jahrhunderts als Mischform zu beschreiben, in der sich Importe aus Nordwesteuropa und dem östlichen Mittelmeerraum mit lokalen süditalienisch-byzantinischen Traditionen verbinden. ${ }^{38}$

Auch die Architektur der hoch- und spätmittelalterlichen griechisch-orthodoxen Kirchen Süditaliens ist geprägt von Mischformen und stand in Verbindung mit den Entwicklungen der lateinischen Sakralarchitektur. Die vornormannischen byzantinischen

33 Vgl. Marina Falla Castelfranchi, Il mausoleo di Boemondo a Canosa, in: Mario D’Onofrio (Hrsg.), I normanni, popolo d'Europa 1030-1200. Venedig 1994, 327-330.

34 Vgl. Günter Urban, Der Normannendom von Aversa: Untersuchungen zur Baustruktur, in: Kai Kappel (Hrsg.), Kunst im Reich Kaiser Friedrichs II. von Hohenstaufen. München 1996, 94-105; Corrado Bozzoni, Saggi di architettura medievale. La Trinità di Venosa. (Saggi di storia dell'architettura, Bd. 3.) Rom 1979; Guiseppe Occhiato, La SS. Trinità di Mileto e l'architettura normanna meridionale. Catanzaro 1977 (Überarb. Neuaufl. unter dem Titel La Trinità di Mileto nel romanico italiano. Cosenza 1994).

35 Vgl. Grazio Gianfreda, Basilica Cattedrale di Otranto: architettura e mosaico pavimentale. Galatina 4. Aufl. 1978.

36 Vgl. Giuseppe Occhiato, Il duomo di Gerace: persistenze bizantine in un edificio romanico calabrese, in: Calabria bizantina: civiltà bizantina nei territori di Gerace e Stilo. Catanzaro 1998, 501-516.

37 Vgl. Pina Belli D'Elia, La Basilica di S. Nicola a Bari: un monumento nel tempo. (Documentari, Bd. 9.) Galatina 1985.

38 Valentino Pace, Kunstdenkmäler in Süditalien. Apulien, Basilicata, Kalabrien. Darmstadt 1994, 16, konzediert der süditalienischen Kunst und Architektur in der Normannenzeit „das völlige Fehlen negativer Vorurteile gegenüber den Erfahrungen und Traditionen der anderen Völker Süditaliens“, wodurch „ein außergewöhnliches künstlerisches Panorama unterschiedlichster Stilmerkmale entwickelt [wurde], die vom islamischen Bereich bis zur Normandie und vom byzantinischen Mittelmeer bis nach Rom führen." 


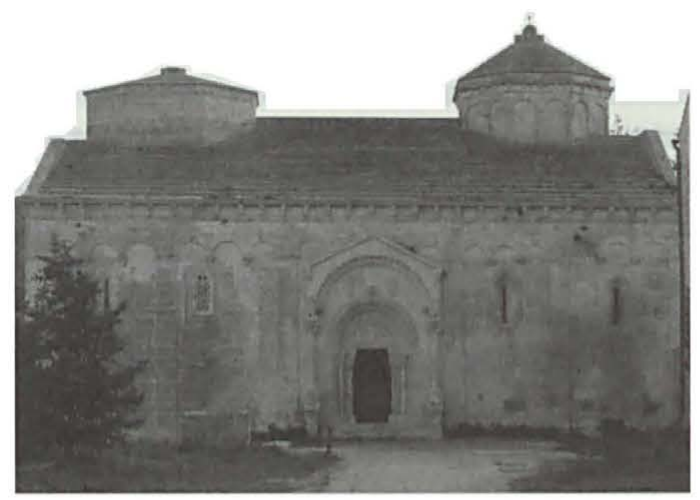

$A b b$. 1a: San Leonardo di Siponto (Foto: M. Mersch)

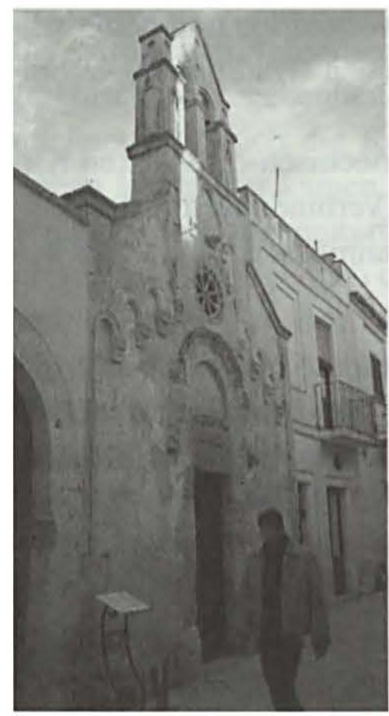

Abb. 1c: Soleto, S. Stefano (Foto: M. Mersch)

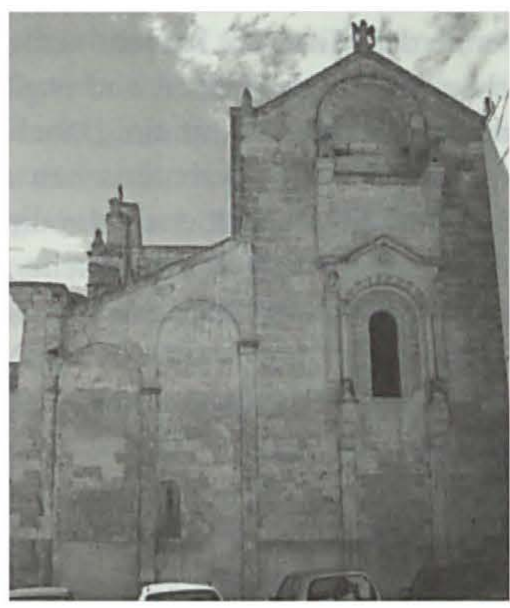

$A b b .1 b$ : Matera, S. Giovanni Battista (Foto: M. Mersch)

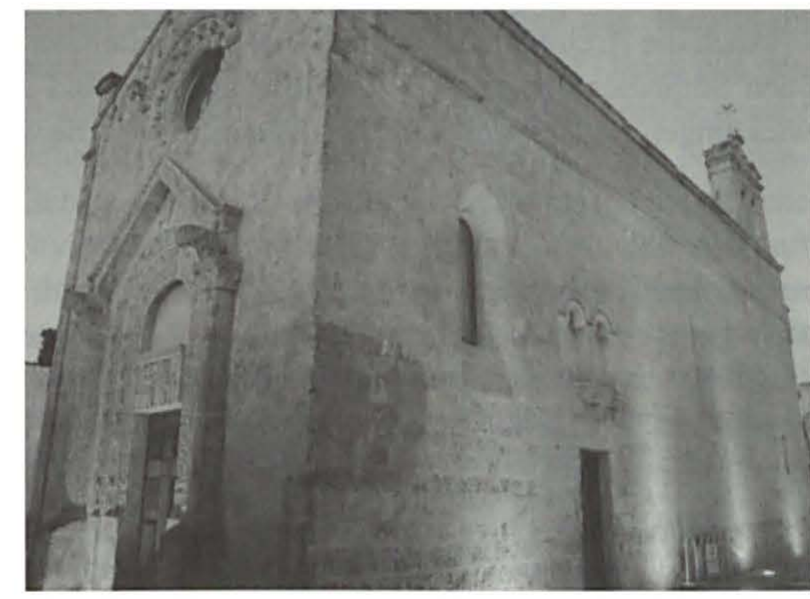

Abb. 1d: Taurisano, S. Maria della Strada (Foto: M. Mersch)

Bautypen, etwa Zentralkuppelbauten wie S. Pietro in Otranto (10. Jahrhundert), ${ }^{39}$ wurden nun weitgehend abgelöst von zumeist recht kleinen einschiffigen Sälen mit Apside wie zum Beispiel S. Marina in Muro Leccese (11. Jahrhundert) oder dreischiffigen Basiliken mit dreiapsidialem Chorschluss und Kuppeln sowie Kuppeltambouren wie etwa

39 Vgl. Linda Safran, S. Pietro at Otranto: Byzantine art in South Italy. (Collana di studi di storia dell'arte, Bd. 7.) Rom 1992. 
die Cattolica in Stilo (12. Jahrhundert). ${ }^{40}$ Kuppelkirchentypen wiederum - nun nicht mehr als Zentralbauten, sondern in langgestreckter Form - sind nicht auf griechisch-orthodoxe Kirchbauten beschränkt. Sie finden sich bei Ognisanti in Valenziano (11. Jahrhundert) und am alten Dom in Molfetta (12./13. Jahrhundert). Kuppeln und Kuppeltamboure in zylindrischer oder oktogonaler Form finden sich unter anderem auf den lateinischen Kirchen SS. Nicolò e Cataldo in Lecce, S. Cataldo in Taranto, S. Corrado in Molfetta, S. Sabino in Bari etc.41 Ähnliches gilt für Pyramidendächer, wie sie in der Terra di Bari gehäuft vorkommen (z. B. S. Benedetto in Conversano, ca. 1085; Ognissanti bei Valenzano, ca. 1080; S. Francesco in Trani, 1187). Sie sind offenbar als genuine lokale Tradition aufzufassen, die mindestens seit dem 9. Jahrhundert in Apulien (Seppanibale bei Fasano) bekannt war.42

Während sich in anderen europäischen Regionen gotische Architektur mit neuen Bautypen und Stilelementen (überregionaler Art, mit mehr oder weniger starker lokaler Prägung) durchsetzte, wurde in Süditalien weiterhin diese besondere apulische Mischarchitektur, die mit ,Romanik' unzureichend beschrieben ist, bevorzugt - im 14. und frühen 15. Jahrhundert erlebte sie im Salento sogar noch einmal eine späte Renaissance. Den meisten mittelalterlichen Kirchen Apuliens - und zwar sowohl den lateinischen als auch den griechischen - ist der schlichte Bautyp des einschiffigen Saalbaus oder der dreischiffigen Basilika mit und ohne Kuppelkonstruktion gemeinsam; daneben stehen einige wenige Zentralbauten und Kreuzkuppelkirchen. Die Außenwände dieser Gebäude werden zumeist nur durch Rundbogenfries und flache Blendbogenreihen strukturiert. Solche Aneinanderreihungen von flachen Arkaturen und Lisenen, mit Variationen des Bogenrhythmus oder durch Profilrahmen zu Wandfeldern erweitert, wiederholen sich wie ein ,Leitmotiv“ an den apulischen Kirchbauten von der Normannenzeit bis weit in die Ära der Anjou (Abb. la-d).43 In dieser Formensprache wird gemeinhin auch ein ,orientalischer Einfluss“ erkannt, der über die Verbindungen zum islamischen Sizilien und lateinischen Osten wirkte und der im 14. Jahrhundert durch erneute Kontakte mit orientalischen Modellen neu belebt wurde. ${ }^{44}$

40 Vgl. Città di Muro Leccese (Hrsg.), Tra oriente e occidente: Santa Marina. Muro Leccese 2003; Antonio Antonaci, Muro Leccese: storia e arte. Galatina 1995; Corrado Bozzoni, La Cattolica di Stilo: guida artistica, storica, letteraria. Chiaravalle 2. Aufl. 1979.

41 Vgl. die Zusammenstellungen und Kommentare bei Dorothee Kemper, SS. Niccolò e Cataldo in Lecce als ein Ausgangspunkt für die Entwicklung mittelalterlicher Bauplastik in Apulien und der Basilicata. Worms 1994, 56; Consiglia De Venere, Note sulla chiesa dei SS. Nicolò e Cataldo a Lecce, in: Studi in memoria di P. Adiuto Putigniani. Cassano Murge 1975, 83-93, hier 89-92.

42 Pace, Kunstdenkmäler (wie Anm. 38), $471 \mathrm{f}$.

43 Adriana Pepe, La cultura architettonica fra età normanna e aragonese, in: Benedetto Vetere (Hrsg.), Storia di Lecce. Dai Bizantini agli Aragonesi. Lecce 1993, 617-660, hier 625.

44 Maria Stella Calò Mariani, Considerazioni sull'architettura medievale in Puglia, in: Atti del Primo Simposio Internazionale di Arte Armena 1975. Venedig 1978, 417-433, hier 422; Pepe, Cultura architettonica (wie Anm. 43), 625. 
Während im Bereich der Skulptur ein entsprechend breites Möglichkeitenspektrum mit einer besonderen Verbindung zur gegenüber liegenden Adriaküste nachzuvollziehen ist, ${ }^{45}$ wird die Entwicklung der hoch- und spätmittelalterlichen Malerei in Apulien generell als ununterbrochene Nachfolge byzantinischer Tradition gewertet, die erst mit Einführung der Gotik durch die Anjou ausklingen sollte. Von der byzantinischen Vergangenheit der Region sowie deren Nachwirkungen zeugt z. B. der Bildschmuck zahl-

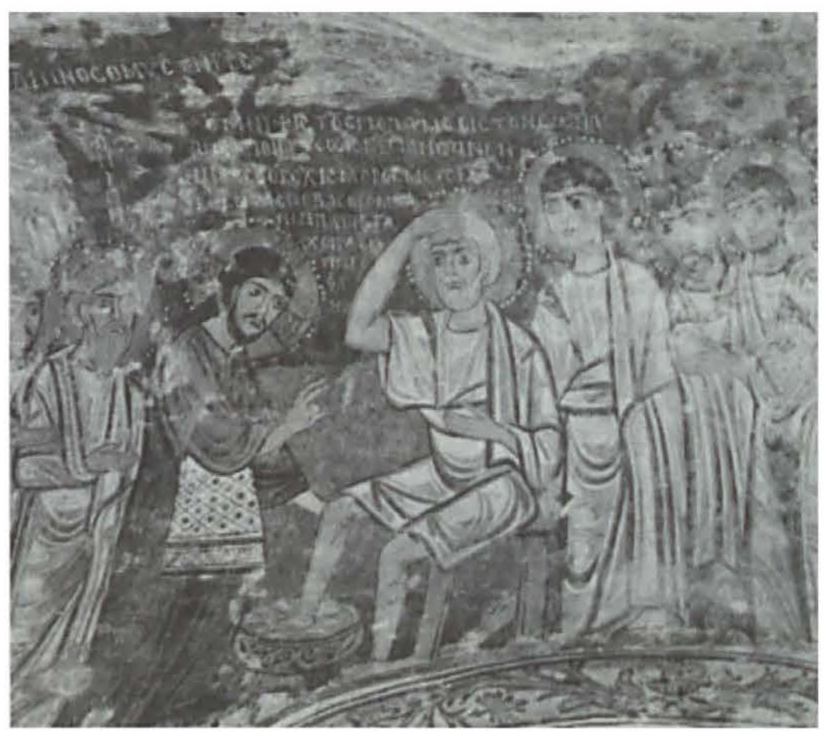

Abb. 2: Otranto, S. Pietro, Fußwaschung im Tonnengewölbe vor der linken Apis (Foto: U. Ritzerfeld) reicher Höhlenkirchen sowie die frühe Ausmalung von S. Maria di Cerrate und S. Pietro in Otranto (Abb. 2). Dabei ist jedoch nicht von einer absoluten Einheitlichkeit der Kunst auszugehen, kamen doch Elemente von verschiedenen Punkten des byzantinischen Reiches zusammen. So ist für die ,byzantinische“ Malerei im 11. Jahrhundert die Verbindung nach Griechenland bezeichnend, vom Ende des Jahrhunderts an traten darüber hinaus Zypern, das Heilige Land, Syrien und Ägypten in den Blick, z. B. in S. Maria di Cerrate und in S. Pietro, wo pseudokufische Inschriften zu beobachten sind. ${ }^{46}$ Mit der Machtübernahme der Anjou gewannen neben Epirus und Korfu Serbien und Dalmatien sowie insbesondere Neapel an Bedeutung. Vom Trecento an traten vermehrt Elemente aus dem Balkan und

45 Hierzu z. B. Clara Gelao, La scultura pugliese del Rinascimento nel contesto della koiné culturale adriatica, in: Raffaella Cassano/Rosa Lorusso Romito/Marisa Milella (Hrsg.), Andar per mare. Puglia e Mediterraneo tra mito e storia. Mostra Bari, Castello Svevo, 14.6.-16.11.1997. Bari 1998, 369-378; Pina Belli D'Elia, I rapporti con l'area dalmata, in: ebd. 341-348; Maria Stella Calò Mariani, Echi d'oltremare in Terra d'Otranto: imprese pittoriche e committenza feudale fra XIII e XIV secolo, in: Maria Stella Calò Mariani (Hrsg.), Il cammino di Gerusalemme. Atti del II Convegno internazionale di studio. Bari, Brindisi, Trani, 18.-22.5.1999. Bari 2002, 235-274; Linda Safran, Exploring Artistic Links between Epirus and Apulia in the Thirteenth Century: The Problem of Sculpture and Wall Painting, in: Praktika Diethnous Symposiou gia to Despotato tis Epeirou, Proceedings of the First International Symposium on the Despotate of Epiros, Mai 1990. Arta 1992, 455-74.

46 Zur Entwicklung der Bildkunst in Apulien vgl. Valentino Pace, La pittura delle origini in Puglia (secc. IX-XIV), in: La Puglia fra Bisanzio e l'Occidente. (Civiltà e culture in Puglia, Bd. 2.) 
Griechenland sowie dem Nahen Osten aus unterschiedlichen Kunsttraditionen hinzu. In der an Variantenreichtum gewinnenden Malerei und Keramik der zweiten Hälfte des Trecento sind über die Begegnung mit der Terra Sancta hinaus auch der Sinai, Syrien und Zypern präsent. ${ }^{47}$ Diese Periode wird als Endphase der ,byzantinischen` Malerei Apuliens gesehen, deren Produkte bereits ,inquinate da linfe diverse“ sein sollen. ${ }^{48}$

Gleichwohl ist bereits vom Ende des 13. Jahrhunderts an eine gewisse kreative Eigenständigkeit der, italo-griechischen` Kunst zu beobachten, die sie durchaus von der Kunst in den Gebieten des byzantinischen Reiches unterscheidet. ${ }^{49}$ Dieses Phänomen ist mit der Entstehung einer, griechisch-salentinischen ' Kultur begründet worden, welche sich zwischen 1280 und 1320 entwickelte und bis zum 18. Jahrhundert fortsetzen konnte. ${ }^{50}$ Dabei ist auch die enge Einbindung in die Kunstentwicklung des Adriagebiets zu berücksichtigen; konstatiert wurde eine ,variegata corrente figurativa adriatica che percorre tutto il litorale fino alla punta del Salento e che si intreccia via via con influenze piu interne (...) “.51 Im 15. Jahrhundert machte sich vor allem die enge Beziehung zu Venedig bemerkbar, zu sehen in erster Linie in Altarretabeln.52 Zugleich wurden in diesem Zeitraum Ikonen aus Kreta prägend . $^{3}$

Neben die von der byzantinischen Vergangenheit geprägte lokale Kunsttradition und aus dem östlichen Mittelmeergebiet und dem Adriaraum einfließenden Faktoren traten

Mailand 1980, 317-400, bes. 354-391; Calò Mariani, Echi d'oltremare (wie Anm. 45). Zur ,byzantinischen“ Malerei vgl. Falla Castelfranchi, Pittura (wie Anm. 32), vgl. ebend. 131 zu den Inschriften in Otranto und Cerrate.

47 Vgl. dazu z. B. die Fresken in der Nikolauskapelle von Celsorizzo und in der Krypta von S. Cataldo in Taranto; Michel Berger/André Jacob, Un nouveau monument byzantin de Terre d'Otrante: la chapelle Saint-Nicolas de Celsorizzo, près d'Aquarica del Capo, et ses fresques (an. 1283), in: Rivista di studi bizantini e neoellenici 27, 1991, 211-257; Calò Mariani, Echi d'oltremare (wie Anm. 45), 238f., 262.

48 Falla Castelfranchi, Pittura (wie Anm. 32), 18.

49 Beispielsweise die Fresken des 13. Jahrhunderts in S. Pietro in Otranto. Safran, Artistic Links (wie Anm. 45), bes. 460.

50 Jacob, Testimonianze (wie Anm. 19), 49-69. Vgl. Pace, Pittura (wie Anm. 46), 394-398.

51 Andrea De Marchi/Tiziana Franco, Il gotico internazionale: Da Nicolò di Pietro a Michele Giambono, in: Valter Curzi (Hrsg.), Pittura veneta nelle Marche. Cinisello Balsamo 2000, 53-85, bes. 79. Vgl. Rosa Lorusso Romito, Cultura figurativa „adriatica“ in Puglia tra XIV e XV secolo, in: Raffaella Cassano/Rosa Lorusso Romito/Marisa Milella (Hrsg.), Andar per mare. Puglia e Mediterraneo tra mito e storia. Mostra Bari, Castello Svevo, 14.6.-16.11.1997. Bari 1998, 351358.

52 Vgl. dazu Mario Salmi, La pittura veneta in Puglia, in: Rassegna d'arte antica e moderna 7, 1920, 209-215; Antonio Cassiano, L'arte al tempo dei principi, in: Antonio Cassiano/Benedetto Vetere (Hrsg.), Dal giglio all'orso. I principi d'Angiò e Orsini del Balzo nel Salento. Lecce 2006, 262305, bes. $300-304$.

53 Clara Gelao, La pittura cretese in Puglia e i suoi riflessi sulla pittura locale tra la seconda metà del Quattrocento e la prima metà del Cinquecento, in: Raffaella Cassano/Rosa Lorusso Romito/ Marisa Milella (Hrsg.), Andar per mare. Puglia e Mediterraneo tra mito e storia. Mostra Bari, Castello Svevo, 14.6.-16.11.1997. Bari 1998, 383-388. 


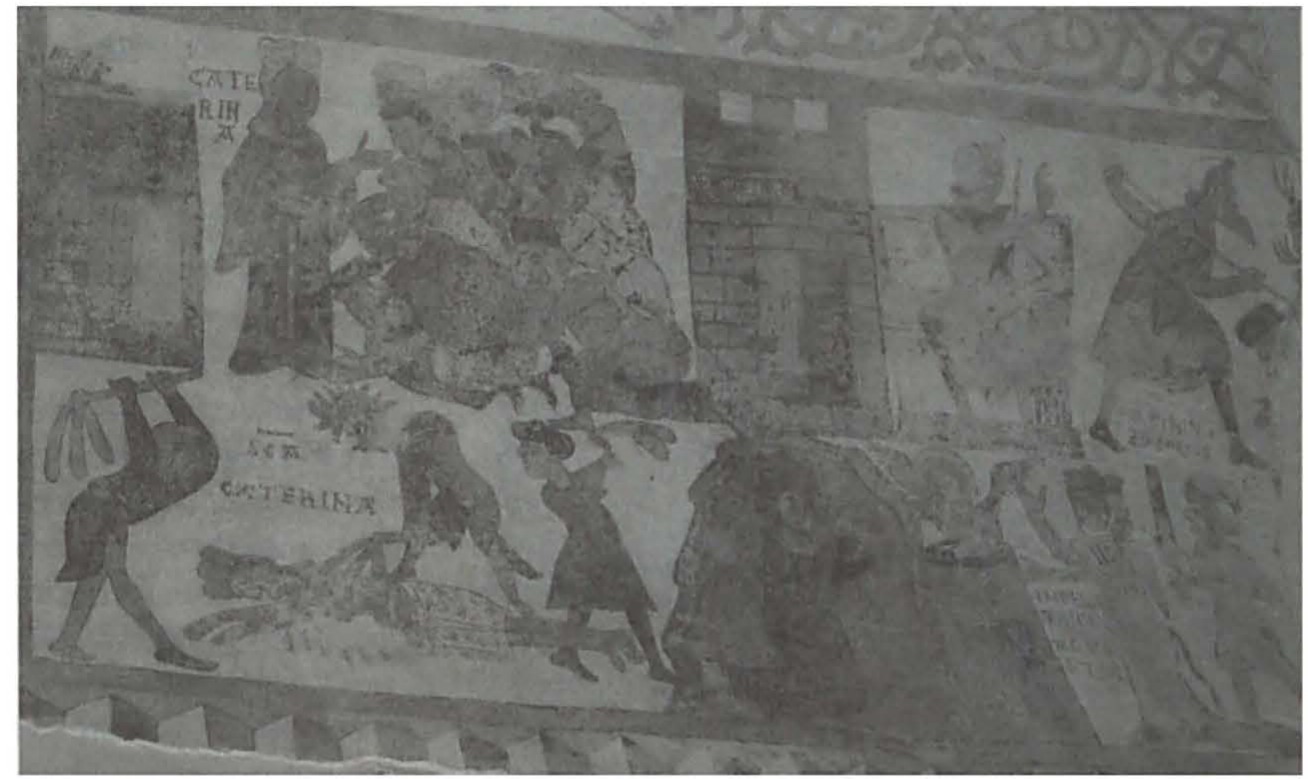

Abb. 3: Casaranello, S. Maria, Hauptschiff, Katharinenlegende im Tonnengewölbe (Detail) (Foto: U. Ritzerfeld)

bereits frühzeitig Elemente aus dem übrigen Italien sowie aus Frankreich. Im 12. Jahrhundert bezeugen zahlreiche figürliche Mosaikfußböden abgesehen von der Einbindung dekorativer Muster ursprünglich byzantinisch-orientalischer Herkunft die Kenntnis französischer Profanliteratur. ${ }^{54}$ Auch im Wanddekor, so im Katharinenzyklus aus der Mitte des 13. Jahrhunderts in S. Maria a Casaranello (Abb. 3), ist diese Orientierung nachzuvollziehen.55 Als Einfallstor unterschiedlicher Strömungen und impulsgebendes Zentrum trat während des gesamten Spätmittelalters Neapel in Erscheinung, wo die Werke Pietro Cavallinis, Giottos und Simone Martinis als Inspiration dienten und mittelitalienische Elemente im Süden implementierten ${ }^{56}$ Als Vermittler neapolita-

54 Adriana Pepe, Produzione artistica nel regno al tempo di Tancredi, in: Hubert Houben/Benedetto Vetere (Hrsg.), Tancredi. Conte di Lecce re di Sicilia. Atti del convegno internazionale di studio, Lecce, 19.-21.2.1998. Lavello 2004, 341-368, hier 347-351. Bald dazu Ungruh, Bodenmosaik (wie Anm. 27).

55 Falla Castelfranchi, Pittura (wie Anm. 32), 148. Interessanterweise schufen 1314/15 die Maler Nicola und Demetrio aus Soleto in S. Michele Arcangelo in Copertino einerseits eine lokal geprägte Verkündigung und andererseits an französische Minneszenen erinnernde Darstellungen. Vgl. Calò Mariani, Echi d'oltremare (wie Anm. 45), 238f., Abb. 3-9.

56 Vgl. z. B. Pierluigi Leone de Castris, Pittura del Duecento e del Trecento a Napoli e nel Meridione, in: La pittura in Italia. Il Duecento e il Trecento. Bd. 2. Venedig 1986. 
nischer Kunst wirkte vor allem der in den Jahren um 1400 entstandene und besonders nachfolgereiche Dekor von S. Caterina in Galatina (Abb. 18, 26).

Spätestens im 14. Jahrhundert ist eine Verschmelzung der ikonographischen Muster wie auch Details und stilistischer Charakteristika zu beobachten, so bereits im Jüngsten Gericht in S. Maria del Casale und in S. Stefano in Soleto aus dem 14. bzw. 15. Jahrhundert (Abb. 4, 13).57 Jedoch verlief diese Entwicklung keineswegs einheitlich. Im Gegenteil sind die verschiedenen Regionen Apuliens dank verschiedener geographischer und historischer Voraussetzungen unterschiedlich geprägt, so zeigt sich die Terra d'Otranto über lange Zeit der griechisch-byzantinischen Tradition verbunden und Einflüssen aus dem östlichen Mittelmeer gegenüber offen, während sich der übrige Teil tendenziell eher gen Norden sowie am Adriaraum orientierte..$^{58}$ Abgesehen von forma-

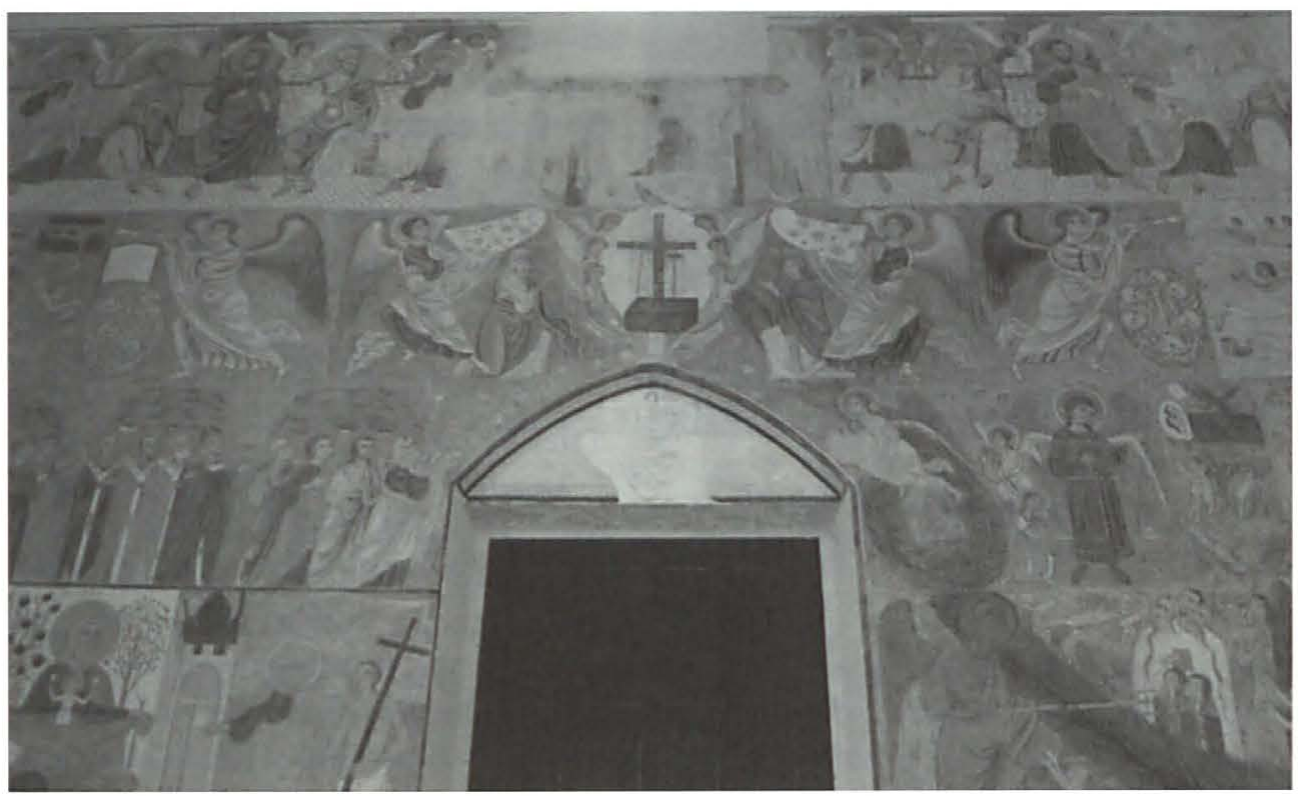

Abb. 4: Brindisi, S. Maria del Casale, Jüngstes Gericht an der Westwand (Detail) (Foto: U. Ritzerfeld)

len Unterschieden deutet die Präferenz für bestimmte Themen und Figuren unterschiedlicher Kulturkreise auf diverse devotionale Schwerpunkte, die Art ihrer Darstellung auf verschiedene Sehkonventionen und Umgangsweisen mit dem religiösen Bild hin. Inschriften lassen die unterschiedliche Sprachzugehörigkeit erkennen und auf die

57 Vgl. dazu Maria Stella Calò Mariani, La chiesa di Santa Maria del Casale presso Brindisi. Fasano 1967; Sergio Ortese, Sequenza del lavoro in Santo Stefano a Soleto, in: Antonio Cassiano/Benedetto Vetere (Hrsg.), Dal giglio all'orso. I principi d'Angiò e Orsini del Balzo nel Salento. Lecce 2006, 336-396.

58 Falla Castelfranchi, Pittura (wie Anm. 32), 158. 
Verbreitung verschiedener Liturgieformen schließen. ${ }^{59}$ Dabei ist auch eine thematische wie linguistische Angleichung an die Erfordernisse eines religiös wie sprachlich gemischten Gebiets und somit eine gewisse

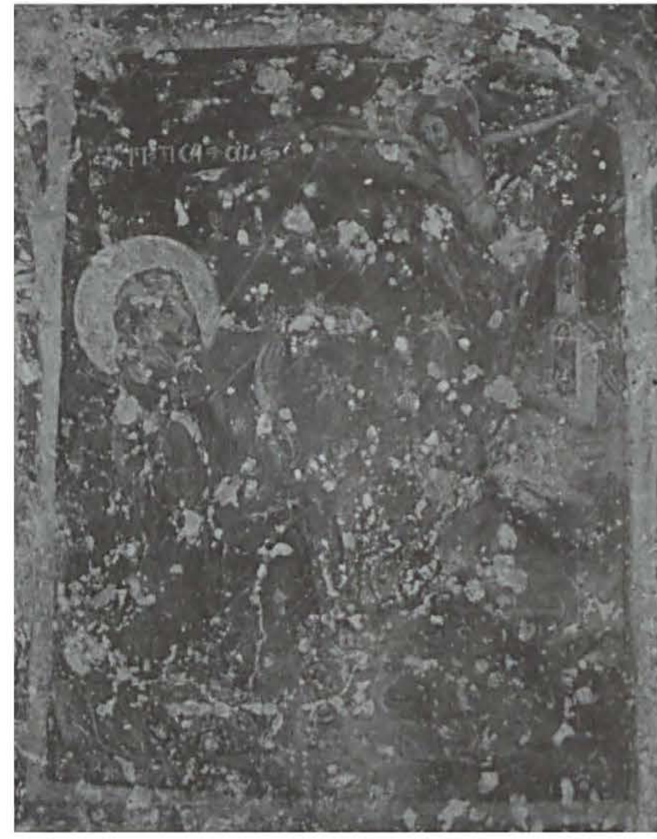

Abb. 5: Veglie, Favana, Stigmatisierung des Hl. Franziskus an der Ostwand (Foto: U. Ritzerfeld) Annäherung zu belegen. Die wohl als Zentrum einer griechischen Gemeinde dienende und zunächst in östlicher Tradition dekorierte Höhlenkirche S. Stefano bei Vaste wurde vom 14. Jahrhundert an mit für diesen Bereich ungewöhnlichen Themen und Heiligen, einer Apokalypse-Szene und den Hll. Martin, Katherina, Franziskus und Antonius geschmückt.60 In der Coelimanna in Supersano wie in der Cappella di Celsorizzo sind Heilige aus dem 13. Jahrhundert bilingual betitelt. ${ }^{61}$ In der Dekoration der Favana aus dem 15. Jahrhundert sind der Erzengel Michael und der $\mathrm{Hl}$. Antonius Abbas griechisch, die Hll. Antonius von Padua und Franziskus lateinisch beschriftet (Abb. 5, Tafel VI 1) 62

Deutlich wird in diesem Überblick, dass sich die spätmittelalterliche Kunstentwicklung Süditaliens weder als passive Repetition byzantinischer Modelle noch als eine von Neapel ausgehende Verbreitung der Gotik zusammenfassen lässt. Damit wäre der Bandbreite, dem Eklektizismus und der Kreativität der stilistischen, ikonographischen und konstruktiven Lösungen, die sowohl am Hof als auch im ganzen

59 Jacob sieht z. B. in einem in den Apsisfresken von Santo Stefano in Soleto erscheinenden eucharistischen Gebetstext einen Hinweis auf Kontakte nach Ägypten. Jacob, Testimonianze (wie Anm. 19), 56-60.

60 Linda Safran, The Art of Veneration: Saints and Villages in the Salento and the Mani, in: Jacques Lefort/Cécile Morrisson/Jean-Pierre Sodini (Hrsg.), Les villages dans l'Empire byzantin, I$\mathrm{Ve}_{\mathrm{e}} \mathrm{XV}$ e siècle (Réalités Byzantines, Bd. 11.), Paris 2005, 179-92, bes. 184; Cosimo Damiano Fonseca u. a., Gli insediamenti rupestri medioevali nel Basso Salento. (Saggi e ricerche, Istituto di Storia Medioevale e Moderna Lecce, Bd. 5.) Galatina 1979, 227-243.

61 Vgl. Fonseca, Insediamenti (wie Anm. 60), 205-211; Calò Mariani, Echi d'oltremare (wie Anm. 45), 238.

62 Fonseca, Insediamenti (wie Anm. 60), 245-249. Zuletzt Sergio Ortese, Ancora sulla pittura tardogotica nel Salento. Postille al ciclo della Favana a Veglie, in: Francesco Abbate (Hrsg.), Ottant'anni di un Maestro. Omaggio a Ferdinando Bologna. Neapel 2006, 173-183. 
Reich vom 13. bis 15. Jahrhundert erprobt wurden, nicht gerecht zu werden.63 In Apulien zeigt die Kunst in ihrer Entwicklung aus der unter byzantinischer Herrschaft geprägten Tradition heraus und mit Anleihen aus verschiedenen Regionen des Mittelmeerraumes, aus dem Adriagebiet, aus Frankreich und Italien ein eigenes und je nach Region durchaus unterschiedliches Gesicht. Die gängige Gegenüberstellung von Traditionen, die in der bis 1071 dauernden byzantinischen Herrschaft wurzelten und sie überdauerten, und ,westlichen' Traditionen, die seit der Normannenherrschaft programmatisch eingeführt worden sein sollen, stößt somit auf deutliche Schwierigkeiten.64 Die Realität ist wesentlich komplexer, macht doch die Kombination und Vermischung verschiedener Elemente und zeitlicher Strömungen den Charakter der apulischen Kunst im Spätmittelalter aus. Gerade die Position zwischen den Kunstrichtungen bestimmte die Wesenheit der apulischen Kunstwerke und eröffnete zugleich eine große Spannweite an Möglichkeiten und fließenden Übergängen zwischen unterschiedlichen Polen.

\section{Die Kunst der Mendikanten in Apulien}

Angesichts dieses weiten Spektrums an Möglichkeiten sind selektive stilitstische Entscheidungen und ihre Motivation in der Kunstpraxis der Mendikanten von besonderem Interesse, übten sie doch einen wesentlichen Einfluss auf die Entwicklung von Architektur und Bildkünsten aus, der als gezielte, Verwestlichung ' der Region gewertet worden ist. ${ }^{65}$ Die ersten Mendikanten in Apulien nutzten wahrscheinlich auch die sog. Höhlenkirchen, die in weiten Teilen der Region orthodoxen Mönchen und Gemeinden als religiöse Zentren dienten und den Neuankömmlingen gute Startbedingungen hätten bieten können.66 Ein wahrer Gründungs- und Bauboom der Bettelorden setzte in Süditalien unter den Anjou ein. Im Laufe des 13. und 14. Jahrhunderts entstand in Apulien,

63 Wie Caroline Bruzelius gezeigt hat, kam es zudem ab den 1290er Jahren zu einem ,powerful revival of Italian building traditions“. So wirkten in den Projekten von Karl II. bevorzugt in lokaler Tradition verwurzelte Baumeister, zugleich sind Referenzen auf Montecassino sowie auf Rom und frühchristliche Prototypen sichtbar. Caroline Bruzelius, Stones of Naples. Church Building in Angevin Italy 1266-1343. New Haven u. a. 2004, vii, 130. Ein Rückbezug auf frühchristliche Modelle ist ebenfalls in der Malerei des 13. Jahrhunderts konstatiert worden. Falla Castelfranchi, Pittura (wie Anm. 32), 158.

64 Selbst Calò Mariani, die in ihrem Aufsatz verschiedenste Einflüsse auf die Kunst der Region aufzeigt, spricht von einer Bipolarität der Kunst und Kultur, die bis Anfang des 15. Jahrhunderts zu spüren sei. Calò Mariani, Echi d'oltremare (wie Anm. 45), 239.

65 Calò Mariani, Note (wie Anm. 4), 140f., 158. Beispielsweise wird die Verbreitung des einschiffigen, mit einem überwölbten Chor kombinierten Grundrisses dem Einfluss der Mendikanten zugeschrieben; Calò Mariani, Echi d'oltremare (wie Anm. 45), 255.

66 Dies vermutet auch Giuseppe Castelluccio, Gli affreschi staccati dalla chiesa di San Francesco a Tricarico (Matera), in: Francesco Abbate (Hrsg.), Interventi sulla „Questione meridionale“. Rom 2005, 11-18, bes. 16. Bei der Existenz von Ikonostasen ist von einer Nutzung für den orthodoxen Ritus auszugehen. Von diesen abgesehen erlauben die architektonischen Eigenschaften der Höhlenkirchen aber keine eindeutige konfessionelle Zuweisung. Die legendäre Verbindung einer sol- 
der Basilicata und Kalabrien eine relativ homogene Bautengruppe. ${ }^{67}$ Unter den überlieferten Gebäuden gibt es fast ausschließlich einschiffige, flach gedeckte, seltener auch gewölbte Saalkirchen mit einem oftmals eingezogenen, rechteckigen oder polygonalen, kreuzgewölbten Chorhaus. Dieser Typ wurde ebenso auf kleinere Bauten wie auf Kirchen mit beachtlichen Raummaßen angewendet und er konnte je nach Dekor und Ausmalung schlicht oder aufwändig wirken. Als Beispiele seien hier S. Francesco in Lucera, S. Domenico in Manfredonia, die Chiesa del Christo in Brindisi (Dominikaner), die Chiesa del Carmine in Mesagne, S. Domenico in Matera, S. Donato in Ripacandida (Franziskaner) und S. Francesco in Irsina erwähnt (Abb. 6). Es fällt auf, dass weder die im übrigen europäischen Raum wichtigen basilikalen Bautypen noch der bedeutende mittelitalienische Dreikapellensaal bei den Mendikantenniederlassungen Süditaliens eine große Rolle spielen.68 Während der hier vorherrschende Bautyp des einschiffigen Saals mit offener oder flacher Holzdecke und kreuzgewölbtem Rechteckchor offensichtlich nicht direkt an mittel- oder norditalienische Entwicklungen in der Ordensarchitektur der Franziskaner und Dominikaner anschließt, lässt die Fassadengestaltung durchaus an eine Orientierung an S. Francesco und S. Chiara in Assisi denken. Häufig findet man das zentrale Portal mit einem Rad- oder Rundfenster darüber und bisweilen auch eine dreizonige Strukturierung. Es ist deshalb nicht auszuschließen, dass auch für den Süden gilt, was Wolfgang Schenkluhn allgemein mutmaßt, dass nämlich „S. Francesco über Sta. Chiara, Padua und Perugia den Anstoß für Saalraumkonzeptionen im Orden gegeben und gotischen Strukturelementen zum Durchbruch verholfen" hat.99 Der süditalienische Bautyp gleicht andererseits in grundlegenden Aspekten durchaus den älteren ortstypischen, kleinen und schlichten einschiffigen Pfarrkirchen der lateinischen wie griechischen Gemeinden und konnte so sicherlich zwischen traditioneller lokaler Architektur und neuen Formen vermitteln.

chen mit dem Hl. Franziskus, spätere Klosterbauten in der Nähe sowie franziskanische Motive im Raumschmuck können Hinweise auf eine franziskanische Nutzung sein, so wie beispielsweise im Falle der Favana in Veglie (Abb. 5). Vgl. dazu Fonseca, Insediamenti (wie Anm. 60), 245249. Auch über der Höhlenkirche SS. Pietro e Paolo in Matera wurde die Kirche S. Francesco gebaut. Der Legende nach wurde die Kirche vom Hl. Franziskus selbst besucht. Heißenbüttel, Italienische Malerei (wie Anm. 24), 168.

$67 \mathrm{Zu}$ den apulischen Bauten vgl. noch immer: Michela Tocci, Problemi di architettura minorita: esemplificazioni in Puglia, in: Bollettino d'Arte 60, 1975, 201-208; Michela Tocci, Architetture mendicanti in Puglia, in: Storia della Città 9, 1978, 24-27. Zu Kalabrien vgl. nun: Francesca Paolino, Architetture degli ordini mendicanti in Calabria nei secoli XIII-XV. (I saggi di opus, Bd. 9.) Pescara 2002; Attilio Spanò, Insediamenti francescani nella Calabria angioina. Il paradigma Gerace. Soveria Mannelli 2006.

68 Zur europäischen Mendikantenarchitektur vgl. Wolfgang Schenkluhn, Architektur der Bettelorden. Die Baukunst der Dominikaner und Franziskaner in Europa. Darmstadt 2000, hier 45-52, 64-71.

69 Schenkluhn, Architektur (wie Anm. 68), 63. 

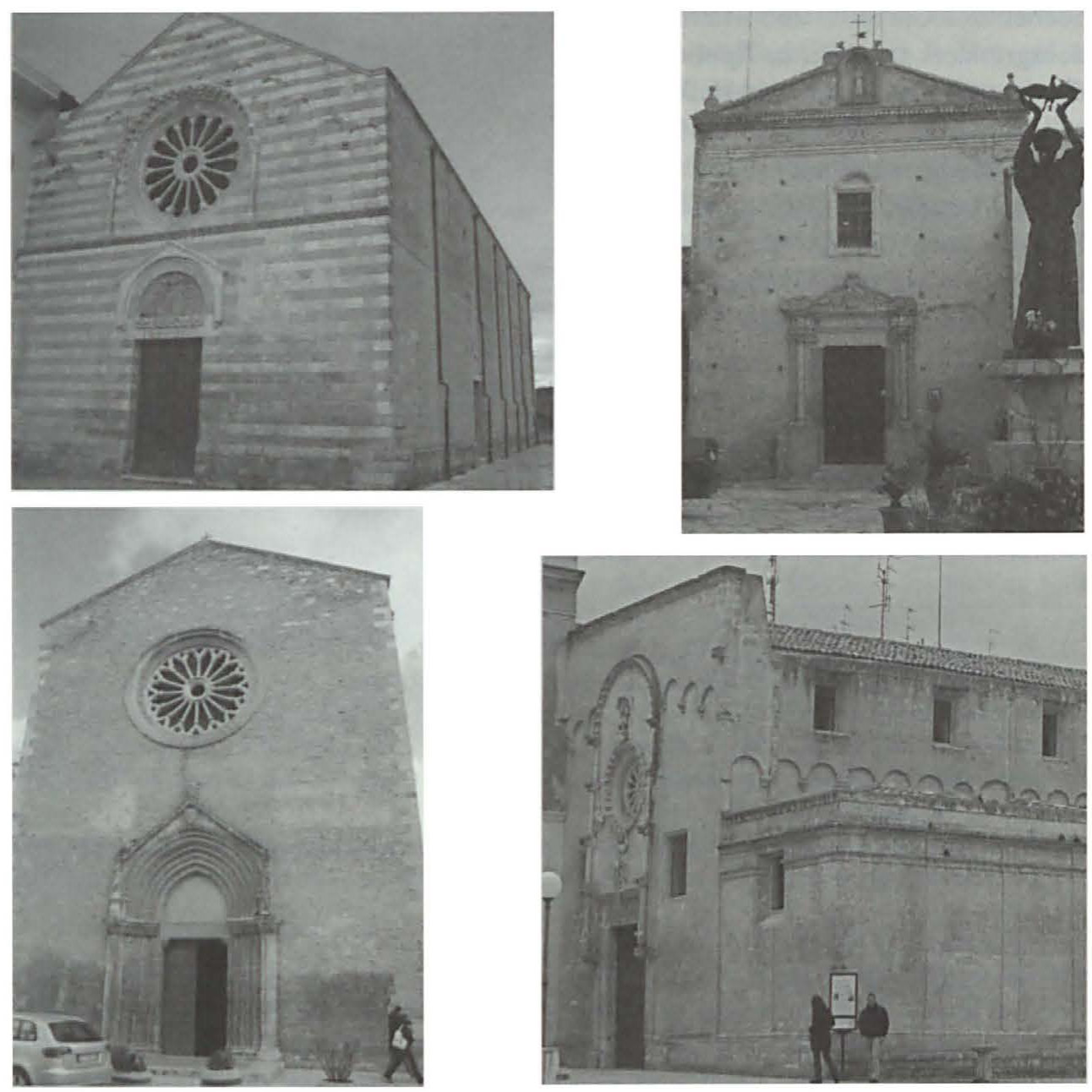

Abb. 6: Mendikantenkirchen in Apulien. Oben v. l. n. r.: Brindisi, Chiesa del Christo; Irsina, S. Francesco. Unten v. 1. n. r.: Lucera, S. Francesco; Matera, S. Domenico (Fotos: M. Mersch)

Für den Bildschmuck der Mendikantenkirchen Apuliens wird prinzipiell ein ,westlicher ${ }^{\star}$ Charakter vorausgesetzt. $\mathrm{Zu}$ berücksichtigen bleibt jedoch grundsätzlich die problematische Überlieferungslage, sind doch in der Regel jeweils nur wenige Dekorationsfragmente aus den Mendikantenkirchen, und zwar vor allem den Minoritenbauten, aus dem 14. und 15. Jahrhundert überkommen. Umfassende Zyklen mit Bildfolgen zu Themen des Alten und Neuen Testaments haben sich in S. Caterina in Galatina sowie in S. Donato in Ripacandida erhalten, die Kapelle unter S. Francesco in Irsina ist mit 


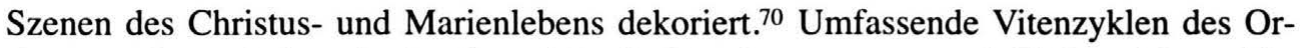
densgründers scheinen in Apulien nicht die Regel gewesen zu sein.71 Bezeichnend ist dagegen die Auswahl von Heiligen, zumeist Ordensmitglieder und im Umkreis des neapolitanischen Königshauses besonders verehrte Gestalten wie die Hll. König Ludwig, Ludwig von Toulouse und Elisabeth von Ungarn als auch biblische Figuren wie Maria Magdalena. ${ }^{72} \mathrm{Zu}$ kanonisierende Personen konnten bildlich propagiert werden, beispielsweise Urban V. in S. Francesco in Lucera und in der Kapelle unter S. Francesco in Irsina. ${ }^{73}$ Deutlich ist eine Präferenz der für Bettelorden typischen ikonographischen Bildformeln. ${ }^{74}$ Ein in den Minoritenkirchen häufiges Thema ist die Stigmatisierung des Heiligen, zum Beispiel in S. Francesco in Bitonto. ${ }^{75}$ Eine Darstellung der Stigmatisierung der Hl. Katherina von Siena ist aus dem Dominikanerkloster S. Giovanni Battista in Lecce überkommen. ${ }^{76}$ Die Chinisia in Bitonto wurde mit dem $\mathrm{Hl}$. Bonaventura und dem Lebensbaum sowie der Regelübergabe des Hl. Franziskus an seine drei Orden dekoriert, deren letztere sich an einer Darstellung im neapolitanischen Kloster von S. Chiara orientiert (Abb. 7) ${ }^{77}$ Generell wurden häufig neapolitanische

$70 \mathrm{Zu}$ S. Caterina s. u. Zur Kapelle unter S. Francesco in Irsina immer noch am ausführlichsten, wenn auch mit falscher Datierung: Margherita Nugent, Affreschi del Trecento nella cripta di S. Francesco ad Irsina. Bergamo 1933. Auch zu S. Donato in Ripacandida stehen neuere Untersuchungen aus. S. Giuseppe Gentile/Vittorio Bellocci, Il ciclo pittorico di Ripacandida. Rom 1969; Nuccia Barbone Pugliese, Ripacandida (Potenza). Chiesa di San Donato, in: Bollettino d'Arte 70, 1985, 29, 141-145.

$71 \mathrm{Zu}$ diesem Schluß kommt auch Louise Bourdua bezüglich der Minoritenkirchen im Veneto. Louise Bourdua, The Franciscans and Art Patronage in Late Medieval Italy. Cambridge u. a. 2004, 149.

72 Calò Mariani, Note (wie Anm. 4), $140 \mathrm{f}$.

73 Die Kanonisierung Urbans V. wurde bald nach seinem Tod angestrebt, konnte aber nicht durchgesetzt werden. Auch in Apulien genoss er hohe Popularität, wie zahlreiche Darstellungen beweisen. Zur gerade im Umfeld der Franziskaner sichtbaren Kanonisierungsstrategie vgl. Leo Andergassen, „Santo subito“. Spätmittelalterliche Kanonisationspropaganda am Beispiel des Papstes Urban V. (1362-1370) in Italien, in: Werner Telesko/Leo Andergassen (Hrsg.), Iconographia christiana. Festschrift für P. Gregor Martin Lechner OSB zum 65. Geburtstag. Regensburg 2005, 103-123.

74 Zur Verbreitung ikonographischer Modelle in Apulien vgl. Calò Mariani, Note (wie Anm. 4); Rosa Lorusso Romito, Le rotte ,adriatiche“ del gotico in Puglia. Frequentazioni e modelli iconografici, in: Bonita Cleri (Hrsg.), Adriatico. Un mare di storia, arte, cultura. Atti del convegno, Ancona 20.-22.5.1999. Ripatransone 2000, 33-51.

75 Vgl. Maria Stella Calò Mariani, Monopoli e le correnti dell'arte tra Medioevo e Rinascimento, in: Domenico Cofano (Hrsg.), Monopoli nell'età del Rinascimento. Atti del convegno internazionale di studio, 22.-24.3.1985. 3 Bde. Monopoli 1988. Bd. 2, 652-653.

76 Zur fragmentarischen Szene vgl. Mario Cazzato, Imprese costruttive e ristrutturazioni urbanistiche al tempo degli Orsini, in: Antonio Cassiano/Benedetto Vetere (Hrsg.), Dal giglio all'orso. I principi d'Angiò e Orsini del Balzo nel Salento. Lecce 2006, 306-335, bes. 311, Anm. 18.

77 Stefano Milello, La Chiesa e le chiese di Bitonto, Bitetto 2001, 151f. Zur Darstellung der Regelübergabe und der Verbreitung des Themas in Apulien vgl. Isabella La Selva, Un affresco pug- 


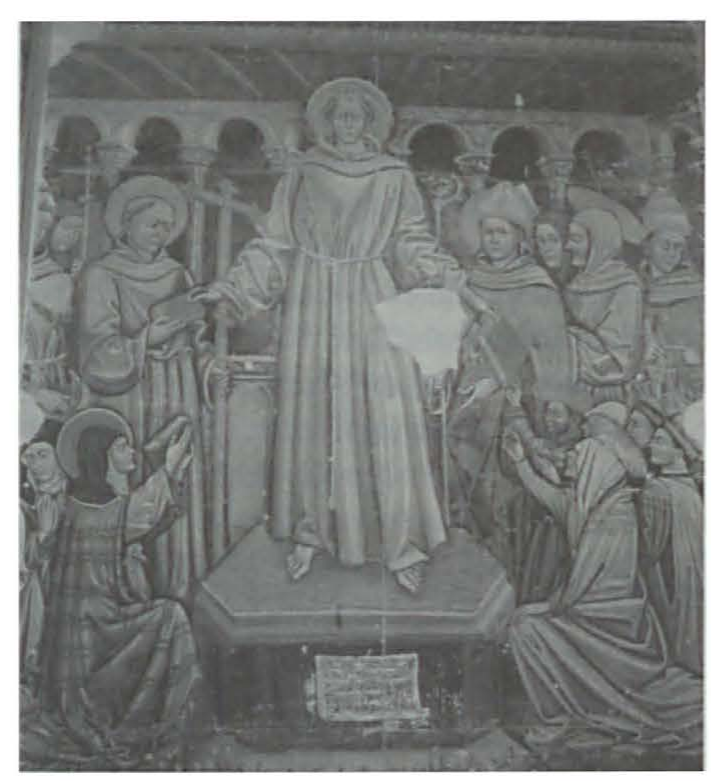

Abb. 7: Bitonto, Chinisia: ,Regelübergabe des $\mathrm{Hl}$. Franziskus' an der Südwand des Westjochs (Foto: U. Ritzerfeld)

der Franziskanerkirche S. Paolo Eremita in Brindisi an derjenigen von S. Maria del Casale. $^{79}$

Ein kurzer Vergleich dieser Bau- und Dekorgewohnheiten der sich in Apulien schnell ausbreitenden Mendikanten mit dem Usus der als Verteidiger der byzantinischen Tradition ${ }^{80}$ gewerteten orthodoxen Klostergemeinschaften lässt sowohl Unterschiede als auch Querbezüge deutlich werden. Das Beispiel der bedeutenden Basilianerklosterkirche S. Maria di Cerrate vom Ende des 12. Jahrhunderts bewies bereits vor Ankunft der Mendikanten die Verwurzelung in der lokalen Bautradition wie auch die generelle Offenheit für Einflüsse von Außen: eine dreiapsidiale Basilika mit offenem Dachstuhl (ohne Kuppel), die mit einem Portaldekor in Anlehnung an die etwa gleichzeitige Benediktinerkirche SS. Niccolo e Cataldo in Lecce (ca. 1180) versehen wurde (Abb. 8). Ihre Wandgliederung ist eine auffällige Weiterentwicklung des Rundbogenfrieses (mit überregionalen Analogien in der Romanik nördlich der Alpen und im Hl. Land) und findet sich im 13. und 14. Jahrhundert an griechischen wie lateinischen

liese del Quattrocento e note di iconografia francescana, in: Studi Bitontini 45/46, 1987/1988, 79-98.

78 Lorusso Romito, Cultura (wie Anm. 51), 353.

79 Vgl. dazu Calò Mariani, Echi d'oltremare (wie Anm. 45), 240-250, $257 \mathrm{f}$.

80 Corsi, Presenza e influssi (wie Anm. 13).
Vorbilder umgesetzt, so ist die Wurzel-Jesse-Darstellung in S. Domenico in Manfredonia auf Miniaturen am neapolitanischen Hof zurückgeführt worden ${ }^{78}$ Auch das in Neapel populäre Thema der Apokalypse fand in Apulien generell wie auch in den dortigen Mendikantenkirchen Anklang, so in S. Caterina in Galatina, wo die stilistische wie ikonographische Ausrichtung an Neapel bis in die Details spürbar ist. Aber auch lokal verehrte Bilder wie die wundertätige Madonna in S. Maria del Casale oder generell die Dekoration bedeutender Kirchen der Region, in diesem Fall einer Wallfahrtskirche, wurden als Modell genommen, besonders nachArbor Vitae und des Jüngsten Gerichts (Abb. 4). So orientierte sich beispielsweise der Freskenschmuck

.


Kirchen (Soleto, S. Lucia und S. Stefano; Castro, Dom; Brindisi, S. Maria del Casale; Ugento, S. Maria del Casale). ${ }^{81}$ Bei einigen der durch die Normannen an reiche lateinische Abteien angegliederten orthodoxen Klöster (S. Maria de Tridetti, Patirion in Rossano, S. Maria di Terreti) sind sogar Bezüge auf cluniazensische Architektur zu finden, die über Montecassino vermittelt sein dürften. ${ }^{82}$ In der Regel begnügten sich die Basilianer jedoch mit kleinen einschiffigen Apsidensälen oder Höhlenkirchen. ${ }^{83}$ Auch Mendikantenkirchen stellten Bezüge zur lokalen Bautradition her. Sie taten dies einerseits in sehr allgemeiner Weise durch die generelle Wahl einschiffiger Baukörper, andererseits mit einigen Bauwerken in spezifischer Form etwa durch Rundbogenfriese und spitzgiebelige Portalbaldachine (vgl. Abb. 6). Michela Tocci konzediert den Franziskanern im Salento, aus Rücksicht auf die gewohnten ,Bilder in den Köpfen“ des Kirchenvolkes auf die lokale romanische Tradition zurückgegriffen zu haben; ihr Anspruch sei die Schaffung einer Architektur gewesen, die schnell und weithin angenommen und verstanden werden sollte. ${ }^{84}$ Doch erscheint diese Darstellung etwas einseitig. Die Mendikantenarchitektur des 13. und 14. Jahrhunderts war offensichtlich nicht nur adaptiv auf Erfolg durch Anpassung angelegt, sondern insbesondere auch ostentativ auf Symbolisierung/Demonstration von Or-

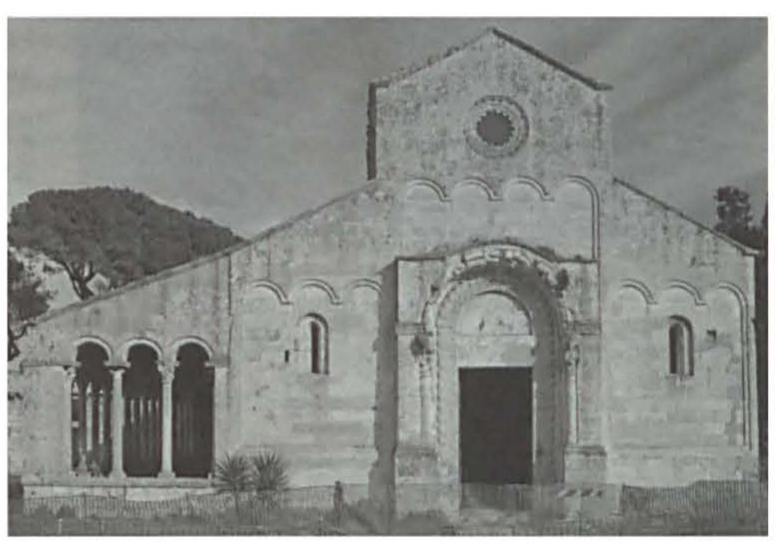

$A b b .8$ : Squinzano, S. Maria di Cerrate (Foto: M. Mersch) densinhalten; denn sie nahm von der großen Bandbreite der apulischen Traditionsstränge nur einen sehr geringen Teil auf und setzte ansonsten eigene programmatische Charakteristika wie zum Beispiel die konsequente Gegenüberstellung von offenem Holzdach im Schiff und Kreuzgewölbe im Chor und eben ihre eigene überregionale Homogenität im Bautypus durch.85 $\mathrm{Zu}$ -

81 Zu S. Maria di Cerrate vgl. Kemper, SS. Nicolò e Cataldo (wie Anm. 41), 68-101, bes. 87 mit Anm. 402.

82 Die Normannen hatten die kleineren orthodoxen Klöster - um ihre wirtschaftliche Existenz zu sichern - an reiche lateinische Abteien, wie etwa Montecassino, übertragen; Arnaldo Venditti, Architettura bizantina nell' Italia meridionale. Neapel 1967, 922, 932-934.

83 Vgl. z. B. Venditti, Architettura (wie Anm. 82), 830-852.

84 Tocci, Problemi (wie Anm. 67), 204.

85 Für eine Diskussion des Verhältnisses von Programmatik und Flexibilität in der Mendikantenarchitektur vgl. Margit Mersch, Programme, Pragmatism, and Symbolism in Mendicant Architecture, in: Anne Müller/Karen Stöber (Hrsg.), Self-Representation of Medieval Religious Commu- 
sammenfassend fällt im Vergleich von orthodoxer Klosterarchitektur und Mendikantenbauten v. a. die Problematik von Generalisierungen auf. Die orthodoxe Architektur war nicht die Verteidigerin der byzantinischen Tradition und die Mendikantenarchitektur war weder Agentin einer überregionalen Gotik noch reine Anpassung an lokale Tradition im Dienste der Mission. Es gibt Überschneidungspunkte von Basilianer- und Mendikantenarchitektur, die in der Dekortradition der so genannten apulischen Romanik wurzeln.86 Einige Mendikantenkirchen sprechen so mit ihrem Portal-, Fenster-, und/oder Wanddekor lokale orthodoxe wie lateinische ,Ästhetik‘ bzw. Sehgewohnheiten an. Viele Mendikantenkirchen enthalten sich aber dieser ,Anpassungsstrategien". Ein nicht geringer Teil der erhaltenen orthodoxen Bauten Apuliens ist in der lokalen Architekturtradition verwurzelt, und zwar weit stärker als die mendikantischen Beispiele; eine eigenständige orthodoxe, wenngleich relativ unauffällige Architektur stellen die sehr kleinen Apsidensäle dar (Abb. 9). Doch auch sie konnten, analog zu den kleinen lateinischen Saalkirchen, einen Anknüpfungspunkt zur üblicherweise einschiffigen Mendikantenarchitektur Apuliens bieten.

Der Bildschmuck orthodoxer Kirchen lässt ikonographische wie stilistische Differenzen zu den Mendikantenkirchen ins Auge springen, offensichtlich in den noch unter byzantinischer Herrschaft bzw. kurz danach entstandenen Fresken in S. Pietro in Otranto und dem Apsisdekor von S. Maria di Cerrate (Abb. 2). ${ }^{87}$ Jedoch schlichen sich auch in diesem Um-

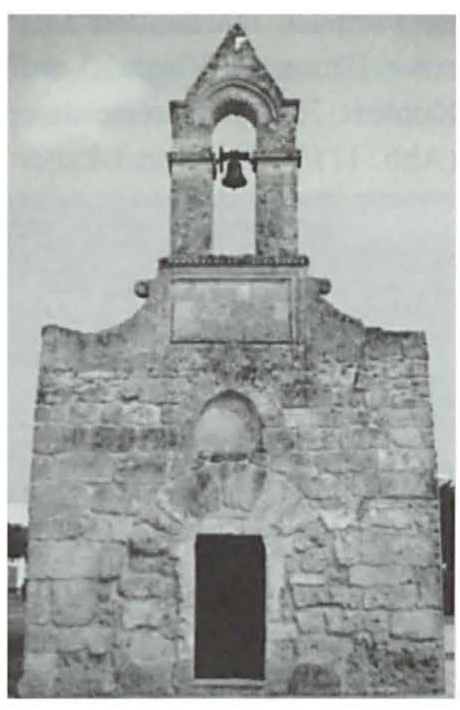

Abb. 9: Muro Leccese, S. Marina (Foto: M. Mersch) feld mit der Zeit Veränderungen ein, wie an dem Bildschmuck in S. Mauro bei Gallipoli (Ende 13. Jahrhundert) sowie einer Koimesis-

nities. The British Isles in Context. (Vita Regularis) Münster (im Druck). Anhand der kalabrischen Franziskanerkirchen verweist Spanò, Insediamenti, (wie Anm. 67), 31f., zu Recht auf die große theoretische Einheitlichkeit der Mendikantenarchitektur in ihrer Beschränkung auf einen Bautyp bei gleichzeitiger (scheinbarer) Heterogenität in der Aufnahme regionaler Architekturidiome. Regionale Idiome, die adaptiert wurden, waren jedoch nur solche, die die Forderung der Franziskaner nach einer schlichten Expressivität und einem einfachen Plan noch unterstrichen, so dass auch diese Adaptionen schlieBlich zum zentralen Anliegen der Vereinheitlichung des Kirchenraums beitragen konnten.

86 In diesem Zusammenhang ist die Rezeption der Skulptur des späten 11. Jahrhunderts aus dem Raum Lecce und Matera von besonderer Bedeutung. Vgl. dazu die Aufstellung von Kemper, SS. Nicolò e Cataldo (wie Anm. 41), 178-206.

87 Vgl. z. B. Pace, Pittura (wie Anm. 46), bes. 353f.; Falla Castelfranchi, Pittura (wie Anm. 32), 123-139 Zu S. Pietro in Otranto vgl. Safran, S. Pietro (wie Anm. 39). 
Darstellung in Cerrate (1. Hälfte 14. Jahrhundert) zu sehen ist (Abb. 10). In S. Mauro wie in Cerrate schiebt sich ein gotischer Architekturhintergrund ein, in der Szene in Cerrate hat zudem ein Stifter das Bild betreten. Demnach fanden selbst in den der griechischen Kultur besonders verbundenen orthodoxen Klöstern zumindest in bestimmten Bereichen Aneignungen statt, die vermutlich vor allem von außenstehenden Stiftern ausgingen sowie aus der Anstellung lokaler Künstler resultierten.$^{88}$ Am Thema des Marientodes ist auch das Vorgehen der Franziskaner nachzuvollziehen. Folgten die ersten Bildbeispiele in Apulien noch getreu der östlichen Tradition der ,Koimesis“, so wurden sie vom 13. Jahrhundert an in Orientierung an neapolitanischen Ausdrucksweisen zu einer ,Dormitio Virginis‘ umformuliert - und zwar überwiegend in franziskanischem Kontext, beispielsweise in der Kapelle unter S. Francesco in Irsina (um 1400) (Abb. 11) ${ }^{89}$ Die Franziskaner machten sich aber nicht nur ursprünglich aus dem Osten

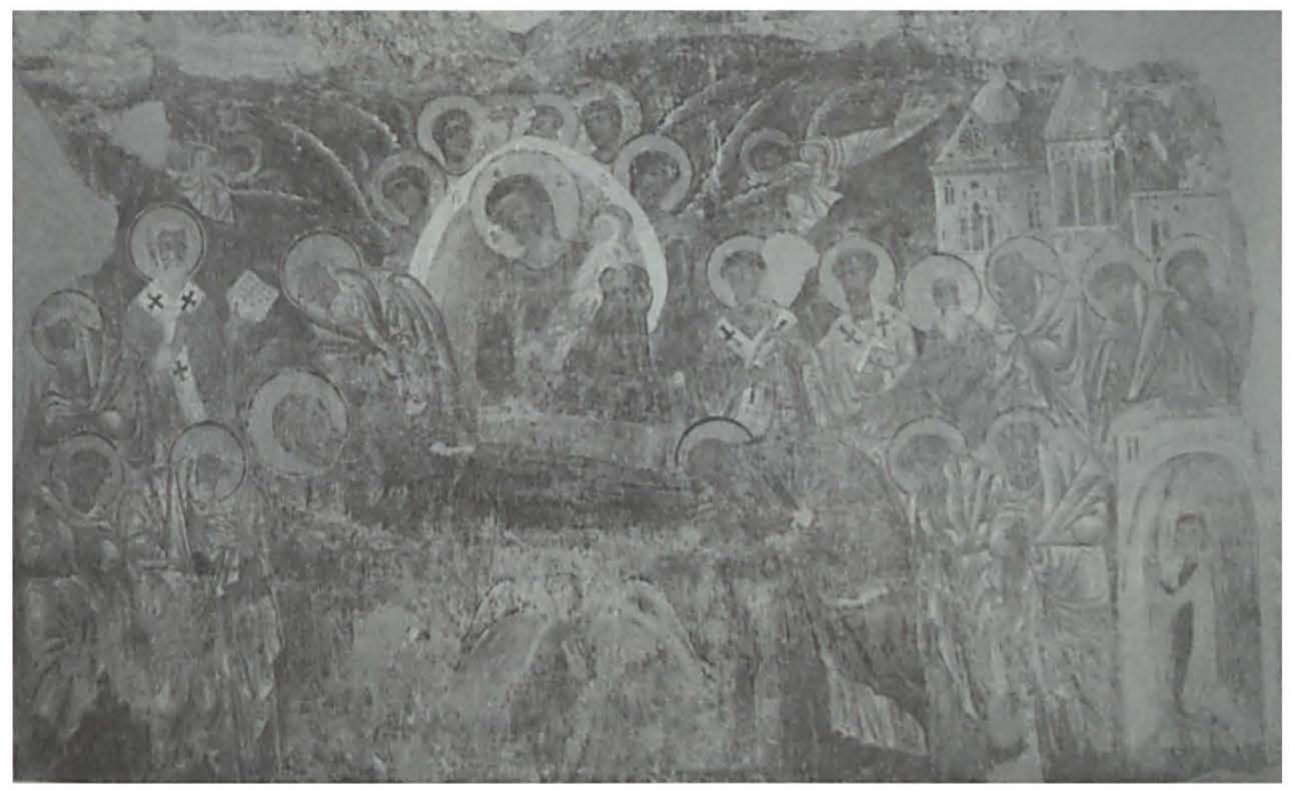

Abb. 10: Squinzano, S. Maria di Cerrate, Koimesis (heute im Klostermuseum) (U. Ritzerfeld)

88 Auszuschließen ist die These von Falla Castelfranchi, die davon ausgeht, dass nur griechische Freskanten tätig wurden. Falla Castelfranchi, Pittura (wie Anm. 32), 110. Dagegen Safran, S. Pietro (wie Anm. 39), 161.

89 Zu Szenen des Marientodes in Apulien vgl. Manuela De Giorgi, La Dormizione della Vergine nella pittura medievale di Puglia e Basilicata, in: Enrico Menestò (Hrsg.), Puglia tra grotte e borghi: insediamenti rupestri e insediamenti urbani. (Atti dei Convegni della Fondazione San Domenico, Bd. 2.), Rom 2007, 191-217; dies. Una „Dormitio Virginis“ angioina poco nota ad Aversa: il caso di San Francesco delle Monache, in: Francesco Abbate (Hrsg.), Ottant'anni di un Maestro: omaggio a Ferdinando Bologna. Neapel 2006, 97-106. Zur Koimesis im Museum von S. Maria di Cerrate vgl. Falla Castelfranchi, Pittura (wie Anm. 32), 135, 222. 
kommende Bildformulare zueigen, indem sie sie ihren Sehgewohnheiten anpassend umformulierten, sondern sie konnten bei Bedarf auch ausgesprochen ,byzantinisch* wirkende Details z. B. in der Kleidung der Heiligen akzeptieren.90

Demnach ist zwar eine scharfe Abgrenzung zwischen einer Kunst der Mendikanten einerseits und einer Kunst orthodoxer Klöster andererseits problematisch, eine tendenzielle Neigung zu einer bestimmten Kunsttradition im Rahmen der eigenen visuellen Kultur scheint aber durchaus existiert zu haben.91 Angesichts dieser Präferenzen stellt sich die Frage, ob die auftraggebenden griechischen Mönche und Mendikanten künstlerische Formen und Stile als kulturelle Versatzstücke verstanden und auf diese Weise auf die politisch-religiöse Lage Bezug nahmen, ob also zum Beispiel ikonographische Muster in Mendikantenkirchen als Versuche der Missionierung oder auch Unterdrü-

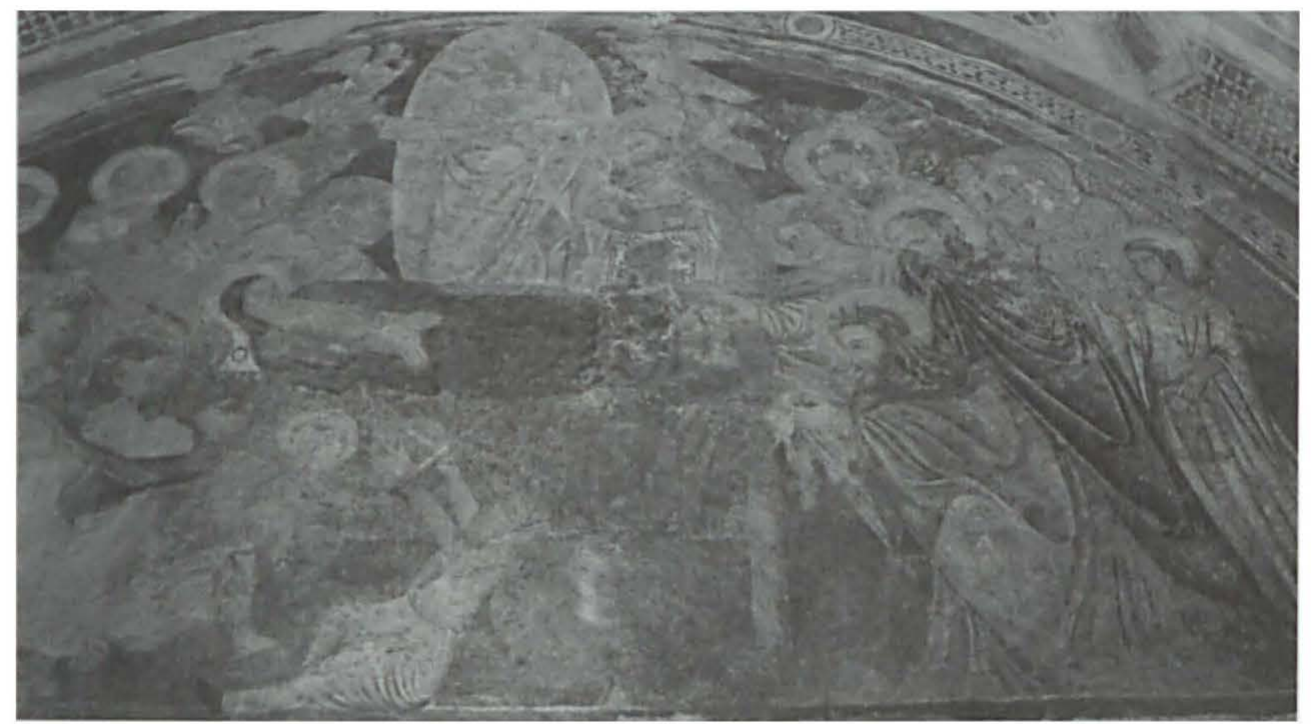

Abb. 11: Irsina, Kapelle unter S. Francesco, Dormitio Virginis an der Ostwand (Foto: M. Mersch)

ckung bzw. die Ausgestaltung orthodoxer Klosterkirchen als Protest gegen die römischkatholische Kirche gewertet werden können.

Zunächst ist vorauszusetzen, dass die relativ homogene Auswahl der Bautypen auf Seiten der Mendikanten als Folge ihrer überregionalen Organisationsform verstanden werden kann. Die Kirchen der orthodoxen Mönche und Gemeinden haben dagegen

90 Beispielsweise wurde der HI. Stephanus in S. Paolo Eremita in Brindisi im 14. Jahrhundert in reicher golddurchwirkter Kleidung präsentiert.

91 Auszuschließen ist die These, nach der die Herkunft der Handwerker verantwortlich für die unterschiedliche Situation war, mussten doch auf Seiten der Mendikanten wie der orthodoxen Mönche vor allem einheimische Künstler zum Einsatz kommen. Vgl. Anm. 88. 


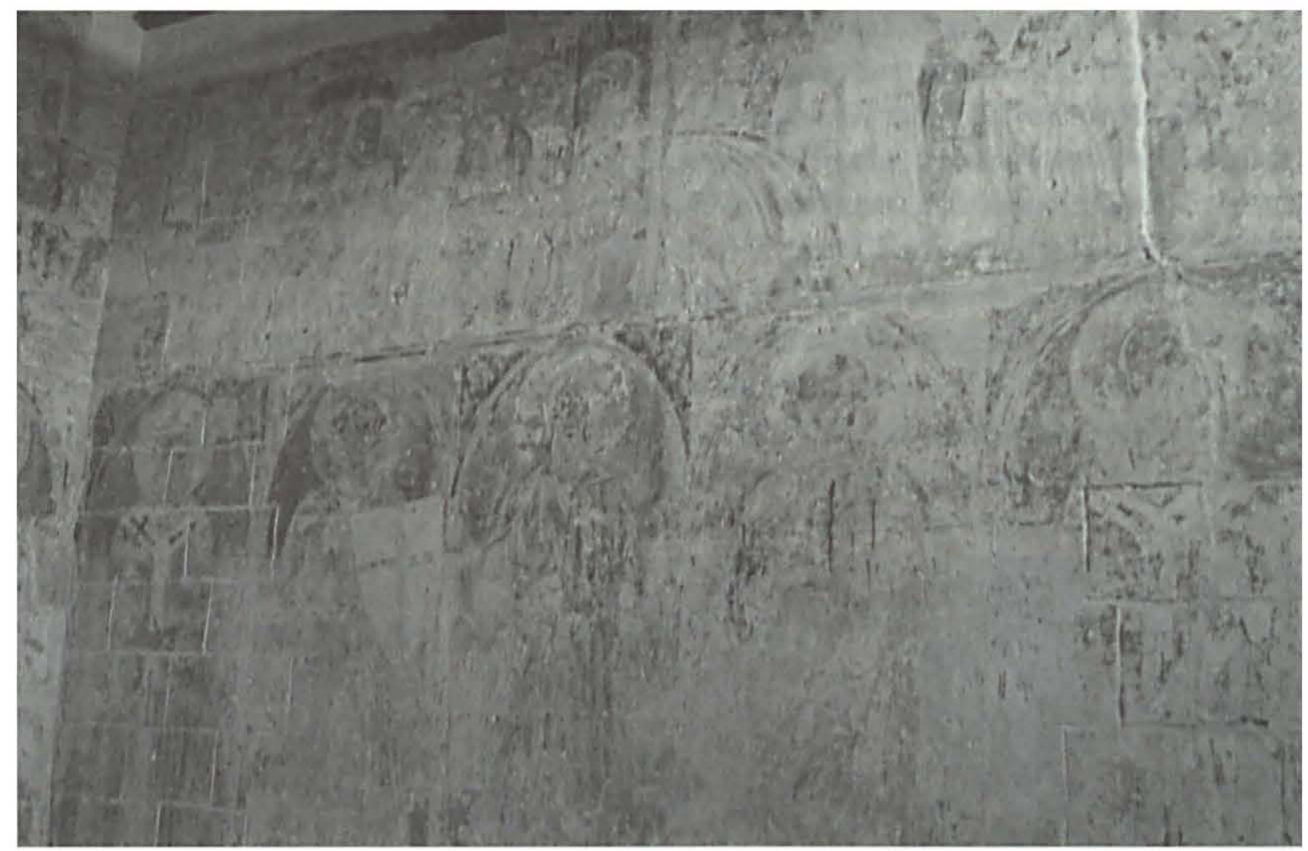

Abb. 12: S. Cesario Lecce, S. Giovanni, Heilige und Szenen der Vita Christi an der Südwand (Foto: U. Ritzerfeld)

einen anderen Bezugsrahmen, handelt es sich doch um nach Herkunft, liturgischen Usanzen ${ }^{92}$ und Traditionen verschiedene Gruppen, die teilweise katholischen Klöstern bzw. Bischöfen unterstanden.93 Dem griechischen Mönchtum ist eine übergreifende Organisation wie eine einheitliche Liturgie generell fremd. Die in Apulien ansässigen, von lateinischer Seite als ,Basilianer' bezeichneten Gruppen hatten weder eine einheitliche Regel geschweige denn eine Ordenshierarchie. ${ }^{94}$ Ihre Lebensweise war eremitisch geprägt. Ihre Kirchbauten folgten generell dem Ideal der Askese, waren zumeist klein

92 Vgl. dazu Jacob, Testimonianze (wie Anm. 19), 56-60. Jacob sieht z. B. in einem in den Apsisfresken von Santo Stefano in Soleto erscheinenden eucharistischen Gebetstext einen Hinweis auf Kontakte nach Ägypten.

93 Vgl. dazu Cosimo Damiano Poso, Il Salento normanno. Territorio, istituzioni, società. Galatina 1988.

94 Die Bezeichnung ordo s. Basilii taucht zuerst in Papsturkunden des 13. Jahrhunderts auf, ist also wohl eine Fremdbezeichnung; Horst Enzensberger, Der Ordo sancti Basilii, eine monastische Gliederung der römischen Kirche, in: La Chiesa greca in Italia dall'VIII al XVI secolo. Atti del Convegno Storico Interecclesiale, Bari, 30.4-4.5.1969. 3 Bde. Padua 1972-1973. Bd. 3. Padua 1973, 1139-1151; vgl. für einen Überblick auch dens., Art. Basilianer, in: Lexikon des Mittelalters. Bd. 1. München 2002, 1523-1524. 
und anspruchslos, orientierten sich an funktionalen bzw. liturgischen Anforderungen.95 Nur wenige bedeutende und wohlhabendere, eventuell durch bedeutende Stifter finanzierte Zentren wie S. Maria di Cerrate beweisen einen gehobenen Anspruch. Die Bildprogramme orthodoxer Klosterkirchen wiederum waren generell inhaltlich wie stilistisch auf Grund der orthodoxen Bildtheologie relativ festgelegt. Ziel der Klöster war die Aufrechterhaltung und Weitergabe des Glaubens und der Tradition, ihr Kirchendekor zeigte sich Neuerungen gegenüber abgeneigt. ${ }^{96}$ Auch in Apulien konnten in diesen Zentren des orthodoxen Glaubens und der griechisch-byzantinischen Tradition ,neue Heilige oder spezifisch ,katholische' bzw. mendikantische Bildmuster nur schwerlich aufgenommen werden, entsprachen sie doch nicht den traditionellen religiösen Anforderungen und Sehkonventionen. ${ }^{97}$ Ein allmähliches Einfließen formaler Neuheiten und Einzelelemente war damit aber nicht ausgeschlossen. Die diversen Freskenschichten in S. Stefano in Soleto (Ende des 14. bis Mitte des 15. Jahrhunderts) könnten vermuten lassen, dass griechische Gemeindekirchen sich im Laufe der Zeit der Aufnahme neuer Elemente eher geneigt zeigten. ${ }^{98}$ Aber auch hier dauerte der Prozess lange, so ist in dem 1329 von einem Priester gestifteten Bildschmuck von S. Giovanni in S. Cesario Lecce mit den ,byzantinischen" Heiligenreihen ein tendenzielles Festhalten an der Tradition sichtbar, während die christologischen Szenen bereits gotisch wirken (Abb. 12) ${ }^{99}$ Diese Verzögerung könnte mit dem vom 13. Jahrhundert an nachvollziehbaren Engagement der Priester und Gemeinden für die Erhaltung des griechischen Erbes übereinstimmen, ${ }^{100}$ in jedem Fall bestätigt sie aber die sich nur langsam lösende Verwurzelung der Bevölkerung im orthodoxen Bildverständnis, in der Neuerungen entgegenwirkenden traditionellen Seherwartung. Die Bettelorden wiederum hatten ein anders gelagertes Interesse sowie andere Sehkonventionen und Traditionen. Sie übernahmen zwar teilweise lokal verbreitete Bildschemata, passten sie aber den eigenen Bedürfnissen und Gewohnheiten an. Ziel war in erster Linie die Präsentation ihrer Ordensheiligen als Motto und Ausgangspunkt ihrer Tätigkeit und Propagierung dieser Heiligen und ihrer Nachfolger vor Ort.

95 Vgl. z. B. Venditti, Architettura (wie Anm. 82), 830-852.

96 Barbara Schellewald, „Stille Predigten“: das Verhältnis von Bild und Text in der spätbyzantinischen Wandmalerei, in: Andreas Beyer (Hrsg.), Die Lesbarkeit der Kunst: zur Geistes-Gegenwart der Ikonologie. Berlin 1992, 53-73, bes. 55f.; Gary Vikan, Byzantine Art, in: Angeliki Laiou/Henry Maguire (Hrsg.), Byzantium. A World Civilization. Washington (DC) 1992, 81118 , bes. $99-103$.

97 So ist vermutet worden, dass die inhaltlich wie formal, westlichen 'Szenen in Cerrate aus der Mitte bzw. der 2. Hälfte des 15. Jahrhunderts auf die vorherige Abwanderung der griechischen Mönche zurückzuführen ist. Antonio Cassiano, Un presunto ritratto tardo medievale di Tancredi, in: Hubert Houben/Benedetto Vetere (Hrsg.), Tancredi. Conte di Lecce, re di Sicilia. Atti del convegno internazionale di studio, Lecce, 19.-21.2.1998, Lavello 2004, 369-375, bes. 373.

98 Vgl. dazu Ortese, Sequenza (wie Anm. 57).

99 Falla Castelfranchi, Pittura (wie Anm. 32), 186, 214.

100 Corsi, Presenza e influssi (wie Anm. 13), 264. Vgl. Jacob, Testimonianze (wie Anm. 19), 63f. 
Das jeweilige Verhaltensmuster mit der von den eigenen funktionalen und inhaltlichen Interessen geleiteten und den eigenen Sehkonventionen folgenden überwiegenden Umsetzung der, eigenen' Formen und Inhalte in Bau und Dekor ist nicht per se mit einem Protest einerseits bzw. einer aggressiven Verdrängung andererseits gleichzusetzen (selbst wenn diese Intentionen im Einzelfall durchaus vorhanden gewesen sein mögen). Das im Allgemeinen ohne größere Auseinandersetzungen ablaufende relativ unproblematische Miteinander der Gläubigen in Apulien mit zahlreichen Annäherungen im gesellschaftlichen, religiösen und gerade auch künstlerischen Alltag widerspricht einer solchen Deutung, selbst wenn kirchliche Schriften auf beiden Seiten das Gegenteil vermuten lassen möchten. Vielmehr lässt das jeweilige tendenzielle Festhalten an der eigenen Tradition auf einen Akt der Selbstdefinition der jeweiligen Orden bzw. Niederlassungen in einer plurikulturellen Gesellschaft schließen, auf die Konstruktion einer Identität, eines eigenen Profils mit Hilfe von Kunstwerken, die durch den engen Kontakt und in Konkurrenz mit dem religiös und kulturell Anderen vorangetrieben worden sein mag. ${ }^{101}$

\section{Die Bedeutung des Feudaladels für die Kunst Apuliens}

Tatsächlich aber konnten gerade die Mendikanten Apuliens in ihrer Kunstpolitik wohl selten gänzlich autonom agieren. Zu berücksichtigen ist ebenfalls der Einfluss weltlicher Stifter, der je nach deren sozialer Stellung und der jeweiligen Einbringung des Ordens mehr oder weniger ausgeprägt sein konnte. Grundsätzlich waren dem Einfluss des Ordens Grenzen gesetzt, wenn dieser erst während oder nach Fertigstellung des Gebäudes eingesetzt wurde. So ist vermutlich das Erscheinungsbild der Ende des 14. Jahrhunderts errichteten und den Dominikanern übergebenen Kirche S. Giovanni Battista in Lecce als Teil der Hospitalstiftung des wohlhabenden Lecceser Bürgers Giovanni d'Aymo in erster Linie auf dessen Wünsche zurückzuführen. Als Motivation für die Stiftungstätigkeit des Kaufmanns wurde die versuchte Wiedergutmachung seiner Wucherpraktiken für sein Seelenheil hypothetisiert, eine politische Intention der von ihm in Auftrag gegebenen Kunst ist eher unwahrscheinlich. ${ }^{102}$

Anders sieht es aber für den lokalen Feudaladel aus, der mit den Mendikanten, vor allem den Franziskanern, in enger Verbundenheit operierte, als Stifter für die Entwick-

101 Vgl. dazu die Situation im mittelalterlichen Griechenland. Monika Hirschbichler, Monuments of a Syncretic Society. Wall Painting in the Latin Lordship of Athens, Greece (1204-1311). Diss. phil. College Park (MD) 2005, 206. Online im Internet: URL: http://hdl.handle.net/1903/ 3134 (Stand 20.07.2007).

102 Das Erscheinungsbild der Kirche ist nur in Ansätzen bekannt. Sie war mehrschiffig und gewölbt. Errichtet wurde sie zwischen 1388 und 1408. 1390 ersuchte der Stifter um die Einsetzung des Dominikanerordens nach. In den folgenden Jahren wurden Konvent und Hospital gebaut. Francesco Panarelli, La fondazione dell'Ospedale di Santa Caterina, in: Antonio Cassiano/Benedetto Vetere (Hrsg.), Dal giglio all'orso. I principi d'Angiò e Orsini del Balzo nel Salento. Lecce 2006, 224-235, hier 231; Cazzato, Imprese (wie Anm. 76), 307-312. 
lung der Bettelordenskunst in Apulien von unmittelbarer Bedeutung war und ein größeres Durchsetzungspotential besitzen musste als ein einfacher, wenngleich reicher Bürger. ${ }^{103}$ Ausgangspunkt dieser Entwicklung war das Königshaus der Anjou. Dominikaner wie Franziskaner genossen die besondere Unterstützung der ursprünglich südfranzösischen Dynastie, die von 1266 an in Absprache mit dem Papst die Herrschaft in Süditalien übernommen hatte. Als Vertraute und Berater der Mächtigen und als Bischöfe erlangten gerade die Minoriten weit reichenden Einfluss, dem die Forschung mit dem Begriff des ,francescanesimo di corte“ Rechnung trägt. Mit Beginn der Herrschaft der Anjou traten Neuerungen insbesondere in den Städten in Erscheinung. Neapel erlebte einen enormen Bauboom und wurde zum künstlerischen Vorbild für diverse Adelsfamilien in der ,Provinz‘. Dort änderte sich das Erscheinungsbild der großen wie kleineren urbanen Zentren vor allem durch den Bau oder die Erneuerung von Stadtmauern und die Gründung zahlreicher Mendikantenniederlassungen. In Apulien wurde vor allem der lokale Adel aktiv. ${ }^{104}$ Die territoriale Reorganisation des Gebiets durch Karl I. von Anjou hatte die Einsetzung französischer Adeliger zur Führung der Grafschaften beinhaltet. Wie die Anjou so zeigten sich auch diese den Minderbrüdern besonders geneigt

103 Grundlegend für das Zusammenwirken von Feudalaristokratie und Franziskanern hinsichtlich der Auswirkungen auf die Kunst der Region sind die folgenden Publikationen: Calò Mariani, Note (wie Anm. 4); Tocci, Problemi (wie Anm. 67); Tocci, Architetture (wie Anm. 67) sowie Pina Belli D'Elia, Principi e mendicanti. Una questione d'immagine, in: Caterina Lavarra (Hrsg.), Territorio e feudalità nel mezzogiorno rinascimentale. Il ruolo degli Acquaviva tra XV e XVI secolo. Atti del primo convegno internazionale di studi su la casa Acquaviva d'Atri e di Conversano, Conversano/Atri, 13.-16.9.1991. 2 Bde. Galatina 1995-1996. Bd. 2. (Biblioteca di cultura pugliese. Serie seconda, Bd. 101.) Galatina 1996, 274-292, und der Sammelband von Antonio Cassiano/Benedetto Vetere (Hrsg.), Dal giglio all'orso. I principi d'Angiò e Orsini del Balzo nel Salento. Lecce 2006.

104 Lange Zeit herrschte in der Geschichtsschreibung die Auffassung vor, dass der Erfolg der Bettelorden von der Unterstützung des Königshauses der Anjou abhing. Vgl. für die jüngere Literatur etwa Pellegrini, Territorio (wie Anm. 9). Inzwischen haben sich die Akzente etwas verschoben: Während die Haltung der verschiedenen Generationen der Anjou zu Dominikanern und Franziskanern nun differenzierter gesehen wird, betonen jüngere Studien vor allem die Bedeutung des lokalen Adels als Hauptförderers der Mendikanten. Bruzelius, Stones (wie Anm. 63), 77, 128f., konstatiert erst unter Karl II. eine wirklich ,flächendeckende' Unterstützung von Mendikantenniederlassungen. Samantha Kelly, Religious Patronage and Royal Propaganda in Angevin Naples: Santa Maria Donna Regina in Context, in: Janis Elliott/Cordelia Warr (Hrsg.), The Church of Santa Maria Donna Regina. Art, Iconography, and Patronage in Fourteenth Century Naples. Aldershot 2004, 27-43, ist der Meinung, dass die Anjou die Bettelorden nicht übermäBig bevorzugten, sondern ihre kirchliche Stiftungstätigkeit wohl durchdacht zwischen den verschiedenen Orden ausbalancierten. Tanja Michalsky, Sponsoren der Armut. Bildkonzepte franziskanisch orientierter Herrschaft, in: Tanja Michalsky (Hrsg.), Medien der Macht: Kunst zur Zeit der Anjous in Italien. Berlin 2001, 121-148, hingegen erkennt eine demonstrative Identifikation des Königspaares Robert von Anjou und Sancia von Mallorca mit dem Franziskanerorden, insbesondere mit den reformorientierten Kräften. Zur Bedeutung des lokalen Adels vgl. Giovanni Vitolo, La noblesse, les ordres mendants et les mouvements de réforme dans le 
und veranlassten die Gründung zahlreicher Konvente in kleineren Zentren und auf dem Land. ${ }^{105}$ Erst mit ihrer Hilfe konnten sich die Franziskaner flächendeckend in der Region ausbreiten. In der ersten Hälfte des 14. Jahrhunderts traten zunächst die angiovinischen Fürsten von Taranto mit Stiftungen hauptsächlich in Taranto und Brindisi in den Vordergrund. In der zweiten Hälfte des 14. und im 15. Jahrhunderts gewannen spezielle lokale Feudalfamilien an Bedeutung, zunächst die Grafen von Lecce, in erster Linie die d'Enghien und Brienne, und dann vor allem die Del Balzo Orsini, Chiaromonte, Maremonti und Acquaviva.106 So wurden, um nur einige wenige Beispiele aufzuzählen, S. Francesco in Lucera von Karl II. von Anjou, S. Caterina in Galatina von den Del Balzo Orsini, S. Maria dell'Isola in Conversano von den Acquaviva gegründet. Dabei waren auch von den Bettelorden unabhängige wichtige Gründungen dem Adel zu verdanken, so wurde wahrscheinlich S. Maria del Casale bei Brindisi von den Fürsten von Taranto Ende des Duecento gestiftete. ${ }^{107}$ Der Einfluss der feudalen Stifterfamilien ging also über die Kunst der Bettelorden hinaus, die apulische Kunstlandschaft des 14. und 15. Jahrhunderts zeigt sich zu größten Teilen von ihnen geprägt.

Es stellt sich die Frage nach den künstlerischen Präferenzen dieser Führungsschicht. Über ihre Stiftungen fanden vor allem Impulse aus der Provence sowie aus dem Zentrum Neapel als Sitz des Königshauses Eingang in die Kunst Apuliens. Gerade im Umfeld der neapolitanischen Königsfamilie beliebte Heilige und Themen wie die Apokalypse verbreiteten sich von den prestigeträchtigen Bauten des Adels aus in der Region. ${ }^{108}$ Jedoch ist dies nicht mit einer hermetischen Abgeschlossenheit ihrer Kunst gleichzusetzen. So beweist beispielsweise der unter Auftraggeberschaft verschiedener Adeliger entstandene Freskendekor des Trecento in S. Maria del Casale bei Brindisi die Anstellung lokaler Künstler und eine Offenheit gegenüber Motiven östlicher Herkunft (Abb. 4).109 Kirchen unterschiedlicher Funktion, etwa eben S. Maria del Casale oder die Kirchen von Ugento und Alezio oder die Dominikanerkirche Chiesa del Cristo in

royaume de Sicile, in: La noblesse dans les territoires angevins à la fin du moyen âge. Actes du colloque organisé par l'Université d'Anger. (Collection de L'École Française de Rome, Bd. 275.) Rom 2000, 553-566; Vgl. auch Arnaldo Venditti, Urbanistica e architettura angioina, in: Storia di Napoli. 11 Bde. Neapel 1967-1987. Bd. 3. Napoli angioina. Neapel 1969, 667888.

105 Vitolo, Ordini mendicanti (wie Anm. 7), 75f.

106 Vgl. dazu Belli D'Elia, Principi (wie Anm. 103), 261-294; Calò Mariani, Echi d'oltremare (wie Anm. 45), Cassiano, Arte (wie Anm. 52).

107 Dieses wird zumindest in der Forschung vermutet. Cassiano, Arte (wie Anm. 52), 279f.; Calò Mariani, Santa Maria del Casale (wie Anm. 57).

108 Vgl. dazu Calò Mariani, Note (wie Anm. 4), 139-164; Cassiano, Arte (wie Anm. 52), 263.

109 So wurde z. B. das Fresko des Jüngsten Gerichts an der Westfassade von Rinaldo da Taranto Anfang des Trecento gemalt. Es ist in seiner Anlehnung an das Mosaik in Torcello als Verbindung eines byzantinischen Modells mit Einflüssen aus dem Adriaraum und dem Nahen Osten 
Brindisi, weisen stilistische Analogien zu Bauten auf dem Peloponnes und in Ungarn auf. 110

Demnach wurden durch die Stiftungen des Feudaladels verschiedene Modelle nach Apulien eingeführt, was aber eine Berücksichtigung der einheimischen Kunsttradition nicht ausschloss. Es ging offenbar auch den adeligen Auftraggebern nicht generell um eine forcierte Latinisierung der Region mit Hilfe ,westlicher' Kunst.111 Dafür spricht auch die Umgangsweise der Herrscher Apuliens mit der lokalen Kultur und Bevölkerung. Gingen in Kalabrien die Ortsbischöfe mit Unterstützung der Königin Johanna von Neapel und unter Einsatz der Bettelorden aktiv mit den Mitteln der Inquisition gegen die griechischen Gemeinden vor, so verliefen die lateinisch-griechischen Begegnungen im Salento weniger konfliktreich. ${ }^{12}$ In der Terra d'Otranto etwa arbeiteten zwar die Bischöfe zusammen mit den Benediktinern auf eine verstärkte Kontrolle der griechischen Klöster hin,113 die Gemeinden blieben aber offensichtlich unbehelligt. Erst vom Ende des 14. Jahrhunderts an übten in Apulien die Päpste - mit unterschiedlichem Erfolg - politischen Druck auf die griechischen Gemeinden aus. ${ }^{114}$ Der herrschende Feudaladel ist in den Quellen nicht als aktiver Contrapart der griechischen Bevölkerung zu erkennen. Er scheint vielmehr die auf religiöser Ebene vorhandenen Zwistigkeiten nach Möglichkeiten entkräftet zu haben und konnte, wie im Folgenden deutlich werden wird, der Erhaltung der griechischen Tradition sogar förderlich sein.

\section{Die Kunstpolitik der Del Balzo Orsini und S. Caterina in Galatina}

Die Stiftungs- und Kunstpolitik der Del Balzo Orsini, der bedeutendsten Herrscherfamilie Apuliens im 14. und 15. Jahrhundert, zeigt exemplarisch das in engem Zusammenschluss mit den Franziskanern wie auch unter Berücksichtigung der Griechen durchgeführte gezielte und politisch bedingte Vorgehen feudaler Auftraggeber. An ihm wird offensichtlich, dass die ursprüngliche und eventuell bereits lange zurückliegende

gedeutet worden. Calò Mariani, Echi d'oltremare (wie Anm. 45), 246f.; Cassiano, Arte (wie Anm. 52), 279-286.

110 Sie dürften mit den damaligen politischen Einflusssphären der Anjou in diesen Regionen - als Prinzen von Achaia und Könige von Ungarn - in Verbindung stehen; Bruzelius, Stones (wie Anm. 63), 128. Doch muss ein solches mutmaßliches aktuell-politisches Architekturprogramm auch vor dem Hintergrund der über mehrere Jahrhunderte existierenden Beziehungen zwischen Apulien und den Gebieten östlich der Adria (Ragusa, Epirus, Achaia, Armenien, Georgien, Ungarn etc.) gesehen werden.

111 So noch z. B. Calò Mariani, Note (wie Anm. 4), 140f., 158. - Zur gezielten Latinisierung unter den Normannen vgl. Vito Sivo, Lingua e cultura nella Puglia dell'età normanna, in: Silvio Fioriello (Hrsg.), Bitonto e la Puglia tra tardoantico e regno normanno. Atti del Convegno, Bitonto, 15.-17.10.1998. (Il Grifo, Bd. 3.) Bari 1999, 265-289.

112 Thomas Hofmann, Papsttum und griechische Kirche in Süditalien in nachnormannischer Zeit (13.-15. Jahrhundert). Diss. phil. Bamberg 1994, 184-192.

113 Vgl. Houben, Benedettini (wie Anm. 6).

114 So Hofmann, Papsttum (wie Anm. 112), 192. 
,westliche“ Herkunft der Adelsfamilien nicht automatisch mit einer entsprechenden Prägung und Zielsetzung der lokalen Herren gleichzusetzen ist. Die aus Frankreich stammenden Del Balzo hatten die Grafschaft Soleto Mitte des 14. Jahrhunderts übernommen und entwickelten sich Ende des Jahrhunderts unter fortwährender Ausweitung ihres Einflussbereichs mit Raimondo del Balzo Orsini (1350/55-1406) zur wichtigsten politischen Macht in Apulien. Die Herrschaft der Familie zeichnete sich durch eine besondere politische und kulturelle Flexibilität aus. Sie hielten zwar einerseits eine enge Verbindung zum päpstlichen Stuhl und zu den Franziskanern, förderten aber gleichzeitig auch die griechische Kirche vor Ort. Zum Beispiel sorgte die Ehefrau von Raimondo del Balzo, Maria d'Enghien (1367-1446), im Jahre 1420 mit einer Intervention bei Papst Martin V. dafür, dass die griechische Klosterkirche S. Maria di Cerrate, die sich der Bischof hatte kommendieren lassen, einem Mönch des Klosters zurückgegeben wurde. ${ }^{115}$ Ihr Sohn, Giovanni Antonio del Balzo Orsini (1386/93- 1463), richtete 1452 einen fünftägigen Markt bei S. Maria di Cerrate ein. ${ }^{116}$ Darüber hinaus entwickelte die Hofkultur des Fürstentums von Taranto unter den Del Balzo Orsini einen eigenen autochtonen, neogriechischen Humanismus, der mit der byzantinischen Welt in engem Kontakt stand. Maria d'Enghien sammelte beispielsweise antike Münzen. Die Bibliothek der Familie enthielt zahlreiche griechische Codices, in Auftrag gegeben bei griechischen Skriptorien in Galatina und Nardò. ${ }^{117}$ Gerade in ihrem Herrschaftsgebiet bestand zwischen Nardò, Soleto, Maglie und Gallipoli ein reiches, an das griechische Gemeindenetz gebundenes kulturelles Leben. ${ }^{118}$ Demnach wurde das südliche Apulien nicht nur durch die gut ausgestatteten Bibliotheken von Basilianerklöstern wie S. Maria di Cerrate und S. Nicola di Casole und die Aktivitäten griechischer Geistlicher zum Hort griechischen Schriftguts. Auch die herrschende Adelsfamilie pflegte das östliche Erbe, das in ihrem Umkreis weiterentwickelt wurde.

Auch die Bauprojekte der Familie Del Balzo widersprechen der Hypothese einer forcierten Implementierung, westlicher' Kunst. Im Gegenteil zeugen sie von einem freien und problemlosen Umgang mit verschiedenen Kunstrichtungen. Raimondo ließ in Soleto, einer Nachbarstadt Galatinas, die Kirche S. Lucia und die sog. Guglia errichten. Die Guglia, wohl als Turm einer römisch-katholischen Pfarrkirche gedacht, wurde in

115 Poso, Salento normanno (wie Anm. 93), 104f.

116 Michela Pastore, Fonti per la storia di Puglia: Regesti dei Libri Rossi e delle pergamene di Gallipoli, Taranto, Lecce, Castellaneta e Laterza, in: Michele Paone (Hrsg.), Studi di storia pugliese in onore di Giuseppe Chiarelli. 7 Bände. Galatina 1972-1980. Bd. 2, Galatina 1973, 153-295, hier 247, documento 27.

117 Ferruccio Canali/Virgilio Galati, L' „Umanesimo grecanico“ e Firenze: Galatina in Terra d'Otranto tra cultura umanistica e attenzioni ottocentesche, in: Bollettino della Società di Studi Fiorentini 1, 1997, 9-33, hier 10f.; Rosario Coluccia, Lingua e politica. Le corti del Salento nel Quattrocento, in: Paolo Viti (Hrsg.), Letteratura, verità e vita: studi in ricordo di Gorizio Viti. (Storia e letteratura, Bd. 223.) Rom 2005, 129-172, hier 152f.

118 Jacob, Testimonianze (wie Anm. 19), 63f. 
einer spätgotischen Architektur realisiert. ${ }^{119} \mathrm{Ihr}$ reicher ornamentaler Dekor wurzelt in der Regionaltradition, während sich das Maßwerk der Zwillingsfenster und die Durchbrechungen von Balustrade und Fiale an einer überregionalen und zur Bauzeit höchst aktuellen Formensprache orientieren. ${ }^{120}$ Dagegen war S. Lucia als Kirche einer griechischen Gemeinde in ihrem Außendekor deutlich dem romanischen Formengut der alten Klosterkirche des Basilianerklosters S. Maria di Cerrate verpflichtet. ${ }^{121}$ Die Außenwände des nicht mehr erhaltenen Saalbaus wurden auf dieselbe Weise wie bei S. Maria di Cerrate durch profiliert gerahmte Wandfelder mit Rundbogenfries als oberem Abschluss gegliedert. Die von den Del Balzo Ende des 14. Jahrhunderts ebenfalls in Soleto gestiftete, offensichtlich einer griechischen Gemeinde dienende Kirche Santo Stefano (Abb. 1c) wurde in mehreren Phasen mit einem griechisch beschrifteten Programm ausgemalt. Die Inschriften stehen in ostkirchlicher Tradition.122 Gleichzeitig sichert die Darstellung frommer römisch-katholischer Würdenträger im Jüngsten Gericht die sichtbare Oberhoheit der römischen Kirche (Abb. 13, Tafel VI 2).123 Der Sohn Raimondos, Giovanni Antonio del Balzo, trat wohl als Stifter der franziskanischen Chinisia in Bitonto auf, die mit den beiden überkommenen Freskenfragmenten einen deutlich franziskanischen Stempel trägt (Abb. 7). ${ }^{124}$

Wird in diesen Beispielen eine individuelle Anpassung und Auswahl von der jeweils passenden Form und dem adäquaten Inhalt aus verschiedenen künstlerischen Möglichkeiten und kulturellen Traditionen deutlich, so ist besonders interessant, welcher Kunstpolitik die Del Balzo in ihrer monumentalsten Stiftung, in S. Caterina in Galatina folgten. Gerade diese Kirche ist von der Forschung, offensichtlich motiviert durch den eingangs zitierten Bullentext, als exemplarisches Beispiel für die Kooperation von katholischer Kirche, Mendikanten und Feudaladel in der Implementierung ,westlicher Kunst mit dem Zweck einer Latinisierung und Verdrängung des östlich geprägten Lokalstil als Zeichen einer ,orientalischen ' Kultur angesehen worden. ${ }^{125}$ Kirche, Kloster und Hospital von S. Caterina wurden von Raimondo del Balzo Orsini, Graf von Soleto

119 Zur Geschichte der Guglia und zur Diskussion über ihre ursprüngliche Funktion vgl. Luigi Manni, Dalla guglia di Raimondello alla magia di messer Matteo. Galatina 1997; Cassiano, Arte (wie Anm. 52), 299.

120 Pace, Kunstdenkmäler (wie Anm. 38), 462, sieht in diesen architektonischen Lösungen möglicherweise über Neapel vermittelte Kenntnisse der gleichzeitigen katalanischen Architektur.

$121 \mathrm{Zu}$ der nur noch durch wenige Abbildungen überlieferten Kirche vgl. Kemper, SS. Nicolò e Cataldo (wie Anm. 41), 201. Ältere Beschreibungen liefern De Giorgi, Provincia (wie Anm. 3), 47f.; Giuseppe Gigli, Il tallone d'Italia. 2 Bände. Bergamo 1911-1912. Bd. 1: Lecce e dintorni. (Collezione di monografie illustrate 1, Bd. 61.) Bergamo 1911, 79-82.

122 Vgl. Roberto Mastacchi, Il Credo nell'arte cristiana italiana. Siena 2007, 37f.; Jacob, Testimonianze (wie Anm. 19), $59 \mathrm{f}$.

123 Vgl. dazu Ortese, Sequenza (wie Anm. 57).

124 Calò Mariani, Note (wie Anm. 4), 161; Milello, La Chiesa (wie Anm. 77), 151 f.

125 De Giorgi, Provincia (wie Anm. 3), 414; Anna Maria Matteucci, Gli affreschi di S. Caterina in Galatina, in: Napoli Nobilissima 5, 1966, 189. Vgl. Vittorio Zacchino, In umbilico totius penin- 


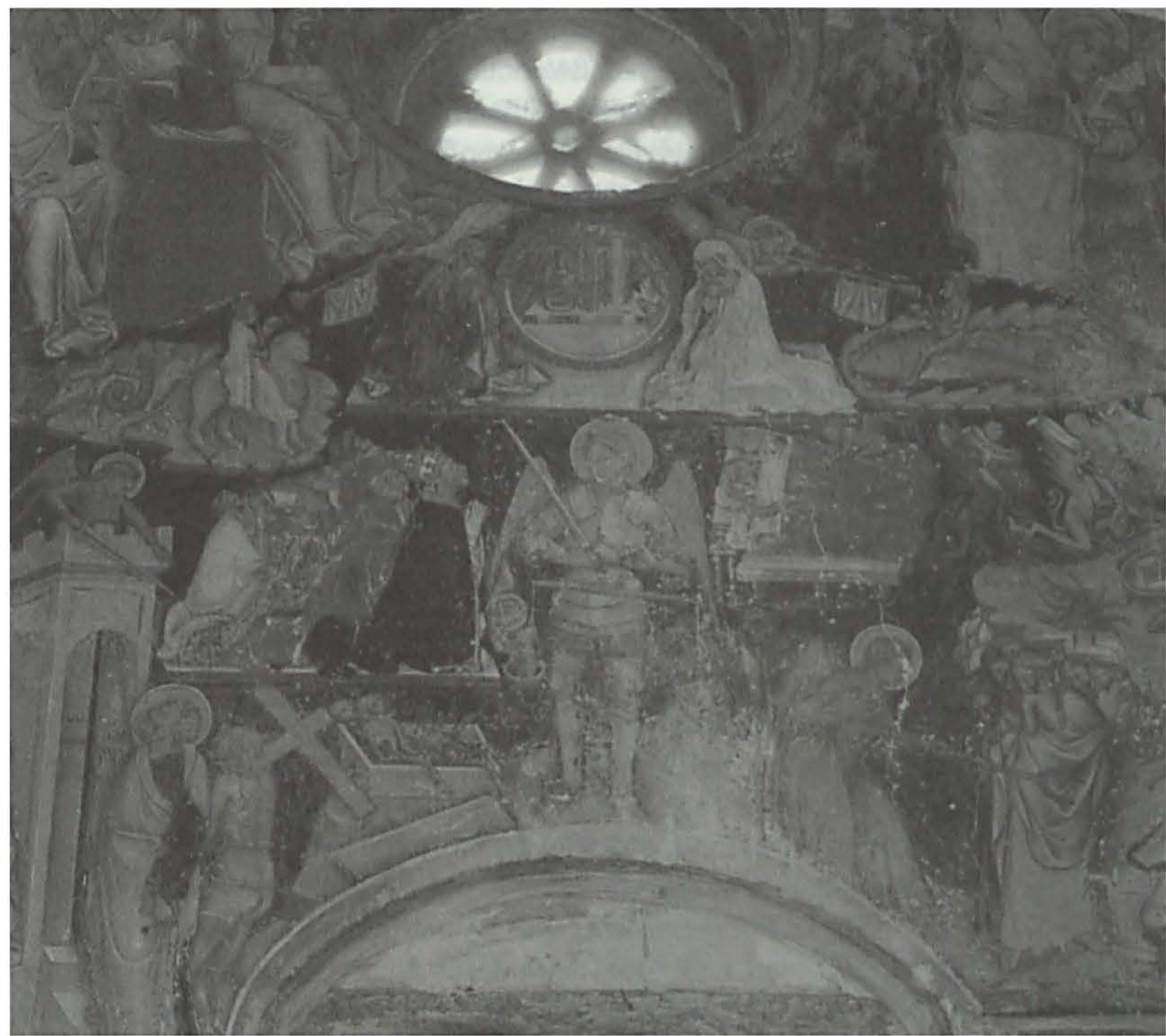

Abb. 13: Soleto, S. Stefano, Jüngstes Gericht an der Westwand (Foto: M. Mersch)

und Lecce, gegründet. ${ }^{126}$ Die Kirche war zum Zeitpunkt ihrer päpstlichen Bestätigung,

sulae: Galatina e dintorni dai bizantini ai napoleonidi, in: Mario Cazzato (Hrsg.), Dinamiche storiche di un'area del Salento. Galatina 1989, 131-259, bes. 193, 256-266. - Für weitere Details verweisen wir auf unsere Veröffentlichung: Differenzwahrnehmung in Architektur und Malerei der Franziskanerkirche S. Caterina in Galatina (Apulien), in: Michael Borgolte/Juliane Schiel/Bernd Schneidmüller/Annette Seitz (Hrsg.), Mittelalter im Labor. Die Mediävistik testet Wege zu einer transkulturellen Europawissenschaft. (Europa im Mittelalter, Bd. 10.) Berlin 2008, 50-83.

126 Vgl. generell zur Geschichte des Konvents Benigno Francesco Perrone, Neofeudalesimo e civiche Università in Terra d'Otranto. (Biblioteca di Cultura Pugliese, Bd. 19.) Galatina 1978; Cosimo Damiano Poso, La fondazione di Santa Caterina: scelta devozionale e committenza artistica di Raimondo Orsini del Balzo, in: Antonio Cassiano/Benedetto Vetere (Hrsg.), Dal giglio all'orso. I principi d'Angiò e Orsini del Balzo nel Salento. Lecce 2006, 194-223; Panarelli, Fondazione (wie Anm. 102). 
im Jahr 1385, bereits im Bau. Eine zweite Bulle dieses Datums belegt die auf Verlangen des Stifters hin erfolgte Berufung von Franziskanerkonventualen der Provinz Kalabrien. ${ }^{127}$ Fertig gestellt war die Kirche vermutlich im Jahre 1391, dessen Datum als Inschrift über dem linken Seitenportal der Fassade angebracht ist. Aus demselben Jahr datiert eine Bulle, mit der Papst Bonifatius IX. auf Wunsch von Raimondo del Balzo nunmehr den Vikar des Vikariats Bosnien bittet, einige fratres nach Galatina zu schicken. ${ }^{128}$ Bereits aus dieser kurzen Datenübersicht wird eines deutlich: Die angeblich für die Latini von Galatina erbaute Kirche S. Caterina wurde keineswegs auf Anregung des Vatikan oder der Mendikanten hin errichtet, sondern entstand auf Betreiben des feudaladeligen Stifters, hauptsächlich als Familiengrablege. ${ }^{129}$ Sie wurde erst nachträglich vom Papst autorisiert und nachträglich wurden die Franziskaner berufen. Ihre Entstehung ist demnach nicht als gezielte kirchliche Aktion gegen die orthodoxen Gläubigen zu verstehen, selbst wenn sie im Nachhinein mit dieser Deutung belegt wurde. ${ }^{130}$ Vielmehr tritt die Stifterfamilie als treibende Kraft hervor, auf deren Willen hin die Kirche mit dem Zweig der bosnischen Franziskaner verbunden und unter den speziellen Schutz des päpstlichen Stuhls gestellt wurde. ${ }^{131}$ Die ausschlaggebende Bedeutung der Stifter für das Kirchenprojekt ist auch bei der Betrachtung von Architektur und Dekoration in Erinnerung zu behalten.

127 Für beide Urkunden s. Anm. 1.

128 Montinari, Galatina antica (wie Anm. 1), VIII-IX, Documento 14.

$129 \mathrm{Zu}$ den Grablegen in der Kirche und der entsprechenden Bestimmung des Sakralbaus vgl. Dagmar Zimdars, Die Ausmalung der Franziskanerkirche S. Caterina in Galatina/Apulien. München 1988, 156-160, 171-176.

130 Nur selten werden die genaueren Entstehungsumstände der beiden Papsturkunden berücksichtigt, die darauf hinweisen, dass in diesem Fall die Initiative eher beim Stifter als beim Papst lag. Raimondo del Balzo Orsini hatte längst mit dem Bau der von ihm gegründeten Kirche begonnen (fundari et construi facere iam incepit), als er sich die Stiftung nachträglich von Papst Urban VI. bestätigen lieB. Der Papst stellte die beiden von Seiten des Feudalherren erbetenen Urkunden unmittelbar nach seiner Befreiung durch Raimondo aus einer eineinhalbjährigen Belagerung durch Karl III. von Durazzo in Nocera aus, noch bevor er nach Genua abreiste. Sie sind also wohl eher als eine Dankesgabe denn als eine kirchenpolitische Intervention zu sehen. Vgl. Perrone, Neofeudalesimo (wie Anm. 126), 157-159; Cosimo Damiano Poso, Vescovi e potere politico in Terra d'Otranto durante il grande scisma d'Occidente, in: Puglia medievale. Politica, istituzioni, territorio tra XI e XV secolo. (Università degli Studi di Lecce, Dipartimento de scienze storiche e sociali: Serie 2, Saggi e Ricerche, Bd. 10.) Galatina 2000, 83-138, hier 103 mit Anm. 80.

131 Die Einweihungszeremonie eines Hospitals in Andrano beweist, dass karitative Einrichtungen nicht unter dem Segen einer speziellen Kirche stehen mussten. Anfang der 1370er Jahre erfolgte dort die Einweihung eines von einem Privatmann finanzierten Hospitals unter Anwesenheit von Bischöfen verschiedener Konfession. $\mathrm{Vgl}$. André Jacob, Une fondation d'hôpital à Andrano en Terre d'Otrante (Inscription byzantine du Musée provincial de Lecce), in: Mélanges de l’École française de Rome. Moyen âge - Temps modernes 93, 1981, 683-693. 


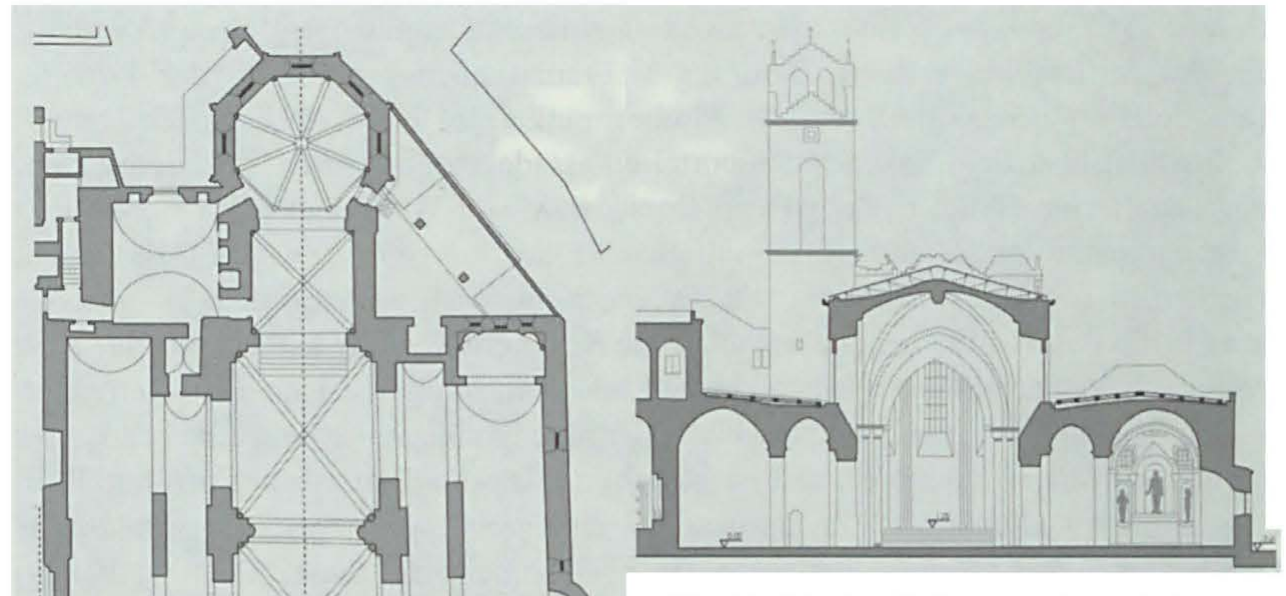

$A b b$. 15: Galatina, S. Caterina, Querschnitt (unter Verwendung der Konventszeichnung bei Russo, La basilica [wie Anm. 132], 61)

$A b b$. 14: Galatina, S. Caterina, Grundriss (unter Verwendung des Konventsplans bei Russo, La basilica [wie Anm. 132], 59)

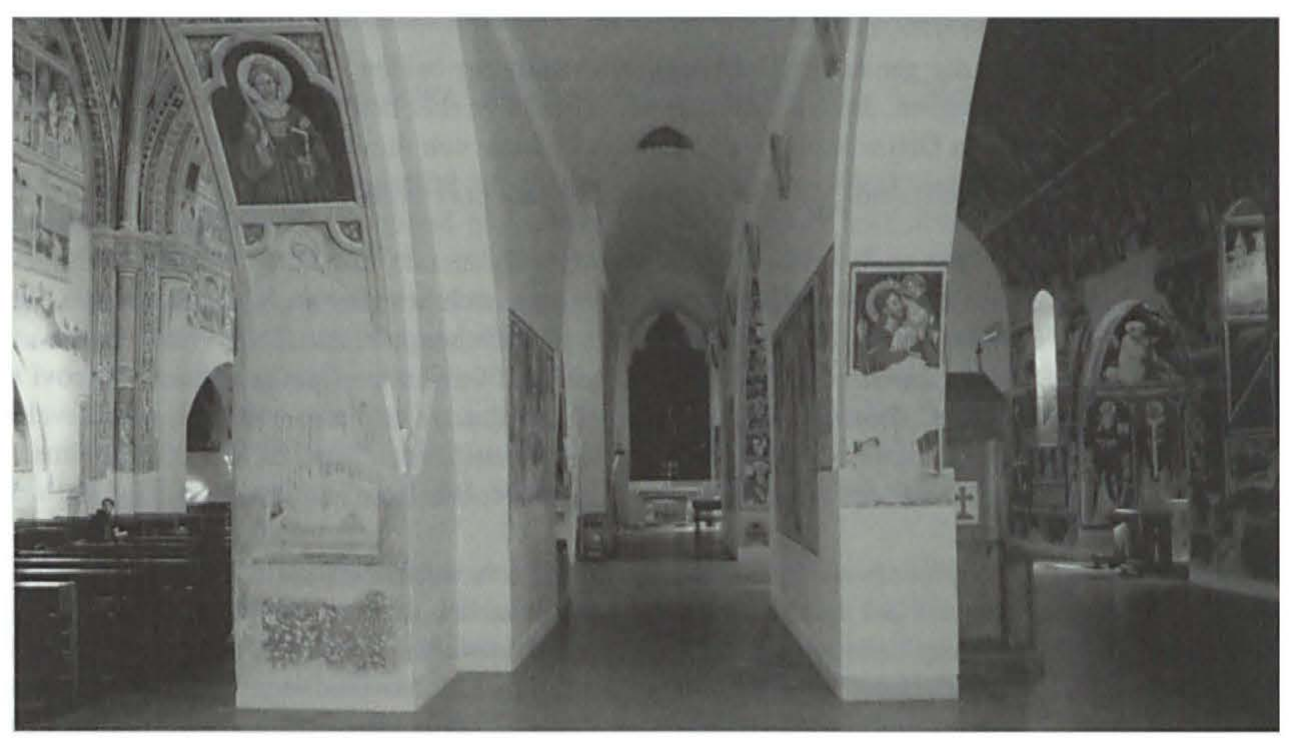

Abb. 16: Galatina, S. Caterina, Mittelschiff (links) und südliche Seitenschiffe (Foto: M. Mersch) 
Es handelt sich bei dem Bau um das für lateinische Kirchen jener Zeit höchst außergewöhnliche Konzept einer fünfschiffigen Basilika auf annähernd quadratischem Grundriss mit quadratischem Chorhaus (Abb. 14).132 Die oktogonale Chorhauptkapelle wurde nachträglich, um die Mitte des 15. Jahrhunderts, unter Giovanni Antonio Orsini als Grabkapelle angebaut. Im Unterschied $\mathrm{zu}$ anderen fünfschiffigen Basiliken Italiens ${ }^{133}$ sind die inneren Seitenschiffe deutlich schmaler und auch niedriger als die äußeren (Abb. 15) und wirken - auch durch ihre Portalzugänge in der Fassade - eher wie Korridore. Zwischen den Schiffen vermitteln nicht wie üblich Arkaden mit Pfeileroder Säulenreihen, sondern massive Wände mit nur einer Bogenöffnung pro Joch. Das Mittelschiff und das Sanktuarium werden von Kreuzrippengewölben überfangen, die inneren und äußeren Seitenschiffe aber von Spitztonnengewölben, die für diese Bauzeit anachronistisch wirken. Das rechte äußere Seitenschiff besitzt zudem an ungewöhnlicher Stelle, nämlich in der Mitte der Längsmauer, eine Apside.

Hauptschiff und äußere Seitenschiffe sind als eigenständige Räume erlebbar (Abb. 16). Die dunklen, nur mit einem Rundfenster in der Fassade versehenen, tonnengewölbten Seitenschiffe evozieren den Raumeindruck zeitgenössischer bzw. älterer griechischer Pfarrkirchen der Region, wie zum Beispiel S. Maria della Croce bei Casa-

132 Wichtige Beiträge und Bemerkungen zur Baugeschichte finden sich bei: Baldassar Papadia, Memorie storiche della città di Galatina nella Japigia. Neapel 1792, bes. 30, 35f.; Gian Luigi Blasi, Galatina e la sua gemma. Galatina 1934, bes. 57-67; Heinrich Wilhelm Schulz, Denkmäler der Kunst des Mittelalters in Unteritalien. Nach dem Tode des Verfassers hrsg. von Ferdinand von Quast. 4 Teilbde. Dresden 1860. Bd. 1, 274-286. Camille Enlart, Origines françaises de l'architecture gothique en Italie. (Bibliothèque des Écoles françaises d'Athènes et de Rome, Bd. 66.) Paris 1894, 162; Wolfgang Krönig, Hallenkirchen in Mittelitalien, in: Kunstgeschichtliches Jahrbuch der Bibliotheca Hertziana 2, 1938, 1-142, hier 58f.; Antonio Antonaci, Gli affreschi di Galatina. Mailand 1966, 3-8; Adiuto Putignani, Il tempio di S. Caterina in Galatina. Galatina 1947, ${ }^{2}$ 1968; Teodoro Presta, La basilica orsiniana Santa Caterina in Galatina. Con saggio sugli affreschi di Clemente Marsicola. Avegna Genua 1984, 17-42; Zimdars, Ausmalung (wie Anm. 129), 90-95; Kemper, SS. Nicolò e Cataldo (wie Anm. 41), 187-190; Belli D'Elia, Principi (wie Anm. 103), 261-294, hier 275; Fernando Russo, La storia della basilica, in: ders. (Hrsg.), La parola si fa immagine. Storia e restauro della basilica orsiniana di Santa Caterina a Galatina. Venedig 2005, 13, 20f.; ders., La basilica, in: ebd. 23, 35. Cazzato, Imprese (wie Anm. 76), 307-325. Trotz zweier umfangreicher Restaurierungskampagnen 1974/75 und 2002/ 2003 fehlt noch immer eine dokumentierte historische Bauforschung. Fehlende Publikationen zur archäologischen Forschung schmerzen umso mehr, da der knappe Überblick in Ministero per i Beni Culturali e Ambientali/ Soprintendenza per i Beni Ambientali, Architettonici, Artistici e Storici della Puglia (Hrsg.), Restauri in Puglia 1971-1981. Mostra Bari, Castello Svevo, 3.-10.1982. 2 Bde. Fasano 1983, Bd. 2, 421-427, erkennen lässt, dass neben groben Eingriffen zum Zweck der Wandentfeuchtung mindestens im ehemaligen Presbyterium Grabungen stattgefunden haben, die diverse Mauerbefunde erbrachten; vgl. ebd. 422, Abb. 68. 3.

133 Die italienischen Beispiele fünfschiffiger Basiliken des Spätmittelalters basieren auf frühchristlichen Vorgängerbauten oder waren ursprünglich dreischiffige Basiliken, die später durch Lateralkapellen bzw. Kapellenschiffanbauten erweitert wurden. Vgl. z. B. San Lorenzo Maggiore in Neapel; Bruzelius, Stones (wie Anm. 63), 47-73, bes. 48f., 60f. 


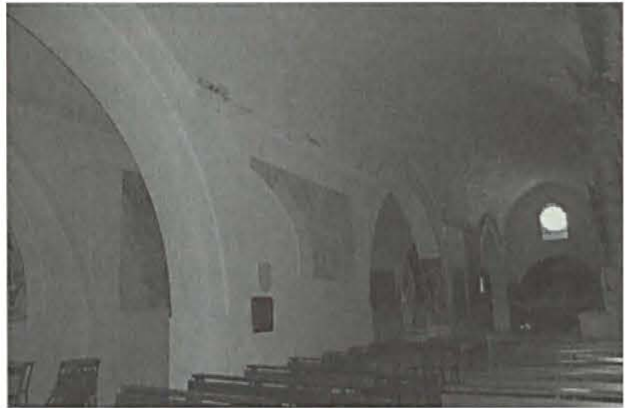

$A b b .17 a$ : Galatina, S. Caterina, Nordseitenschiff (Foto: M. Mersch)

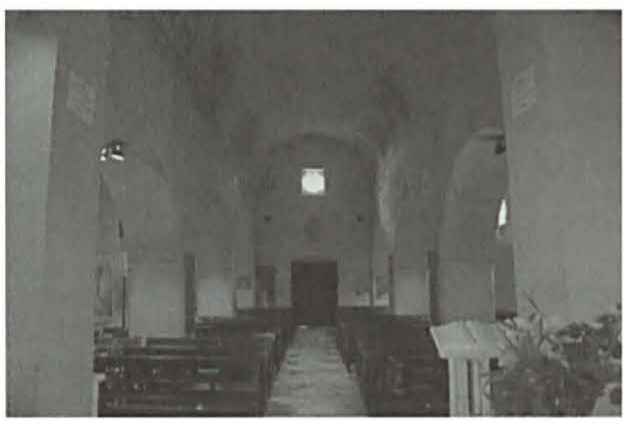

Abb. 17b: Casarano, S. Maria della Croce, Hauptschiff (Foto: M. Mersch) rano (Abb. 17a, b); ${ }^{134}$ im rechten Seitenschiff kommt eine kleine Apside hinzu, wie sie für die Ostpartie byzantinischer Zentralbauten und Basiliken typisch ist. Das lang gestreckte Mittelschiff hingegen ist ein relativ heller, durch seine Proportionen und die Kreuzrippengewölbe sehr hoch und schlank wirkender Raum, der an die Oberkirche von S. Francesco in Assisi erinnert (Abb. 18, Tafel VI 3) - freilich ohne Querhaus und polygonale Apsis, also nur auf das Langhaus bezogen, wobei zu betonen ist, dass wir den ursprünglichen Ostabschluss des Chorhauses von S. Caterina nicht kennen. ${ }^{135}$ Die Grundrissproportionen der beiden Bauten, die einen enorm langgestrecken Raum erzeugen, sind recht ähnlich: $1: 4$ in Assisi bei Innenmaßen von $13,5 \mathrm{~m}$ x $54 \mathrm{~m}$ (vier Langhausjoche) und $1: 4,4$ in Galatina bei Innenmaßen von $9 \mathrm{~m}$ x $40 \mathrm{~m}$ (drei Langhausjoche und ein Chorjoch). Gleichwohl wurde mit dem relativ schwerfälligen, mit starken Gurtbögen versehenen Stützensystem in Galatina keineswegs das umbrische Vorbild kopiert und die Kapitellplastik schließt deutlich an die romanisch-apulische Skulptur der normannischen wie auch späterer Zeit an. Die schmalen Gänge der inneren Seitenschiffe halten Hauptschiff und äußere Seitenschiffe gewissermaßen auf Abstand, trennen sie mehr als dass sie zwischen ihnen vermitteln. Auch die großen Wandflächen des Hauptschiffs tragen dazu bei. Die Arkadenöffnungen sind zwar relativ groß, doch wenn der Blick schräg auf sie fällt - etwa vom Hauptportal aus oder von der Mitte des ersten

134 Ein in den Ostpartien bis in das 5. oder 6. Jahrhundert zurückgehender Bau, der im 13. Jahrhundert seine basilikale Gestalt bekam und nochmals um 1400 leicht verändert wurde. Das Tonnengewölbe stammt mindestens aus dem 10. Jahrhundert. Zur Baugeschichte vgl. Restauri in Puglia (wie Anm. 132), 402-407.

135 Der einschiffige Saalbau und seine gotischen Travée wie auch die polygonale Apsis sind die Aspekte, die bei der architektonischen Nachfolge von S. Francesco in Assisi am häufigsten kopiert wurden und weiteste Verbreitung fanden; vgl. Antonio Cadei, „Secundum loci conditionem et morem patriae“, in: Corrado Bozzoni (Hrsg.), Saggi in onore di Renato Bonelli. (Quaderni dell'istituto di storia dell' architettura, n. s., Bd. 15/20.) Rom 1992, 135-142; Schenkluhn, Architektur (wie Anm. 68), 56. 


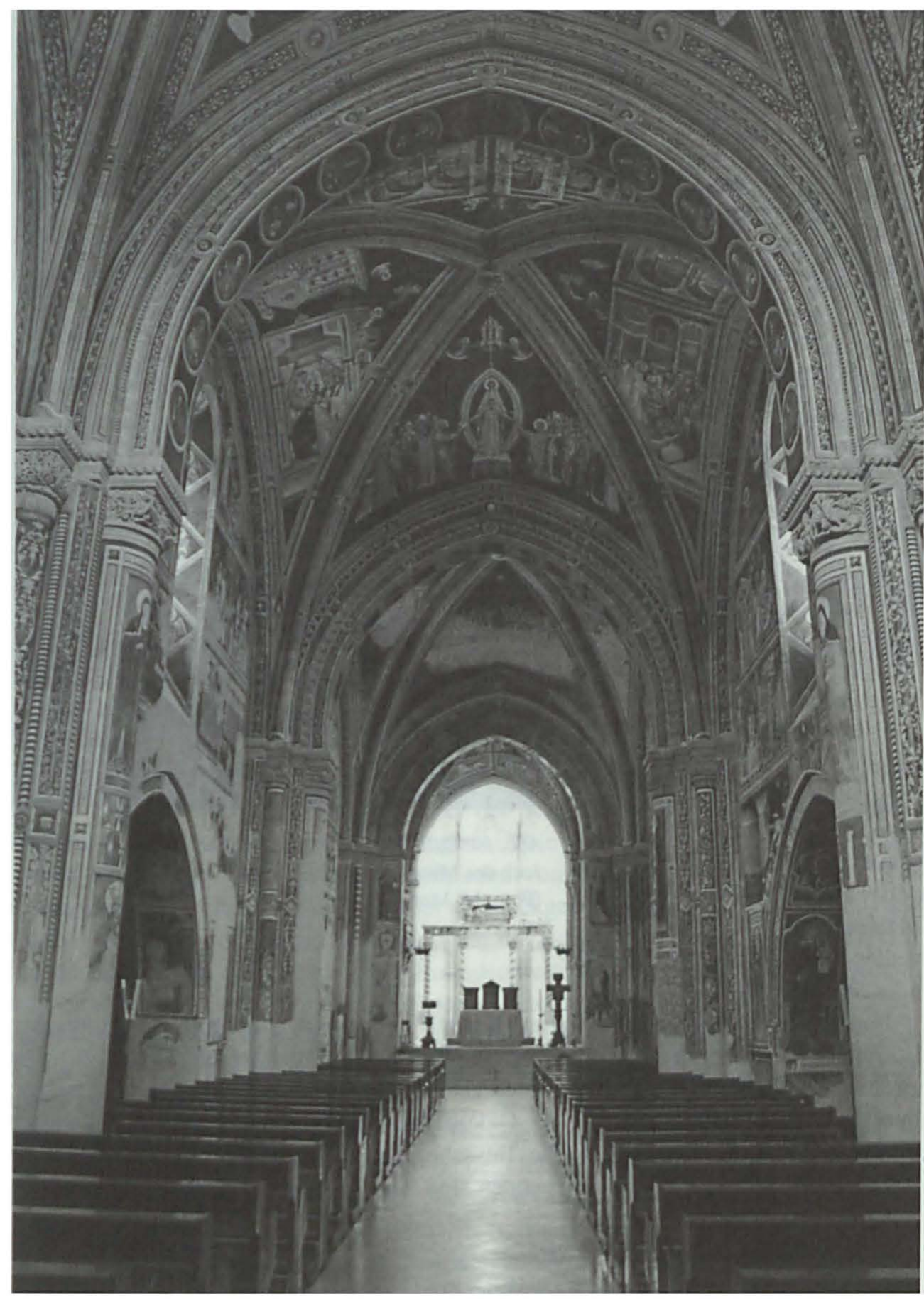

Abb. 18: Galatina, S. Caterina, Mittelschiff, Blick nach Osten (Foto: M. Mersch) 
Jochs in die folgenden Joche -, lassen sie keinen Blickkontakt in die äußeren Seitenschiffe zu. Wechselt der Betrachter jedoch die Blickachse und wendet sich innerhalb eines Jochs der einen oder anderen Seitenwand zu, dann eröffnen die exakt parallel zueinander situierten großen Bögen in den Wänden der Zwischenschiffe eine neue visuelle Achse und einen neuen Raum (Abb. 19). Die funktionale Bestimmung der Zwischenschiffe scheint die von Korridoren zu sein, die Zugänge zu Haupt- oder Seitenschiffen sicherstellten, ohne dass dabei Messfeiern oder Stundengebete in einem der Räume gestört würden. ${ }^{136}$ Dennoch sind solche Gänge keineswegs architektonisch notwendig und stellen eine singuläre Lösung dar. Alle Mendikantenkirchen kombinierten problemlos Stundengebete im Brüderchor (hinter dem Lettner), Messen an Altären im Kirchenschiff und Messen wie Andachten in Privatkapellen in oder an Hauptoder Seitenschiffen.

Die Fassade von S. Caterina wartet ebenfalls mit ungewöhnlichen architektonischen Lösungen auf. Aufgrund der Fünfschiffigkeit ist sie sehr breit gelagert (Abb. 20). Die zusätzlichen inneren Seitenschiffe treten aber in der Fassadengliederung nicht hervor; ihre Existenz verraten allein die vier Okkuli. In auffäligem Gegensatz zum üblichen basilikalen Fassadenschnitt steht die Tatsache, dass die Seitenschiffsdächer nicht als Abdächer an das Hauptschiff angebunden sind. Die inneren und äußeren Seitenschiffe

136 Das Hauptportal wird sicherlich nur zu besonderen Anlässen geöffnet worden sein. Durch die beiden Seitenportale betritt man direkt die Korridore und kann von dort wahlweise in einen Abschnitt der Seitenschiffe oder in eines der Joche des Hauptschiffs gelangen, ohne einen anderen Kirchenraum durchqueren zu müssen. 


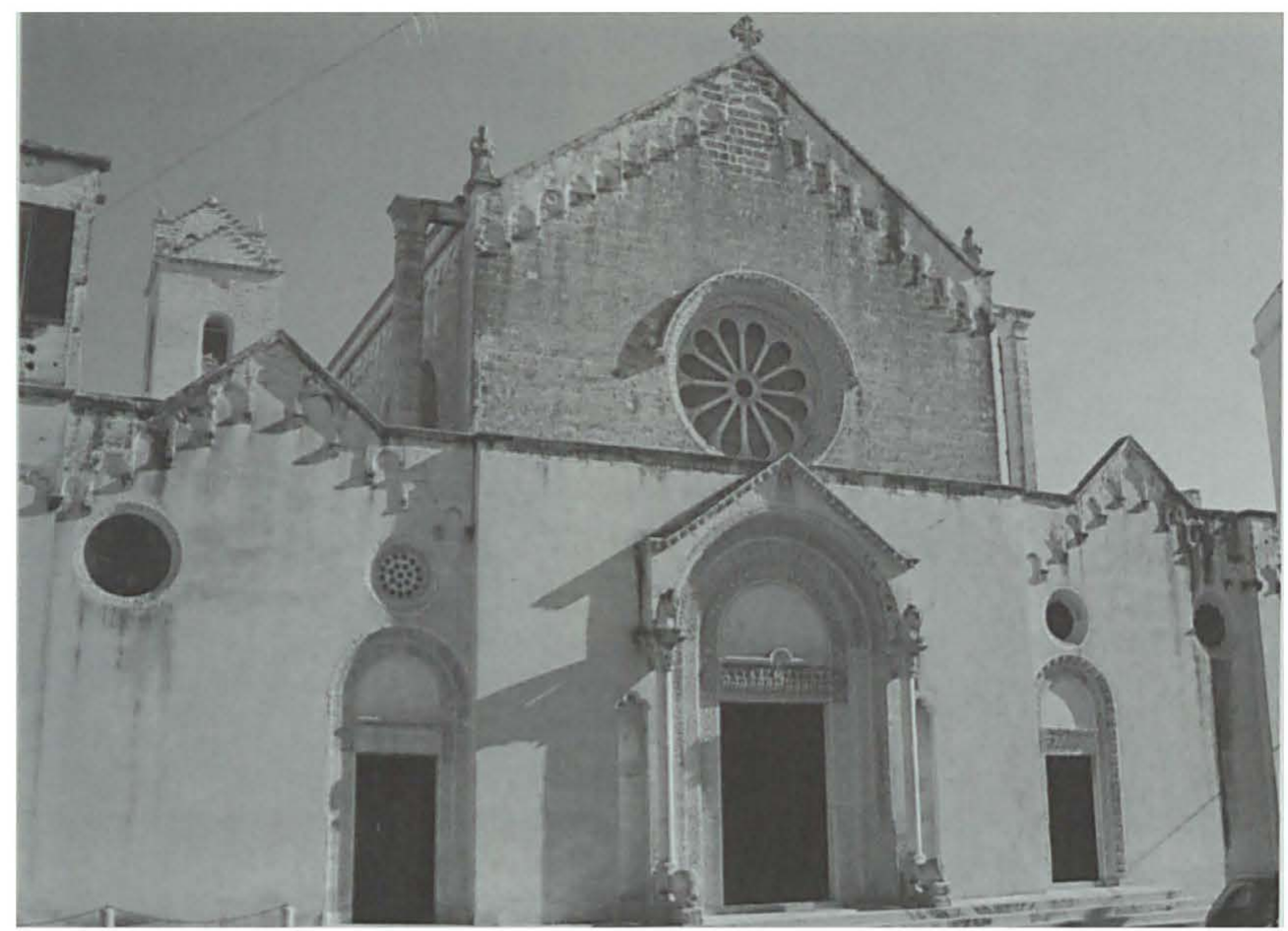

Abb. 20: Galatina, S. Caterina, Fassade (Foto: M. Mersch)

sind stattdessen jeweils hinter einem Spitzgiebel zusammengefasst, bei denen es sich um Blendmauern handelt; denn die Dächer der Seitenschiffe sind flach und aufgrund der niedrigen Innenseitenschiffe zum Hauptschiff hin geneigt. Rundbogenfriese in identischer Ausführung begleiten die Mauerkronen von Haupt- und Seitenschiffen. Das Kranzgesims der Seitenschiffe wird dabei als Stockgesims vor dem Hautpschiff fortgesetzt und bildet so ein horizontales Band um die Bauglieder, das zusammen mit den flachen Eckrisaliten den Eindruck der Fassadenbreite noch verstärkt. Das Hauptschiff wird dennoch als Einzelelement der Fassade betont, indem es in der unteren Zone leicht hervorgezogen wird. Mit seiner schlichten Gestaltung durch ein Rosenfenster über Rundbogenportal gleicht es - für sich allein genommen - den typischen mendikantischen Kirchenfassaden Süditaliens.

Der sehr qualitätvolle Dekor der drei Fassaden-Portale orientiert sich deutlich an dem Portaldekor der 200 Jahre älteren, von dem letzten Normannenkönig Tankred von Lecce erbauten Benediktinerkirche SS. Niccoló e Cataldo in Lecce und der ebenso alten griechischen Klosterkirche der Basilianer S. Maria di Cerrate bei Squinzano. Hinsichtlich der Details seien hier nur einige Beispiele herausgegriffen: Besonders ähnlich ist etwa die Kombination von Akanthusband und Kreisranke am linken Seitenportal in Galatina und am Hauptportal von S. Maria di Cerrate (Abb. 21a, b). Von einer Kopie 

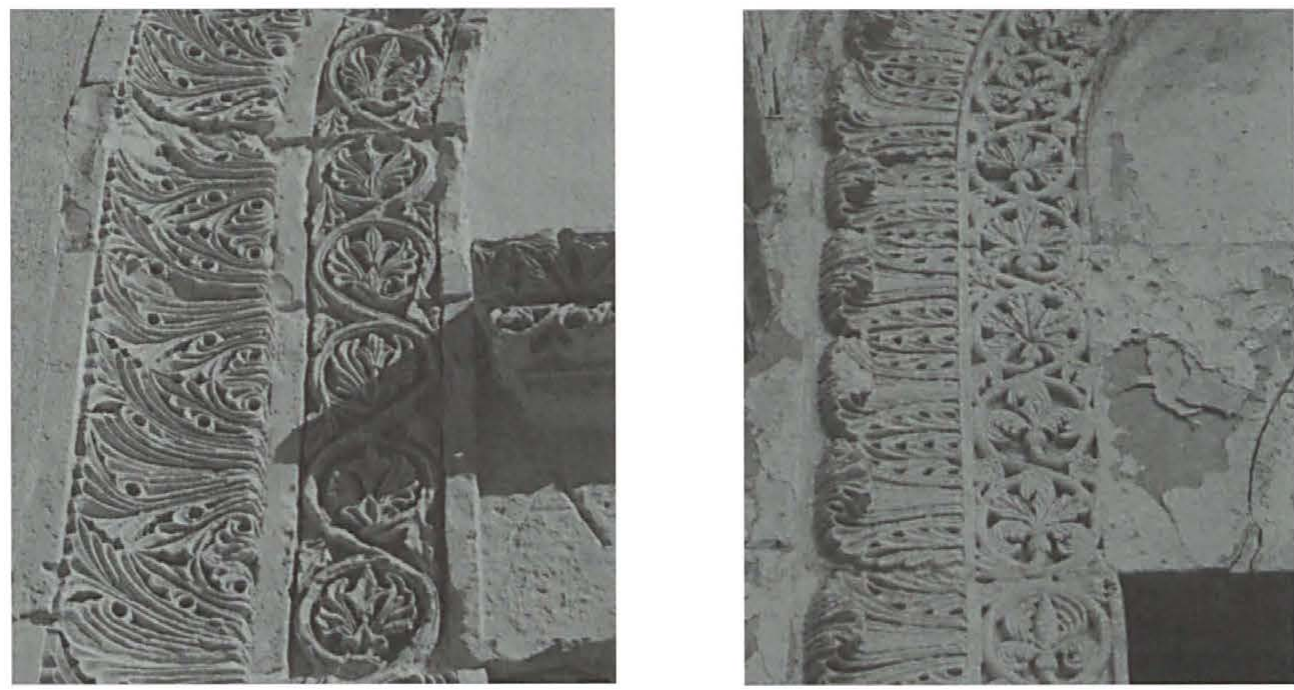

Abb. 21 ( (links): Galatina, S. Caterina, Rahmung des linken Fassadenportals (Detail) (Foto: M. Mersch)

$A b b .21 b$ (rechts): Squinzano, S. Maria di Cerrate, Hauptportalrahmung (Detail) (Foto: M. Mersch)
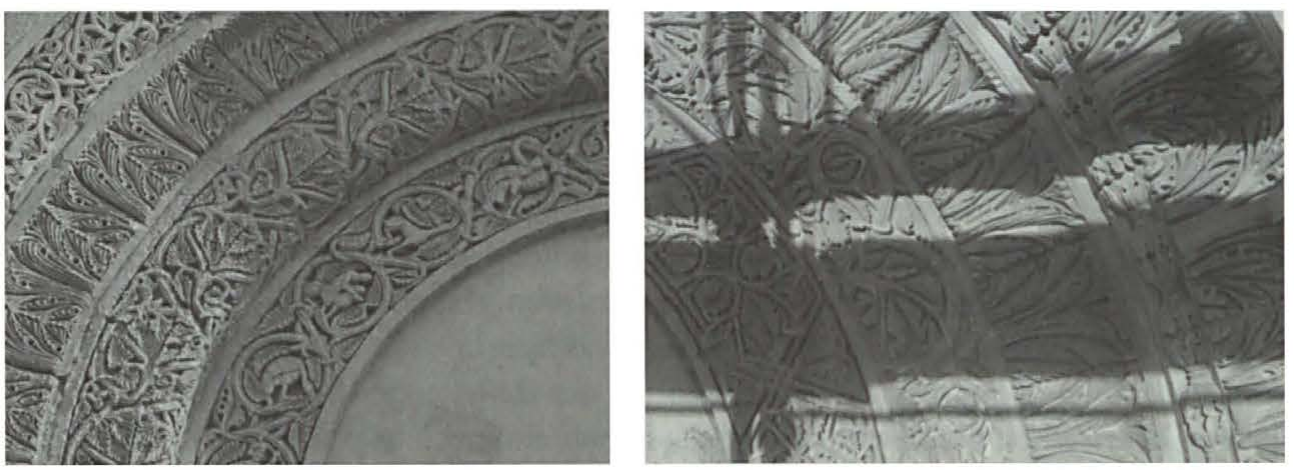

Abb. 21c (links): Galatina, S. Caterina, Hauptportalrahnumg (Detail) (Foto: M. Mersch) Abb. 21d (rechts): Lecce, SS. Nicolò e Cataldo, Hauptportalrahnumg (Detail) (Foto: M. Mersch)

kann man bei dem jeweiligen mittleren Rahmenband mit Kreisrankenmuster an den Hauptportalen in Lecce und Galatina sprechen (Abb. 21c, d). Auch ist der Architrav des Hauptportals in Galatina wie jener in Lecce auf der Unterseite mit einem sehr ähnlichen Rankenband versehen. Die Baldachinform des Portals mit der Abfolge von Löwe, Säule und Kapitell mit Adler findet sich am Dom von Matera - an der Porta dei Leoni und einem Schmuckfenster an der Südfassade - vorgebildet, der ebenfalls in der Nachfolge von SS. Niccolo e Cataldo und S. Maria di Cerrate steht. Dorothee Kemper 
hat die engen Bezüge zwischen diesen Bauten des späten 12., frühen 13. Jahrhunderts als ,Lecceser Skulpturgruppe ' gefasst und auch die demonstrative Aufnahme dieses normannisch-romanischen Stils in der Bauplastik von S. Caterina thematisiert. ${ }^{137}$ Sie sieht auch eine Verwandtschaft zwischen einzelnen Elementen der Kapitellplastik im Innenraum von S. Caterina in Galatina und der Loggienkapitelle von S. Maria di Cerrate, bei denen es sich vermutlich um ehemalige Lecceser Kreuzgang-Kapitelle handelt, die im 17. Jahrhundert transferiert wurden. So scheint etwa vom Cerratenser Vorbild der Vorhang von Blattenden über den Figuren übernommen worden und sogar der in Cerrate durch das Umgreifen des Halsringes motivierte untere Wulst von Blattansätzen unnötigerweise in Galatina mitkopiert worden zu sein..$^{138}$

Das Architravrelief des Hauptportals von S. Caterina mit Christus und den Aposteln, die zu seinen Seiten aufgereiht sitzen (Abb. 22), variiert laut Kemper das Lecceser Schema der Engelkopfreihen, die an Portalen in Lecce und Matera zu finden sind.

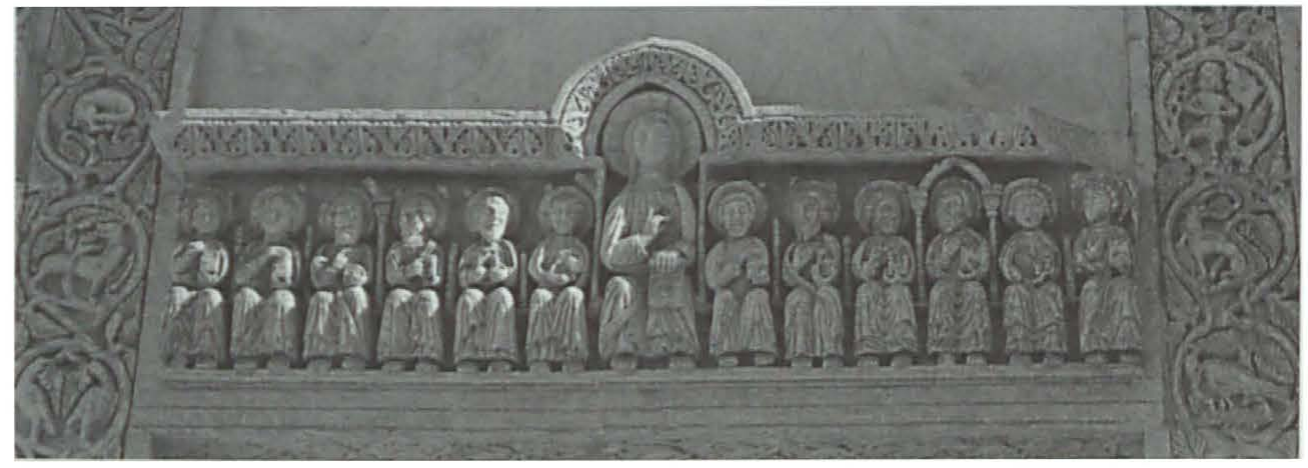

Abb. 22: Galatina, S. Caterina, Hauptportal, Architrav (Foto: M. Mersch)

Doch treten in Galatina zwei bedeutende Elemente hinzu. Der zwischen den Aposteln sitzende Christus hält ein Schriftband mit einem Zitat aus dem Johannes-Evangelium in Händen: Ego vos elegi ut eatis (Ich habe euch erwählt, damit ihr hinausgeht). ${ }^{139}$ Die Darstellung ,Christus mit seinen Aposteln“ wird damit zum Hinweis auf den apostolischen Auftrag der Franziskaner zur lateinischen Mission; ${ }^{140}$ ihre stilistische Gestaltung

137 Kemper, SS. Nicolò e Cataldo (wie Anm. 41), 187-190. Auf den Zusammenhang zwischen der Bauplastik von SS. Nicolò e Cataldo und S. Caterina hat auch Maria Stella Calò Mariani, Sulle relazioni artistiche fra la Puglia e l'Oriente latino, in: Roberto il Guiscardo e il suo tempo. Atti delle prime giornate normanno-sveve, Bari, 28.-29.5.1973. Rom 1975, ND Bari 1991, 35-66, hier $65 f$., hingewiesen.

138 Kemper, SS. Nicolò e Cataldo (wie Anm. 41), 190.

139 Joh 15,16: (...) ego elegi vos et posui vos ut eatis et fructum adferatis et fructus vester maneat.

140 Interessanter Weise wählte man in Galatina nicht den oft zitierten allgemeinen Missionsbefehl Christi in Mt 28,18-20 (.,Mir ist alle Gewalt gegeben im Himmel und auf Erden. Darum gehet 


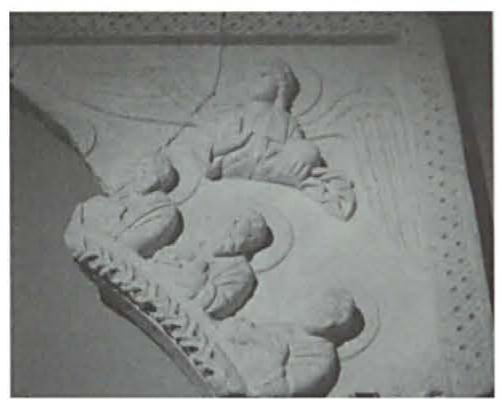

Abb. 23a: Istanbul, Rahmenfragment eines Arkosolgrabes, Archäologisches Museum Istanbul (Foto: M. Mersch)

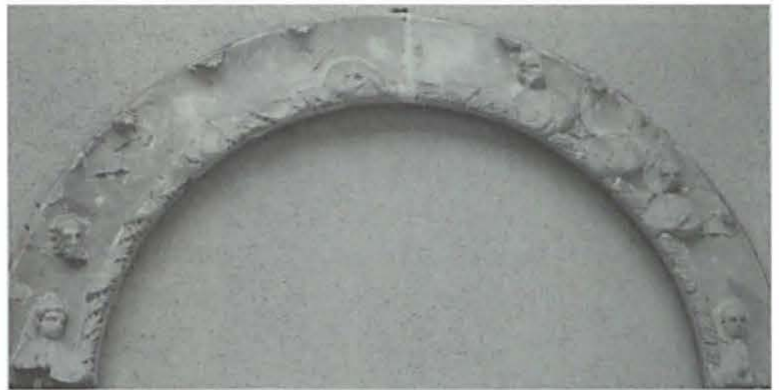

Abb. 23b: Istanbul, Apostelbogen aus dem Konstantin-LipsKloster, Archäologisches Museum Istanbul (Foto: M. Mersch)

mit der frontalen Ausrichtung der Figuren lässt hingegen byzantinische Vorbilder anklingen. Sie erinnert - vor allem in Gestik, Gewandstruktur und Kopfgestaltung der kleinen Apostelfiguren - an etwa zeitgleiche, spätbyzantinische Beispiele in Istanbul, wie den Apostelbogen aus dem Kloster des Konstantin Lips ${ }^{141}$ oder die Apostelgruppe auf dem Rahmen eines Arkosolgrabes aus einer anderen Istanbuler Kirche (Provenienz unbekannt) ${ }^{142}$, beide Anfang 14. Jahrhundert (Abb. 23a, b). Somit ist nicht nur eine künstlerische Anbindung an die vergangene lateinisch-griechische Kunst Apuliens, sondern auch eine Teilhabe an zeitgenössischen überregionalen (und überkonfessionellen) Stilentwicklungen des Mittelmeerraums zu erkennen.

Über dem linken Seitenportal gibt eine Inschrift in lateinischen Buchstaben das mutmaßliche Datum der Fertigstellung des Baus an: A D MCCCLXXXXI (1391). Über dem rechten Seitenportal richtet sich eine leider schon recht verwitterte griechische Inschrift auf dem Architrav direkt an die byzantinisch-ostkirchliche Bevölkerung Galatinas (Abb. 24). ${ }^{143} \mathrm{Zu}$ entziffern ist nur noch etwas mehr als die Hälfte der ersten von

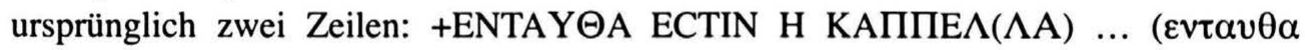

hin und machet alle Völker zu Jüngern und taufet sie auf den Namen des Vaters und des Sohnes und des Heiligen Geistes, und lehret sie alles halten, was ich euch aufgetragen habe."), sondern die allgemeinere Thematisierung und persönlichere Ansprache Christi an seine Jünger bei Joh 15,14-16: „Ihr seid meine Freunde, wenn ihr tut, was ich euch gebiete. (...) Nicht ihr habt mich erwählt, sondern ich habe euch erwählt und euch dazu bestimmt, dass ihr hingeht und Frucht bringt und eure Frucht bleibe, damit, was immer ihr vom Vater in meinem Namen erbittet, er euch gebe."

141 Archäologisches Museum Istanbul, Inventar-Nr. 4570 T. Vgl. Hans Belting, Zur Skulptur aus der Zeit um 1300 in Konstantinopel, in: Münchner Jahrbuch zur Bildenden Kunst 23, 1972, 63 100, hier 67-79.

142 Archäologisches Museum Istanbul, Inventar-Nr. $928 \mathrm{~T}$.

143 Der Architrav ist keine Spolie, wie Presta, Basilica (wie Anm. 132), 27, annimmt, sondern zeitgleich mit den anderen Portalelementen S. Caterinas. Das erweist nicht nur die genaue Passform, sondern auch das Rankenmuster an der Unterseite, das jenem an der Unterseite des Ar- 
$\varepsilon \sigma \tau \iota v \eta \varkappa \alpha \pi \tau \varepsilon \lambda(\lambda \alpha)=$ Hier ist die Kapelle/Kirche ...). Es folgte vermutlich unter an-

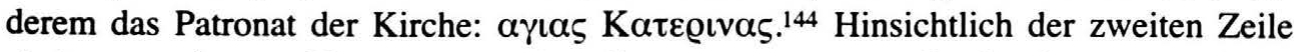
sind nur noch vage Vermutungen über die ersten etwa neun Buchstaben anzustellen, eventuell: $(\mathrm{MH}) \mathrm{T}(\mathrm{ERA}) \mathrm{KAI} \ldots\left(\mu \eta \tau \varepsilon \varrho \alpha \chi_{\alpha \iota}=\right.$ Mutter[kirche?] und ...); nach einer Lücke folgt noch $\mathrm{P} \Theta$ und der erodierte Rest der Zeile.

Mehrere der mit S. Caterina befassten Forscher haben aufgrund der außerordentli-

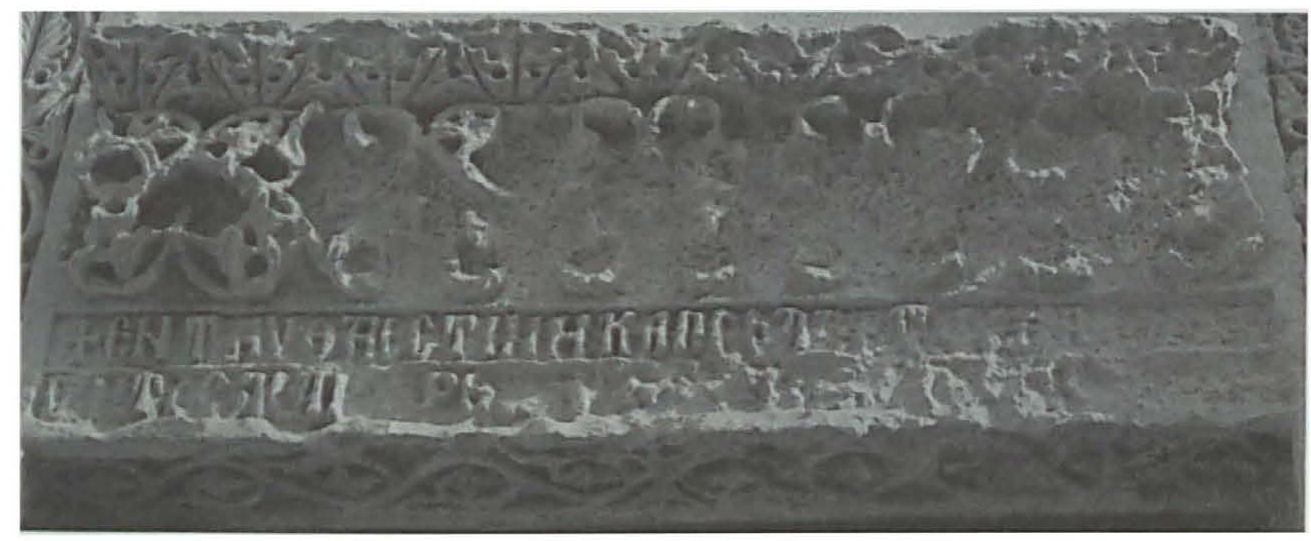

Abb. 24: Galatina, S. Caterina, rechtes Fassadenportal, Architrav (Foto: M. Mersch)

chen Bauform angenommen, dass die Kirche Strukturen eines Vorgängerbaus integriert und in mehreren Bauphasen entstand, wobei das Mittelschiff als einschiffiger - und nach Meinung einiger Autoren flach gedeckter - Ursprungsbau des 13. oder frühen 14. Jahrhunderts erst durch die Baumaßnahmen Raimondos um $1385 \mathrm{zu}$ dieser seltsamen fünfschiffigen Form erweitert worden sein soll. Während Blasi einen Vorgängerbau aus der ersten Hälfte des 14. Jahrhunderts annahm, der den Grundriss des heutigen Baus hatte und dem unter Raimondo del Balzo Orsini nur Gewölbe und Arkaden zu den Seitenschiffen hinzugefügt wurden, plädieren Krönig, Presta, Zimdars, Belli d'Elia und Russo für einen einschiffigen Vorgängerbau, den sie in das 13. Jahrhundert (Presta), in das letzte Drittel des 13. Jahrhunderts (Zimdars), in die erste Hälfte des 14. Jahr-

chitravs am linken Seitenportal entspricht. Das aufwändige durchbrochene und stark plastische Rankenmotiv über der Inschrift hat Calò Mariani, Relazioni (wie Anm. 137), 64, als ,islamisierenden' Dekor bezeichnet.

144 Wir danken Prof. Günter Prinzing, Mainz, und Prof. Linda Safran, Toronto, für ihre freundliche und wertvolle Unterstützung bei der Entzifferung der Inschrift. Linda Safran entziffert insge-

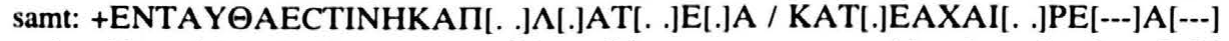

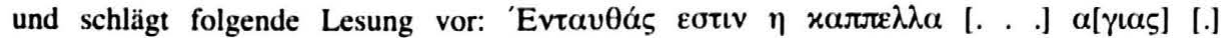
$\operatorname{Kat}[\varepsilon \rho ı v \alpha \varsigma]$ (Korrespondenz vom Oktober 2006). Prof. Vera von Falkenhausen danken wir für ihre Vermittlung zu Prof. André Jacob, Chieti, der ebenfalls die Lesung vorschlägt: + Evז $\alpha v \theta \alpha$

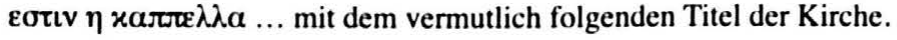


hunderts (Russo) oder in das dritte Viertel des 14. Jahrhunderts (Krönig) datieren. Nach Blasi, Presta und Belli d'Elia soll er ursprünglich eine hölzerne Flachdecke besessen haben; Krönig, Zimdars und Russo sehen das heutige Gewölbe als ursprünglich an. In diesen Ansätzen tauchen einige Widersprüche auf. So ist Blasis Beschreibung des ursprünglichen Baukörpers nur schwer nachzuvollziehen: drei Schiffe mit begleitenden Deambulatorien, wobei das Mittelschiff nicht gewölbt und zu den Seitenschiffen hin nur durch jeweils einen Bogen in der Mitte der Längswände geöffnet war. ${ }^{145}$ Zimdars sieht wie Krönig ${ }^{146}$ - und vor ihnen, aber von beiden nicht genannt, bereits Enlart ${ }^{147}$ in der Vorgängerkirche eine bewusste Kopie der Oberkirche von S. Francesco in Assisi (einschiffiger Wölbungsbau mit geschlossener unterer Wandzone). ${ }^{148}$ Den Widerspruch, dass dieser Vorgängerbau von S. Caterina ihrer Datierung zufolge fast $100 \mathrm{Jah}-$ re vor der Gründung des Franziskanerkonvents von Galatina gebaut worden sein soll, löst sie nicht auf. Keiner der oben aufgeführten Ansätze gibt eine funktionale oder stilistische Erklärung für die Existenz der schmalen inneren Seitenschiffe bzw. Gänge. Sie sind weder zur Erschließung von Seitenschiffen notwendig noch sind sie als Stilmittel bekannt. Überhaupt wird die Frage nach der Motivation des Bauherrn für eine Erweiterung der Kirche in dieser außergewöhnlichen Form nicht beantwortet. ${ }^{149}$ Blasi versuchte eine Erklärung, indem er die These aufstellte, dass mit der Apside an der

Blasi, Galatina (wie Anm. 132), 59.

Krönig, Hallenkirchen (wie Anm. 132), 58.

Enlart, Origines (wie Anm. 132), 162.

Zimdars, Ausmalung (wie Anm. 129), 93f. mit Anm. 131.

Einer Erklärung entzieht sich offenbar insbesondere der fast quadratische Grundriss, den die Kirchenschiffe gemeinsam - ohne das im Vergleich dazu klein wirkende Chorjoch - bilden. Ein mittelalterlicher quadratischer Grundriss (aber keine Fünfschiffigkeit) findet sich in Süditalien bei dem Zentralbau von S. Maria di Siponto bei Manfredonia (11. Jahrhundert, Umbau im 13. Jahrhundert), der mit $18,5 \mathrm{~m} \times 18 \mathrm{~m}$ jedoch wesentlich kleiner ist als $S$. Caterina mit $32,5 \mathrm{~m} \mathrm{x}$ $35 \mathrm{~m}$. Noch kleiner sind die griechisch-orthodoxen Zentralbauten Süditaliens, wie etwa S. Pietro in Otranto. Quadratische Grundrisse und eine ,gewisse Fünfschiffigkeit' im Grundriss (durch die Flankierung eines dreigeteilten Sanktuariums durch zwei Parekklesia) sowie die Kombination unterschiedlicher Wölbesysteme finden sich bei Kreuzkuppelbauten der spätbyzantinischen Zeit auf dem Balkan, im 14. Jahrhundert v. a. in Thessaloniki (z. B. Apostelkirche, St. Panteleimon) und in Epirus (etwa die Paregoretissa) verbreitet. Allerdings entwickeln sich auf diesen Grundrissen ganz andere Raumgefüge. Nun handelt es sich bei S. Caterina in keiner Weise um einen Zentralbau und alle diese Beispiele können nicht als Vorbilder gelten (wenngleich im Anschluss an Richard Krautheimer zu bedenken ist, dass generell bei der mittelalterlichen Auseinandersetzung mit architektonischen Bezugsbauten ganz andere Kriterien als die einer genauen formalen Nachbildung wichtig waren). Allenfalls wäre an eine symbolische Bezugnahme - auf der Ebene der ersten Planungs- und Bautätigkeiten, nämlich der Grundrissfestlegung auf die quadratischen Bautypen der byzantinischen Architektur zu denken, etwa analog zu der Symbolisierung zisterziensischer rectitudo, die in der rechtwinkligen Form des Grundrisses (ohne Konchen, Apsiden, Polygone) gesehen wurde, ungeachtet der darauf aufbauenden Raumtypen und Formensprachen; vgl. dazu Matthias Untermann, Forma Ordinis. Die mittelalterliche Baukunst der Zisterzienser. (Kunstwissenschaftliche Studien, Bd. 89.) München 2001, 670. 
Längsseite des rechten Seitenschiffs Reste einer älteren kleinen byzantinischen Kirche im heutigen Bau enthalten sind. ${ }^{150}$ Der Wunsch, diese Kapelle in den Neubau zu integrieren, soll die Lage und Gestalt der Seitenschiffe bedingt haben. ${ }^{151}$

Doch gibt es für die Thesen von einem oder zwei integrierten Vorgängerbauten von S. Caterina weder einen Hinweis in den Urkunden noch schlüssige Belege am Baubestand. Die Tatsache, dass die Obergadenfenster leicht aus den Mittelachsen der Joche verschoben sind, muss nicht auf einen nachträglichen Einbau der Gewölbe hinweisen, wie Presta und Zimdars meinen. ${ }^{152}$ Abweichungen in solch geringem Umfang - bei den beiden Fenstern des mittleren Jochs und dem linken Fenster des dritten Jochs ist gar keine Abweichung zu erkennen - kommen auch bei einphasigen Bauten vor. An den Außenwänden des Obergadens ist im Übrigen neben jedem

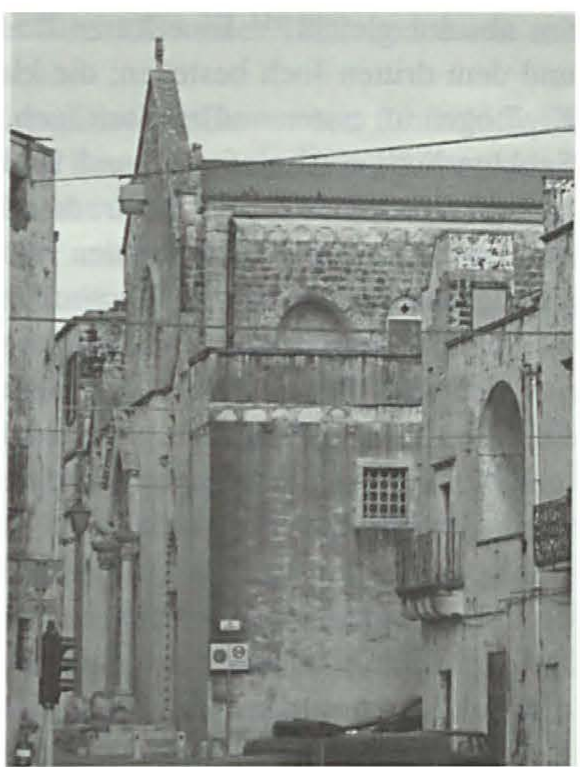

$A b b$. 25: Galatina, S. Caterina, Südwestecke, vom ehemaligen Stadttor aus gesehen (Foto: M. Mersch) Fenster jeweils eine große Rundbogennische primär in das Mauerwerk eingelassen (Abb. 25), die von keinem der Autoren erwähnt werden. Sie waren vermutlich mit Statuen, Reliefs oder Fresken von Heiligen geschmückt - ein Element des Baudekors, das besonders auch aus der Franziskanerarchitektur des 14. Jahrhunderts bekannt ist, wie zum Beispiel die einst freskierten Blendnischen über den Fenstern des Südseitenschiffs von S. Croce in Florenz. ${ }^{153}$ Gegen den nachträglichen Einbau des Gewölbes und gegen ein unterschiedliches Alter von Hauptschiff und Seitenschiffen sprechen die Beobachtungen, die bei Restaurierungsarbeiten gemacht wurden, dass das Stützensystem der Kreuzgewölbe primär mit dem Mauerwerk verbunden ist und dass das Mauerwerk im Hauptschiff dem der Seitenaußenmau-

150 Blasi, Galatina (wie Anm. 132), 57f.

151 In groben Zügen folgen ihm darin Presta, Basilica (wie Anm. 132), bes. 17-34, und Belli D'Elia, Principi (wie Anm. 103), 274-292. Presta, Basilica (wie Anm. 132), 31f., sieht in Gewölbeschäden an den Seiten der freskierten Zone im Mittelteil des rechten Seitenschiffs, in byzantinisierender Ikonographie im Bereich der Apside und in der griechischen Inschrift über dem rechten Seitenportal Belege für eine solche in das rechte Seitenschiff von S. Caterina integrierte griechische Kapelle und nimmt an, dass sie auch zu Zeiten der Orsini von den Italogriechen besucht wurde - bevor Maria d'Enghien entschied, sie als Familienkapelle zu nutzen.

152 Presta, Basilica (wie Anm. 132), 22; Zimdars, Ausmalung (wie Anm. 129), 93.

153 Vgl. etwa Schenkluhn, Architektur (wie Anm. 68), 181, Abb. 117. 
ern absolut gleicht. ${ }^{154}$ Eine kurze Bauzäsur könnte allerdings zwischen dem zweiten und dem dritten Joch bestehen; die kleinen Fensterchen dort zeigen Giebel anstatt der Kielbogen im ersten und zweiten Joch, und auch die Kapitelle des dritten Jochs und des Sanktuariums sind einfacher und flacher. ${ }^{155}$ Doch die Tatsache, dass sie den anderen nachgebildet sind, spricht dafür, dass kein langer Zeitraum zwischen den beiden Bauvorgängen lag; vielleicht standen auch einfach nicht mehr dieselben Steinmetze zur Verfügung. Zudem ist ein Wechsel in der Mauertechnik der Arkaden zwischen dem zweiten und dem dritten Joch zu beobachten, genauer gesagt: zwischen dem westlichen und dem östlichen Gewände der Bögen im zweiten Joch. Auch dies spricht entweder für eine nur kurzfristige Baupause oder einen Wechsel im Baupersonal.

Eine Datierung des Baus nach rein stilistischen Kriterien wäre aufgrund der Langlebigkeit der hier in Portaldekor und Kapitellplastik angewandten apulischen Romanik wenig aussagekräftig. Die bautypologischen Analogien zur Oberkirche von S. Francesco in Assisi und zur Franziskanerarchitektur sprechen jedoch für eine Entstehung des Baus im Zusammenhang mit der Gründung der Niederlassung in Galatina durch Rainaldo del Balzo Orsini. Es ist sicher, dass der Baubeginn vor 1385 lag, denn die beiden Bestätigungsurkunden Papst Urbans VI. vom 25. März 1385 bringen klar zum Ausdruck, dass Raimondo bereits zuvor begonnen hatte, die Kirche S. Caterina gründen und bauen zu lassen und dass er, zusammen mit anderen Gläubigen, ein Hospital neben der Kirche S. Caterina errichtete. ${ }^{156}$ Ein besonderes politisches und militärisches Engagement Raimondos im Salento ist für die Zeit ab 1381 erkennbar. ${ }^{157}$ Bereits 1382 wird das Hospital S. Caterina von Galatina mit einer umfangreichen Erbschafts-Schenkung

154 Cazzato, Imprese (wie Anm. 76), 316.

155 Darauf weist Russo, Storia (wie Anm. 132), 20, hin.

156 Montinari, Galatina antica (wie Anm. 1), IV-VI, Documento 9 u. 10. Documento 9 (die für die Franziskaner ausgestellte Urkunde): Rahimundus de Baucio de Ordinis (...) unum locum pro usu et habitatione Fratrum vestri Ordinis cum Ecclesia sub vocabulo Sanctae Catharinae (...) fundari et construi facere iam incepit. Documento 10 (die für Raimundus ausgestellte Urkunde): (...) fundari et construi facere incaeperas (...) Cum autem (...) tua iam certa bona (...) ad fundandum et construendum in loco dictae ecclesiae contiguo unum hospitale ad usum pauperum donare proponas, pro parte tua nobis fuit humillime supplicatum ut fundandi et construendi hospitale praedictum tibi et aliis Christifidelibus licentiam concedere (...) dignaremur.

157 Raimondo war von 1372 bis 1379 mit dem Deutschen Orden auf dem baltischen Kreuzzug. Nicht belegbar ist die im Anschluss an Papadia, Memorie (wie Anm. 132), 7, und Alessandro Cutolo, Maria d'Enghien. Neapel 1929, 35, in der Literatur weit verbreitete Darstellung, Raimondo sei im Heiligen Land gewesen; vgl. Andreas Kiesewetter, Problemi della signoria di Raimondo del Balzo Orsini in Puglia (1385-1406), in: Antonio Cassiano/Benedetto Vetere (Hrsg.), Dal giglio all'orso. I principi d'Angiò e Orsini del Balzo nel Salento. Galatina 2006, 36-90, hier 39, Anm. 4. Ab 1381 intervenierte er im Kampf zwischen den Anjou und Durazzo um die Krone von Neapel, zunächst auf Seiten Karls III. von Durazzo, der ihn am 24. September 1382 zum Kammerherrn und Hauptmann in der Terra Bari und Terra d'Otranto machte, ab 
bedacht. ${ }^{158}$ So ist also von einem Baubeginn im Jahr 1381 oder 1382 und damit mit einer etwa 10jährigen Bauzeit bis 1391 auszugehen.

Die Kirche scheint nach alledem ein in dieser spezifischen Form einer fünfschiffigen Basilika geplanter Neubau ohne Verwendung älterer Bausubstanz zu sein. ${ }^{159}$ Zumindest ist sie in dieser Form das Ergebnis einer relativ kurzen Bauzeit, in der etwaige Planänderungen oder -erweiterungen ohne größere Zäsur unter einem Bauherrn vonstatten gegangen sein müssen. Denkbar wäre, dass Raimondo mit dem Bau des Mittelschiffs als geplanter Franziskanerkirche begann und etwa drei Jahre später durch seine Verbindung mit der Erbin der Grafschaft Lecce und Ahnfrau des Normannen Tankred von Lecce dazu motiviert wurde, die Kirche durch den Anbau eigenständiger Seitenschiffe in apulischen Raumformen und durch eine enge Anlehnung des Portal- und Kapitelldekors an die von Tankred erbaute SS. Niccoló e Cataldo zu einem Bau umzuformen, der seinem (neuen) dynastischen Selbstverständnis Ausdruck geben konnte. Auf jeden Fall aber - ob nun als originärer Gesamtbauplan oder als frühzeitige Planerweiterung kann man wohl davon ausgehen, dass die Kombination der Bautypen und -stile vom Bauherrn in ihrer Wirkung als ein einzigartiges eklektizistisches Monument beabsichtigt war - unvergleichlich als Gesamtbauwerk, aber zahlreiche Vergleichsmöglichkeiten und Anschlüsse bietend in den Einzelformen. Wie Dorothee Kemper formulierte, muss dieser ,Mischstil“ als „Ausdruck des Gestaltungswillens der Auftraggeber“" aufgefasst werden. ${ }^{160}$ Diese Kombination von franziskanischen und apulischen Architekturelementen findet sich im Bautyp, in der Fassadengestaltung und im inneren wie äußeren Baudekor: Evoziert der in Apulien seltene gotische Raumtypus des Gewölbesaals im Mittelschiff das Bild der Oberkirche von S. Francesco in Assisi, so bieten doch zugleich seine ,romanisch" schweren Gewölbeglieder und Stützen sowie vor allem die reiche Kapitellplastik vertraute Elemente aus der regionalen Tradition. Verweist die Fassadengestaltung des Mittelschiffs in ihrer überregionalen ordensarchitektonischen

Frühjahr 1383 auf Seiten der Anjou. Als Gegenleistung für Raimondos Wechsel in das Lager Ludwigs I. von Anjou wurde möglicherweise schon im April 1384 die Hochzeit zwischen Raimondo del Balzo Orsini und Maria d'Enghien - seit Frühjahr 1384 Gräfin von Lecce - verabredet, die dann im Sommer 1385 stattfand; vgl. Kiesewetter, Problemi, $45 f$.

158 Montinari, Galatina (wie Anm. 1), IV, Documento 8 vom 7. Oktober 1382. Es handelt sich um die Erbschaft eines gewissen Guglielmo di Leone, der u. a. bereits ein Haus zur (provisorischen?) Nutzung als Hospital zur Verfügung gestellt hatte, und der vermutlich einer der in der späteren Papsturkunde angesprochenen Mitbegründer neben Raimondo del Balzo Orsini gewesen sein dürfte. Dass die Schenkung an den Elekten Thericus gerichtet ist, könnte darauf hindeuten, dass die formale Organisation des Hospitals noch nicht lange bestand - falls er denn der erste gewählte Leiter der Anstalt war.

159 Für einen quasi einphasigen Neubau unter Raimondo del Balzo Orsini um 1385 sprach sich schon Papadia, Memorie (wie Anm. 132), 30, aus, in jüngerer Zeit argumentieren in diesem Sinne auch Antonaci, Affreschi (wie Anm. 132), 5; Putignani, Tempio (wie Anm. 132), 21 f., 29 et passim, und Cazzato, Imprese (wie Anm. 76), $315 f$.

160 Kemper, SS. Nicolò e Cataldo (wie Anm. 41), 187 f. 
Einheitlichkeit wie auch das mendikantische Missionsmotiv des Architravreliefs am Hauptportal auf den Erneuerungsanspruch der Franziskaner, so kann die Orientierung des Portaldekors an der spätnormannischen Plastik der ,Lecceser Skulpturgruppe“ als eine durch den Herrschaftsanspruch des Stifters Raimondo del Balzo Orsini motivierte Referenz an die griechisch-lateinische Kultur des normannischen Apuliens aufgefasst werden, der durch seine Heirat mit Maria d'Enghien mit der normannischen Dynastie des Tankred von Lecce verwandt war. Entsprechend ergänzen sich lateinische und griechische Portalinschriften an der Fassade sowie ,lateinisch-gotische " und ,griechischromanische‘ Raumprägungen in den Schiffen. Die Aufteilung des Innenraums in unterschiedlich durchgeformte und deutlich von einander geschiedene Schiffe und die Aneinanderreihung von Einzelgiebeln an der Fassade weckt die Assoziation, dass hier mehrere ,Häuser' in einem Gebäude vereint sind, und tatsächlich hatte S. Caterina mehrere Funktionen zugleich zu erfüllen: die Funktionen der lateinischen Seelsorge, der Franziskaner-Klosterkirche, des Adelsmemorialbaus für die Del Balzo Orsini und zusätzlich der Mission bzw. Häresiebekämpfung sowie der Missionarsausbildung. Denn mit der 1391 erfolgten Berufung von Franziskanern des Vikariats Bosnien nach Galatina stand der Konvent in Beziehung zur Mission auf dem Balkan. ${ }^{161}$ Vermutlich wurden hier Brüder für ihre missionarischen Aufgaben in dem von der ,Häresie' der

161 Die Franziskaner ließen sich in der ersten Hälfte des 14. Jahrhunderts in Bosnien nieder; 1340 wurde das Vikariat gegründet, eine eigenständige Organisation auf der Ebene unterhalb der Provinz, die aber allein dem Ordensgeneralminister direkt unterstellt war; Slišković, Inquisizioni (wie Anm. 11), 401, 403; vgl. auch allgemein Jozo Džambo, Die Franziskaner im mittelalterlichen Bosnien. (Franziskanische Forschungen, Bd. 35.) Werl/Westf. 1991. Die Frage, warum die Niederlassung in Galatina an das Vikariat Bosnien angegliedert wurde, wird in der Literatur zumeist mit der Vermutung beantwortet, dass Raimondo del Balzo Orsini auf seiner Reise ins Heilige Land den damaligen Visitator der Heiligen Stätten, Bartolomeo della Verna, kennengelernt habe, der seit 1367 Vikar von Bosnien war; vgl. Pasquale Corsi, I francescani osservanti della vicaria di Bosnia in Puglia, in: Antonio Cassiano/Benedetto Vetere (Hrsg.), Dal giglio all'orso. I principi d'Angiò e Orsini del Balzo nel Salento. Galatina 2006, 237-249, hier 243, mit der älteren Literatur 238, Anm. 1. Allerdings muss dies angesichts fehlender Belege für Raimondos Aufenthalt im Heiligen Land (vgl. oben Anm. 157) als rein hypothetisch gelten. Eine andere These verknüpft die Gründung von S. Caterina mit der Verbreitung der franziskanischen Observanzbewegung durch Brüder des Vikariats Bosnien und der Unterstützung der Observanten durch den lokalen Adel wie die del Balzo Orsini; vgl. etwa Benigno Francesco Perrone, La regolare osservanza francescana nella terra d'Otranto. Bd. 1. Il divenire storico-legale, 1391-1898. Galatina 1992, 21-28; Vitolo, Noblesse (wie Anm. 104), 565. Schwierigkeiten bereitet jedoch die Tatsache, dass die Anfänge von S. Caterina zwischen 1385 und 1391 in die schlecht dokumentierte Anfangsphase der Observanzbewegung im Süden Italiens fallen. So bleiben Mutmaßungen über Raimondos Förderung der Observanten in Galatina und im Salento an die spätere Evidenz einer ab 1444 belegten Kustodie S. Caterina ordinis fratrum minorum de observantia mit elf zugehörigen Niederlassungen gebunden; vgl. Corsi, Francescani (wie Anm. 161), 247. S. aber auch unten Anm. 179. 
Bogumilen ${ }^{162}$ geprägten Land an der gegenüberliegenden Adriaküste ausgebildet sowie zurückkehrende Missionare aufgenommen. ${ }^{163}$

In der Architektur von S. Caterina zeigt sich also eine Vermischung der unterschiedlichen Funktionen, Traditionen und Einflüsse, und nicht etwa eine Konfrontation zwischen Ost und West. Der auffällige Eklektizismus zeugt von einer geglückten Synthese der Ansprüche von Stifter und Orden.

Auch der Bilddekor von S. Caterina weist in dieselbe Richtung. S. Caterina wurde nach 1391 über eine Zeitspanne von mindestens 30 Jahren von verschiedenen Malerwerkstätten ausgemalt. ${ }^{164}$ Ergebnis sind fünf umfangreiche und stilistisch extrem uneinheitliche ${ }^{165}$ Zyklen, zahlreiche Votivbilder und zahllose Wappen der Stifterfamilie

162 Über die Frage der Bedeutung der dualistischen oder bogomilischen Christen in der bosnischen Kirche konnte in der Forschung noch immer keine Einigung erzielt werden; vgl. z. B. Bernard Hamilton, Die christliche Welt des Mittelalters. Der Osten und der Westen. Düsseldorf, Zürich 2004, 131, mit älterer Literatur.

163 Corsi, Francescani (wie Anm. 161), 243.

164 Siehe dazu Antonella Cucciniello, La decorazione pittorica della chiesa di Santa Caterina d'Alessandria a Galatina. Diss. phil. Neapel 2000/2001, 6-72, und zuletzt Ortese, Sequenza (wie Anm. 57), 346-350. Eine erste Ausmalung der unteren Bereiche des Mittelschiffs sowie der rechten Seitenkapelle mit Heiligen erfolgte wohl direkt nach 1391; vgl. dazu Tina Piccolo, La chiesa di S. Caterina: il restauro degli affreschi, in: Clara Gelao/Gian Marco Jacobitti (Hrsg.), Castelli e cattedrali di Puglia. Mostra Bari, Castello Svevo, 13.7.-31.10.1999. Bari 1999, 629631. Diese wurde anschließend durch die zweite, heute sichtbare Bemalung überdeckt. Unklar ist, warum und zu welchem Zeitpunkt diese Übermalung stattfand. Eine Datierung mit Hilfe der Wappen gestaltet sich für die Dekoration des Mittelschiffs auch angesichts zahlreicher Restaurierungsversuche als problematisch. Die zahlreichen, abwechselnd angeordneten Wappen der Del Balzo Orsini bzw. der D'Enghien-Brienne, also von Raimondo und Maria, in den Gewölben und auf den Strebepfeilern lassen einerseits vermuten, dass die Fresken vor Raimondos Tod (17.1.1406) entstanden. Dementgegen deuten andererseits zwei Wappen Marias als Königin von Neapel im 1. Joch darauf hin, dass Maria die dortigen Fresken erst nach ihrer zweiten Heirat mit Ladislaus von Neapel (13.4.1407) in Auftrag gab. Der Stil der Dekoration spricht zumindest dafür, dass bei der Ausmalung von Osten aus nach Westen vorgegangen wurde, wobei zunächst die Gewölbe, dann die Wände freskiert worden sein dürften. Die Wappen der Familienkapelle lassen den Entstehungszeitraum der dortigen Fresken auf die Mitte des zweiten Jahrzehnts des 15. Jahrhunderts eingrenzen; Presta, Basilica (wie Anm. 132), 121; Cucciniello, La decorazione (wie Anm. 164), 72. Der Bildschmuck im Mittelschiff dürfte zu diesem Zeitpunkt bereits fertiggestellt gewesen sein (s. unten Anm. 188). Der Wortlaut eines Testaments von 1423 lässt auf jeden Fall darauf schließen, dass die Dekoration der Kirche in diesem Jahr zum Großteil abgeschlossen war; Maria Stella Calò Mariani, Predicazione e narrazione dipinta nella chiesa di Santa Caterina d'Alessandria a Galatina (Terra d'Otranto), in: Arturo Carlo Quintavalle (Hrsg.), Medioevo: immagine e racconto, Mailand 2003, 474-478, hier 474. Die zahlreichen Votivfresken der Seitenschiffe entstanden in den folgenden Jahrzehnten.

165 Diese Diversität wird mit der unterschiedlichen Herkunft und Prägung der verschiedenen Maler begründet. Für die Freskendekoration von S. Caterina wurden bislang Malerwerkstätten bzw. spezielle Persönlichkeiten aus Umbrien, aus der Toskana, Latium, Sizilien sowie Neapel oder sogar aus Deutschland verantwortlich gemacht, die wiederum von mittelitalienischem wie kata- 


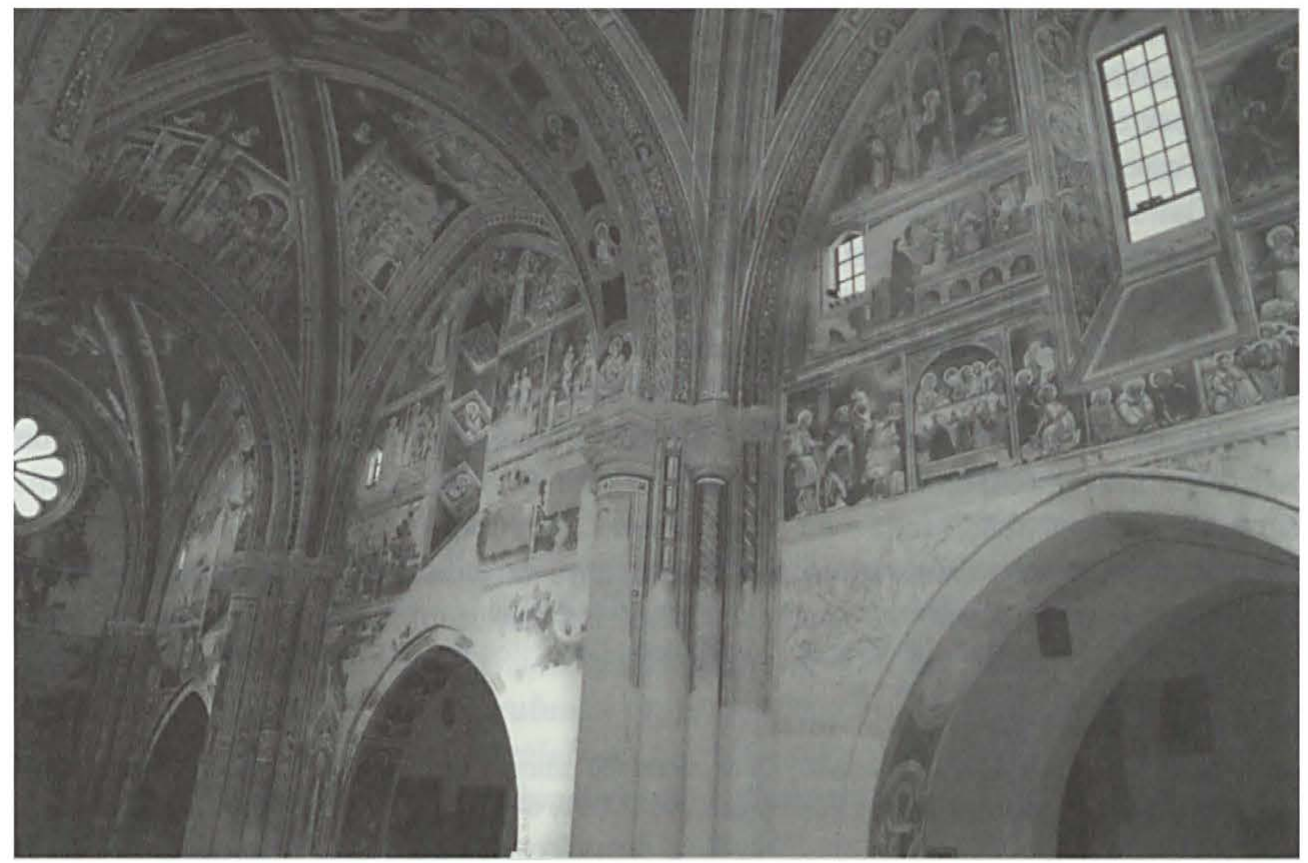

Abb. 26: Galatina, S. Caterina, Mittelschiff (Foto: M. Mersch)

(Abb. 22, 26, 38, Tafel VI 4). Die Zyklen an den Wänden und in den Gewölben im Presbyterium und im Mittelschiff - Szenen aus der Vita der Hl. Katharina unter Evangelisten und Kirchenvätern im Chorbereich, Episoden aus der Christusvita unter Engelschören im dritten Joch, aus dem Alten Testament unter einem Sakramentszyklus im zweiten Joch sowie aus der Apokalypse mit dem Jüngsten Gericht im ersten Joch unter Tugenden und dem apokalyptischen Kampf gegen den Drachen - dürften im ersten Jahrzehnt des 15. Jahrhunderts, die Dekoration der so genannten Familienkapelle mit einem Zyklus des Marienlebens gegen Mitte des folgenden Jahrzehnts entstanden sein (Abb. 27-30, 38, Tafel VI 5-7). ${ }^{166}$

Diese in Apulien einzigartige, äußerst aufwendige Freskenausstattung ist in ihrem Ausmaß und ihrer Thematik durchaus mit dem Dekor der bedeutendsten Franziskanerkirche und dem Mittelpunkt des Ordens, mit S. Francesco in Assisi zu vergleichen. Wie im Bildschmuck von S. Francesco und ebenfalls S. Chiara in Assisi wird ein alttestamentarischer Zyklus mit Szenen der Christus- und Marienvita, der Apokalypse bzw.

lanischem oder byzantinischem Einfluss geprägt sein sollen. Vgl. Putignani, Tempio (wie Anm. 132), 20; Zimdars, Ausmalung (wie Anm. 129), 95; Mario Cazzato, Aspetti e problemi artistici della chiesa di S. Caterina a Galatina: primi sondaggi iconogafici, in: Bollettino storico di Terra d'Otranto 3, 1993, 53-65, bes. 55 f.

$166 \mathrm{Vgl}$. dazu die vorigen Fussnoten sowie Anm. 188. 


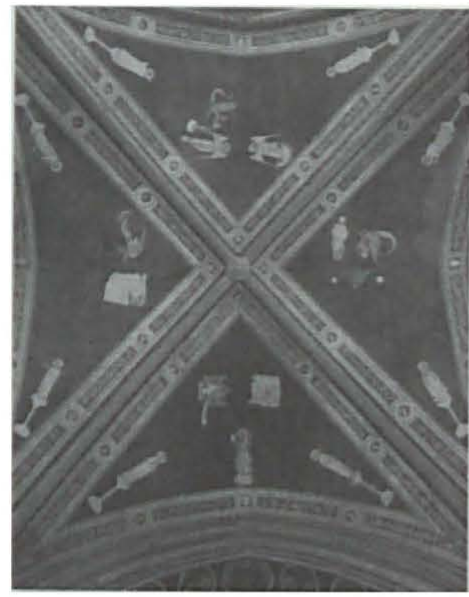

Links, von oben nach unten:

Abb. 27: Galatina, S. Caterina, Gewölbe im ersten Mittelschiffsjoch, Tugenden und apokalyptischer Kampf mit dem Drachen (Foto: M. Mersch)

$A b b$. 28: Galatina, S. Caterina, Gewölbe im zweiten Mittelschiffsjoch, Sakramente und Triumph der Kirche (Foto: M. Mersch)

$A b b$. 29: Galatina, S. Caterina, Gewölbe im dritten Mittelschiffsjoch, Himmelshierarchien (Foto: M. Mersch)
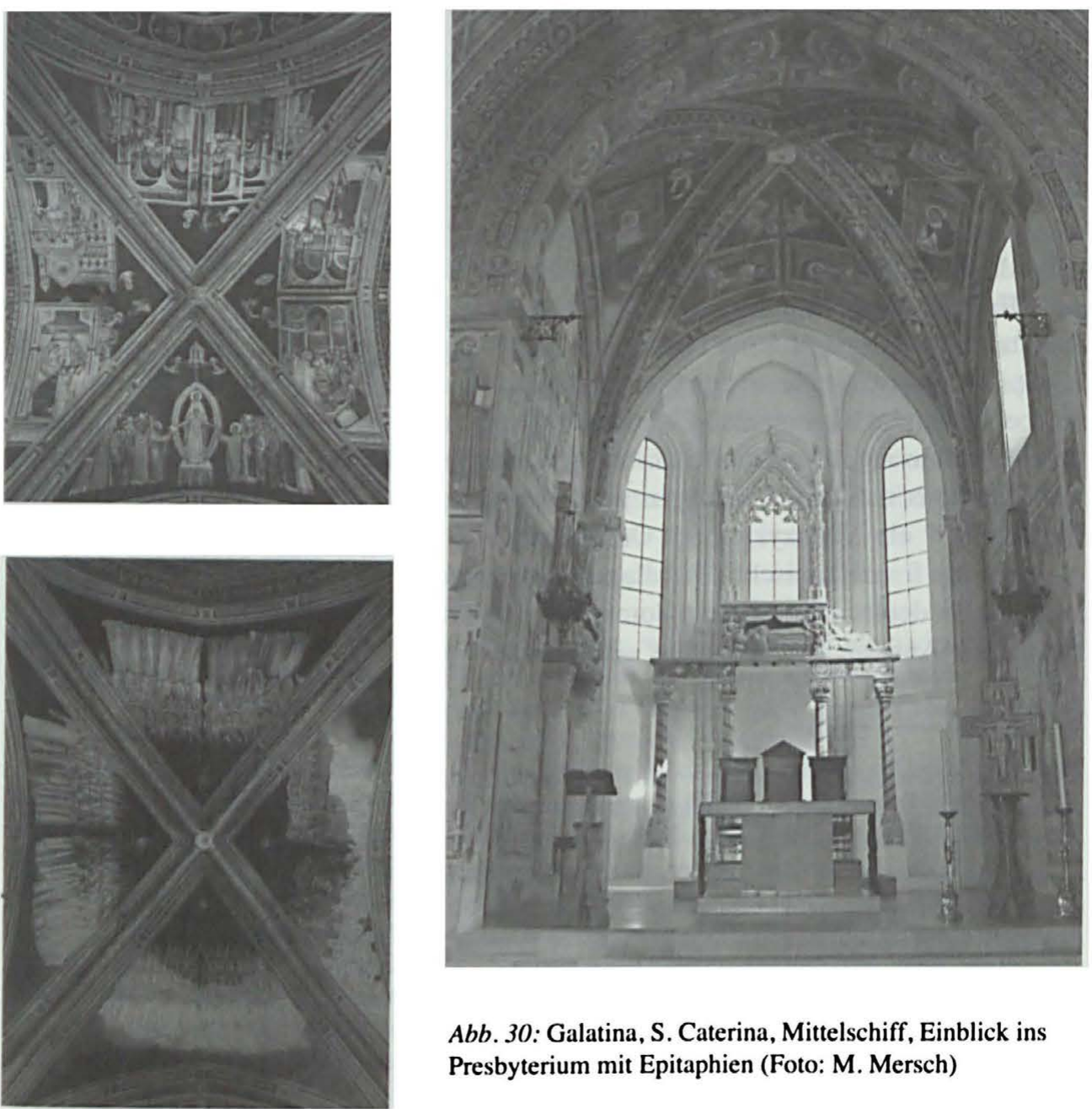

Abb. 30: Galatina, S. Caterina, Mittelschiff, Einblick ins Presbyterium mit Epitaphien (Foto: M. Mersch) 
des Jüngsten Gerichts und der Vita der Schutzpatronin kombiniert. In S. Caterina handelt es sich jedoch nicht um ein Mitglied des Ordens. Stattdessen wurde mit der Darstellung der Kirchenpatronin auf den Besitz der Fingerreliquie der Hl. Katharina angespielt, die von Raimondo selbst dem Kloster geschenkt worden sein soll - und zwar neben den im Presbyterium situierten Epitaphien für Raimondo und seinen Sohn (Abb. 30). ${ }^{167}$ Deren besondere Verehrung der Heiligen zeigt sich ebenfalls in ihrer mit Wappen der Familie umrahmten Darstellung im zweiten Joch (Abb. 31). Ein dichtes Netz von Wappen an den Wänden und in den Gewölben sowie in der Fensterrose zeugt im Mittelschiff von der dominierenden Rolle der del Balzo Orsini im Kirchenprojekt. ${ }^{168}$ Auch die Darstellung der Vita der Gottesmutter in der von Familienwappen der Stifter reich dekorierten Seitenkapelle dürfte auf den Namen der Stifterin Maria d'Enghien zurückzuführen sein (Abb. 38). Bereits auf den ersten Blick inszeniert sich somit die Stifterfamilie als prägende Kraft.

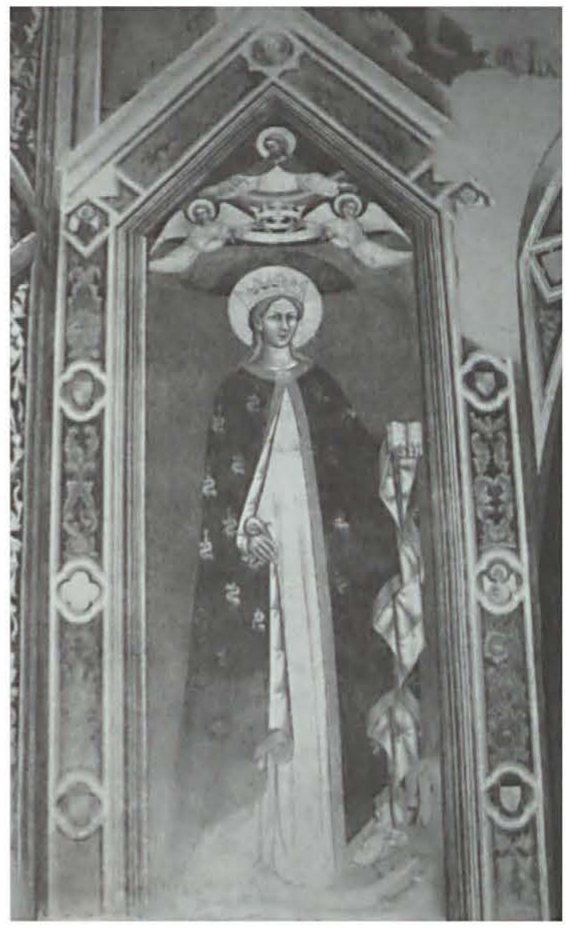

Abb. 31: S. Caterina, Zweites Mittelschiffsjoch, Nordseite, Hl. Katharina (Foto: U. Ritzerfeld) Auf einen ,franziskanischen Charakter ${ }^{\text {' der }}$ Kirche weisen zunächst nur Ordensheilige im unteren Bereich des Mittelschiffs sowie in Medaillons auf dem Gurtbogen zwischen dem ersten und dem zweiten Joch hin (Abb. 35), ${ }^{169}$ ein Vitenzyklus des Ordensgründers fehlt. Bei einer genaueren Betrachtung tritt die franziskanische Grundlage jedoch in zahlreichen Facetten hervor.

Zunächst deutet sich mit dem dominanten Leitthema des Glaubens ein thematischer Bezug zur Aufgabe des Konvents an. Mit der Vorführung der Etappen der Heilsge-

167 Vgl. dazu Paolo Chiappetta, Le origini del tesoro di S. Caterina d'Alessandria in Galatina, in: Michele Paone (Hrsg.), Scritti di storia pugliese in onore di Mons. Carmine Maci. Galatina 1994, 35-59, bes. 39-48. Das Epitaph Raimondos wurde zwar im Nachhinein versetzt. Es ist jedoch davon auszugehen, dass es ursprünglich ebenfalls im Presbyterium stand. Zimdars, Ausmalung (wie Anm. 129), 156; Belli D'Elia, Principi (wie Anm. 103), 267-274.

$168 \mathrm{Zu}$ den Wappen vgl. Presta, Basilica (wie Anm. 132), 119-122; Belli D'Elia, Principi (wie Anm. 103), 278-283. Allein im Mittelschiff befinden sich fast 100 Wappen, die in ihrer Gesamtheit von der Forschung bislang noch nicht berücksichtigt worden sind.

169 Zum spezifisch ,Franziskanischen' in S. Caterina vgl. Zimdars, Ausmalung (wie Anm. 129), 167-170; Belli D'Elia, Principi (wie Anm. 103). 
schichte werden die Hauptmysterien des christlichen Glaubens illustriert und auf diese Weise dem Betrachter ein visualisiertes Credo vorgeführt. ${ }^{170}$ Der wahre und falsche Glaube wird in verschiedenen biblischen und legendären Formen thematisiert. Die Anbetung und Zerstörung von Götzen und Bestrafung der Ungläubigen bzw. die Festigkeit im Glauben und das Martyrium sind Thema in allen Bildzyklen der Kirche, werden im Apokalypsezyklus, in den Genesis- und Christusszenen und der Katharinen-Legende behandelt. Speziell die Glaubensverkündung und das Martyrium, vermutlich auch bedingt durch die missionarische Zielsetzung des Konvents in Apulien sowie auf dem Balkan, werden

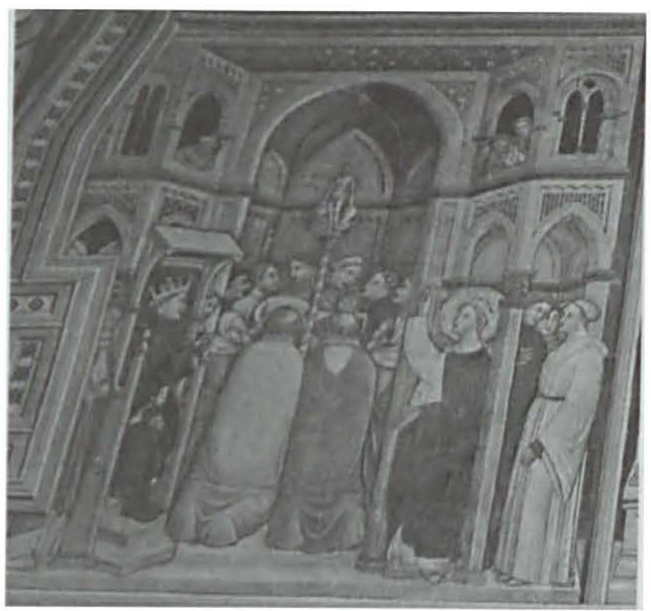

$A b b .32$ : S. Caterina, Mittelschiff, Presbyterium, Nordwand, Katharinenlegende, Katharina debattiert gegen die Götzenanbetung (Foto: $\mathbf{M}$. Mersch) in Szene gesetzt. Nicht nur, wie oben angemerkt, im Architrav-Relief des zentralen Portals (Abb. 22), sondern ebenfalls im Innenraum der Kirche kommt dieser apostolische Auftrag zum Ausdruck. Gerade im Presbyterium in den Fresken zur Legende der Hl. Katharina, die zahlreiche Heiden bekehrte, ist diese Verbindung augenfällig (Abb. 32). Das Bildprogramm setzt demnach das missionarische Ideal der Franziskaner unter Bezug auf den eigenen Reliquienschatz und die devotionale Präferenz der Stifterfamilie visuell um ${ }^{171}$ und motiviert unter Visualisierung der wahren Lehre sowie der Vorführung beispielhafter Vorbilder der Glaubensstärke bzw. der Bestrafung von Ungläubigen zum rechten Glauben.

170 Umgesetzt wird nicht ein kanonischer Credo-Zyklus, wie er im 14. und 15. Jahrhundert in verschiedenen Versionen besonders in Siena verbreitet war. Jedoch sind die Inhalte des Credo, nämlich die wichtigsten Mysterien des christlichen Glaubens im Programm von S. Caterina präsent. Zum Credo in Italien zuletzt Mastacchi, Il Credo (wie Anm. 122).

171 Mit dieser missionarischen Deutung harmoniert die These von Calò Mariani, welche die Zyklen als visuelle, speziell auf die Häresie der Bogumilen antwortende Predigthilfen interpretiert; Calò Mariani, Predicazione (wie Anm. 164), 474-478. Zu belegen ist diese Interpretation jedoch nicht. Vgl. dazu Mersch/Ritzerfeld, Differenzwahrnehmung (wie Anm. 126), 78-81. Auch die zahlreichen Darstellungen der Trinität in S. Caterina sind als Antwort auf häretische Bewegungen gesehen worden; Benedetto Vetere, I del Balzo Orsini e la basilica di Santa Caterina in Galatina. Manifesto ideologico della famiglia, in: Antonio Cassiano/Benedetto Vedere (Hrsg.), Dal giglio all'orso. I principi d'Angiò e Orsini del Balzo nel Salento. Galatina 2006, 2-23, bes. 2If.; Maria Stella Calò Mariani, Rappresentare il mistero. Immagini della Trinità in Puglia fra Medioevo e Rinascimento, in: Tolleranza e convivenza tra Christianità e Islam. L'Ordine dei 
Darüber hinaus zeigt sich das Bildprogramm durch franziskanisches Gedankengut geprägt. Als inhaltliche Grundlage sind Schriften des Hl. Bonaventura (1221-1274) vermutet worden. ${ }^{172}$ In der Tat sind Gesamtkonzeption wie Einzelheiten der Dekoration des Mittelschiffs mit der Theologie des Franziskaners in Übereinstimmung zu bringen, wobei wiederum zahlreiche Parallelen zur Dekoration der Oberkirche von S. Francesco in Assisi festzustellen sind. Vorgeführt wird mit den Szenenabfolgen zum Alten und Neuen Testament sowie den Evangelisten und Kirchenvätern die Konsonanz der Heiligen Schriften, in denen die Zeit beschlossen liegt und die in der Apokalypse enthüllt werden. Die Kirche wirkt als Verwalter der Evangelien und Spiegelbild der mit den Engelschören im dritten Gewölbe aufgezeigten himmlischen Hierarchien und kämpft als Ecclesia militans, verbildlicht im ersten Joch, gegen den Drachen, gegen das Böse (Abb. 27-30, Tafel VI 5-7). ${ }^{173}$ Betont ist neben der Kontinuität der Institution und der Unantastbarkeit der sich auf die himmlische Hierarchie beziehenden kirchlichen Sozialordnung die auch konkrete Bedeutung der Kirche für jeden Gläubigen, ermöglicht sie doch mit den im zweiten Gewölbe dargestellten Sakramenten den Zugang zum Heil.174 Als letztendlich im Kampf gegen das Böse sieghafte Ecclesia triumphans begleitet sie die Menschen auf ihrem Lebensweg und eröffnet ihnen den Weg der Erlösung.

Gerade hier befindet sich in der dem Sakramentszyklus angegliederten Szene der triumphierenden Kirche, die durch Positionierung und Größe in den Mittelpunkt des Bildfeldes des die Kirche betretenden Betrachters gerückt ist, der Schlüsselpunkt ${ }^{175}$ des Programms (Abb. 22, 33, Tafel VI 8). Dargestellt ist die in einer männlichen Figur personifizierte Ecclesia, der Christus von hinten die Arme stützt, während sie gemeinsam

Trinitari (1198-1998). Galatina 1999, 9-27, hier 26f.; Marina Falla Castelfranchi, La teologia trinitaria: aspetti iconologici e iconografici: Le origini e il suo sviluppo in area bizantina, in: Salvatore Palese/Giancarlo Locatelli (Hrsg.), Il Concilio di Bari del 1098. Atti del Convegno storico internazionale e celebrazione del 9. centenario del Concilio. Bari 1999, 285-315, hier 313. Jedoch ist zu betonen, dass das Thema in Apulien generell sehr beliebt war, S. Caterina mit diesem Schwerpunkt also keinen Einzelfall darstellt.

172 Zimdars, Ausmalung (wie Anm. 129), 161-170; Marisa Milella, La parola si fa immagine, in: Fernando Russo (Hrsg.), La parola si fa immagine: storia e restauro della basilica orsiniana di Santa Caterina a Galatina. Venedig 2005, 65-133, hier 76.

$173 \mathrm{Vgl}$. Bonaventura, Sermo De Angelis, in: Sermones de tempore, de sanctis, de B. Virgine Maria et de diversis. Ed. Bernardin a Portu Romatino. (Doctoris Seraphici S. Bonaventurae Opera omnia, Bd. 9) Quaracchi 1901, 609-631

174 Zahlreiche verschiedene Vorstellungen Bonaventuras sind mit dem Programm in Verbindung zu bringen; so behandelt beispielsweise auch dessen ,Breviloquium‘ die Trinität, die Erschaffung der Welt und des Menschen, den Sündenfall und die Sünde generell, die Menschwerdung und die Leiden Christi, den Hl. Geist, die sieben Sakramente und die letzten Dinge. Vgl. dazu Zimdars, Ausmalung (wie Anm. 129), 161-166. Zu weiteren Quellen und im Vergleich mit S. Francesco vgl. Hans Belting, Die Oberkirche von S. Francesco in Assisi. Berlin 1977, bes. $38-45,53-68$.

175 Dies vermutet auch Vetere, I del Balzo (wie Anm. 171), 18, ohne dem jedoch inhaltlich weiter nachzugehen. 


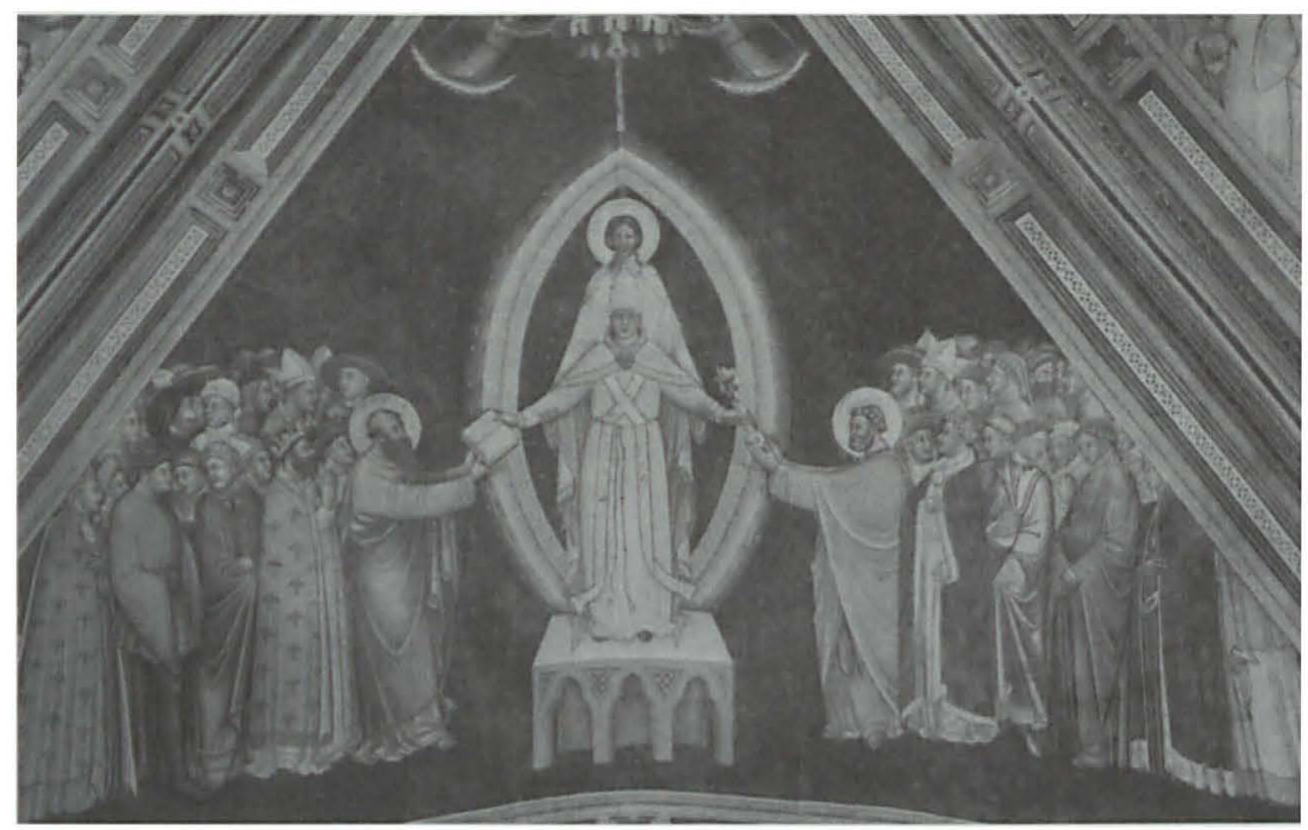

Abb. 33: Galatina, S. Caterina, Gewölbe im zweiten Mittelschiffsjoch, Triumph der Kirche (Foto: M. Mersch)

mit den seitlich unter ihr stehenden Petrus und Paulus Schlüssel und Evangelium in Händen hält und zahlreiche Zuschauer von unterschiedlichem Rang, von klerikalem und weltlichem Status, darunter zwei Königspaare, dem Geschehen beiwohnen. Die Komposition orientiert sich an der Szene des Triumphes der Kirche in der Incoronata in Neapel, weicht jedoch in bezeichnenden Details von diesem Vorbild ab (Abb. 34). Wie in der neapolitanischen Kirche erlaubt auch die zentrale Gestalt und somit die ganze Szene in S. Caterina eine mehrfache Lesung. Sie personifiziert die von Christus gestützte, in der Tradition der Apostelfürsten ruhende triumphierende Kirche und ist zugleich durch ihre Kleidung als Papst und Stellvertreter Christi ausgezeichnet. Jedoch reicht der Gottessohn in S. Caterina, entsprechend einer Darstellung der Traditio legis bzw. clavis, die Au-

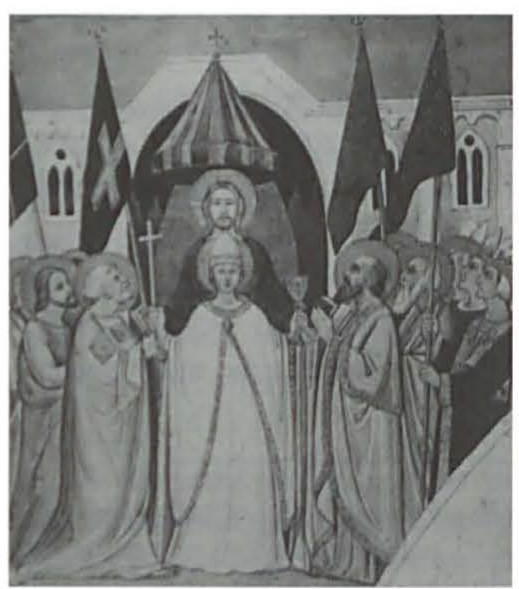

Abb. 34: Johann Anton Ramboux, Aquarell, 1820er Jahre: Neapel, Incoronata, Gewölbe im ersten Mittelschiffsjoch, Triumph der Kirche (Kunstmus. Düsseldorf, Inv. Nr. RV-121) toritätssymbole von Schlüssel und Evangelium an 
Petrus und Paulus weiter, und zwar über die Gestalt der Papst-Kirche. Andersherum gesehen empfängt diese von den Apostelfürsten ihre Machtattribute.176 Der Pontifex steht über seine Amtsgewalt und religiöse Autorität in Primat und Lehre in der Nachfolge der wichtigsten Apostel. Unmissverständlich sind auf diese Weise die auf ekklesialer Tradition beruhende Autorität des päpstlichen Amtes und alleinige Auslegungsbefugnis der Heiligen Schriften formuliert. Gleichzeitig heben die Positionierung der personifizierten Ecclesia vor und der Körperkontakt mit Christus die physisch enge Verbindung des Gottessohns mit der Institution und seinem Vertreter auf Erden und dessen Stellung in der Welt hervor. Christus steht ,hoch über alle Fürsten und Gewalten, Mächte und Herrschaften und über jeden Namen, der nicht nur in dieser Welt, sondern auch in der zukünftigen genannt wird. Alles hat er [Gott] ihm zu Füßen gelegt und ihn, der als Haupt alles überragt, über die Kirche gesetzt. Sie ist sein Leib und wird von ihm erfüllt, der das All ganz und gar beherrscht“ (Eph 1,21-23). Christus ist „Haupt des Leibes, der Leib aber ist die Kirche“ (Kol 1,18).

Dabei präsentiert Christus die Gestalt in Abweichung vom Vorbild in Neapel und in Anlehnung an die ikonographische Formel des in der Kirche mehrfach dargestellten Gnadenstuhls annähernd in Kreuzform: ${ }^{177}$ Die aus dem Leiden Christi - ausführlich dargestellt in der unteren Zone im dritten Joch nahe am Altarbereich - geborene Kirche wird als Vermittler der ebenfalls auf die Passion Christi zurückgeführten, in den übrigen Gewölbeszenen des zweiten Jochs dargestellten Sakramente (Abb. 28) zur Voraussetzung der Erlösung, der Pontifex zu dem von Christus selbst eingesetzten Stellvertreter des Gottessohnes auf Erden. Die Verbindung von Christus und Papst als höchste Verantwortliche für die Spende von Gaben und Würden für den ,Bau des Körpers Christi', also der Kirche, sowie als Befreier von Sündenschuld durch die Erteilung der Sakramente wird bereits im Lignum Vitae Bonaventuras in der Gestalt des ,Christus Pontifex' gezogen - ein Konzept, das die Heilsbedeutung der Kirche unter Führung des Papstes zelebriert und im franziskanischen Kontext auch andernorts bildlich umgesetzt wurde. 178

Diese außergewöhnliche, mit Bildformeln und Symbolen kirchlicher und päpstlicher Macht arbeitende monumentale Visualisierung von Heilsbedeutung, Oberhoheit und Einigkeit der Kirche unter einem von Christus eingesetzten Papst entstand bezeichnen-

176 Es wird dabei offenbar absichtlich im Unklaren gelassen, wer der überreichende und wer der empfangende Part ist, was beide Bewegungsrichtungen ermöglicht.

177 Nicht nur im Freskenschmuck, auch im ehemaligen Altarbild aus S. Caterina ist das Thema des Gnadenstuhls aufgenommen. Cassiano, Arte (wie Anm. 52), 300, Abb. 46.

178 Bonaventura, Lignum Vitae, in: Opuscula varia ad theologiam mysticam et res ordinis fratrum minorum spectantia. Ed. Bernardin a Portu Romatino. (Doctoris seraphici S. Bonaventurae Opera Omnia, Bd. 8) Quaracchi 1898, 68-87. Verbildlicht ist der ,Christus Pontifex ‘ im franziskanisch geprägten Lignum Vitae in S. Maria Maggiore in Bergamo aus den 1340er Jahren. Vgl. dazu Mauro Zanchi, La basilica di Santa Maria Maggiore. Una lettura iconografica della „Biblia pauperum“ di Bergamo. Clusone 2003, 101. 
derweise während einer Krisenperiode der römischen Kirche, nämlich zur Zeit des großen abendländischen Schismas, als Spaltung, häretische Bewegungen und Auseinandersetzungen mit der griechischen Kirche die Institution schwächten. Die im Fresko propagierte päpstliche Machtstellung musste den Franziskanern als Verteidigern des päpstlichen Primats und der römischen Kirche in Apulien am Herzen liegen. ${ }^{179} \mathrm{Be}-$ zeichnenderweise befindet sich die Darstellung auf einer Blickachse mit dem auf dem Gurtbogen zwischen ersten und zweiten Joch, also zwischen dem Sakrament- und dem Apokalypsezyklus positionierten Hl. Franziskus, der im Kreise seiner franziskanischen Mitstreiter in einem Regenbogen als apokalyptischer Engel des sechsten Siegels seine Stigmata vorweist (Abb. 18, 35, 39, Tafel VI 10). Im Amt eines Engels fungiert er nach

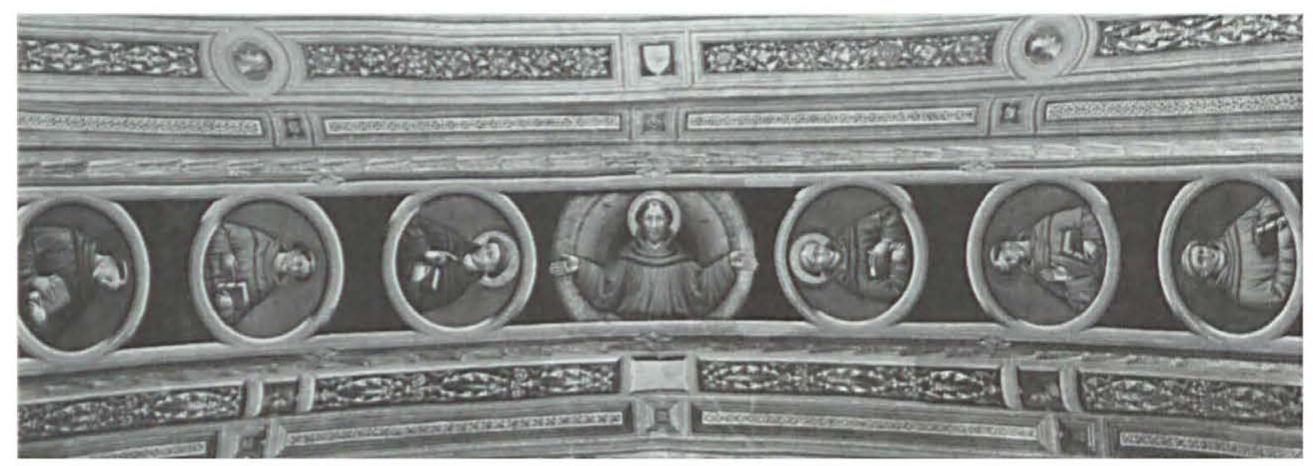

Abb. 35: Galatina, S. Caterina, Gurtbogen zwischem erstem und zweitem Mittelschiffsjoch, Hl. Franziskus und Franziskanermönche (Foto: M. Mersch)

Bonaventura als Vermittler zwischen irdischer und himmlischer Sphäre, als Abgesandter Gottes, der teilhat am Wissen um den göttlichen Heilsplan und dessen Stigmata Siegel seiner Sendung sind. Franziskus gilt als Prophet, als Vorläufer der Wiederkunft Christi. Ihm und seiner Bewegung kommt eine wichtige Rolle im endzeitlichen Kampf gegen den Antichrist zu. ${ }^{180}$ Zugleich ist der Heilige im Geschichtsentwurf Bonaventuras der Gründer des Ordens einer bevorstehenden innerweltlichen Endzeit, einer Ge-

179 Vgl. dazu Zimdars, Ausmalung (wie Anm. 129), 168-170. Die Papstnähe gerade der Observanten und die Bedeutung der Pontifex-Figur im Bildprogramm S. Caterinas spechen dafür, dass es sich bereits vor der ersten urkundlichen Nennung der Observantenkustodie von 1444 tatsächlich um einen Konvent dieses Ordenszweiges handelte (vgl. Anm. 161). $\mathrm{Zu}$ observantischen Bildstrategien im 15. Jahrhundert vgl. Kornelia Imesch Oehry, Die Kirchen der Franziskanerobservanten in der Lombardei, im Piemont und im Tessin und ihre „Lettnerwände“. Architektur und Dekoration, Essen 1991; dies., Franziskanische Ordenspolitik und Bildprogrammatik. Die Leben-Jesu-Fresken von Santa Maria delle Grazie in Bellinzona, Bamberg 1998, hier 170-181.

180 So z. B. bei Ubertin von Casale. S. Stanislao da Campagnola, L'angelo del Sesto Sigillo e I',Alter Christus“. Genesi e sviluppo di due temi francescani nei secoli XIII-XV. Rom 1971, 251-264. 
meinschaft, die einen neuen, künftigen Heilsstand eröffnet. ${ }^{181}$ Die dargestellten Franziskanermönche treten demnach als Zeugen seiner heilsgeschichtlichen Bedeutung, als Vorboten der neuen Heilszeit und Kämpfer gegen den Drachen auf. Erfolgte laut Bonaventura der Sieg über das Böse, wie im Sakramentsgewölbe in S. Caterina umgesetzt, bei der Gründung der Kirche in der Passion Christi, aus der die Sakramente entstanden, und beim Tode jedes gläubigen Menschen, so zeigt sich dieser Triumph ebenfalls in den leiblichen Passionszeichen von Franziskus. ${ }^{182}$ Der Opfertod des Gottessohnes als Ausgangspunkt für die Kirche wie auch für die Sakramente findet in der als Martyrium verstandenen Stigmatisierung des Franziskus seine Spiegelung, explizit dargestellt im ersten Joch unter den Apokalypseszenen (Abb. 36, Tafel VII 9). ${ }^{183}$ Die verschiedenen Themen werden zueinander in Beziehung gesetzt, was auch in den Patronaten der Kirchenschiffe zum Ausdruck kommt. ${ }^{184}$ Wird die (Macht-)Stellung des Papstes als Stellvertreter Christi über seine Position zwischen diesem und der Welt defi-

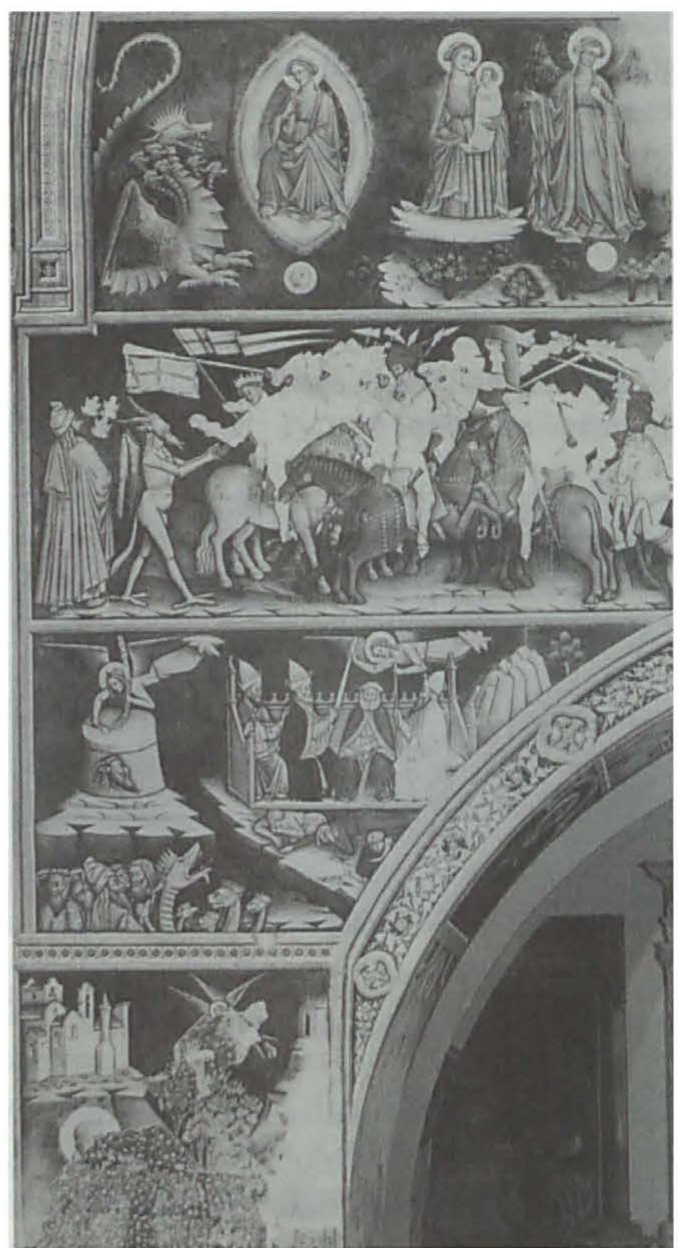

$A b b$. 36: Galatina, S. Caterina, erstes Mittelschiffsjoch, Südseite, Szenen der Apokalypse und Stigmatisierung des Hl. Franziskus (Foto: U. Ritzerfeld)

181 Vgl. Joseph Ratzinger, Die Geschichtstheologie des heiligen Bonaventura. München/Zürich $1959,32-34,47,51$.

182 Vgl. Bonaventura, Sermo De Angelis (wie Anm. 173), 630. Vgl. dazu Zimdars, Ausmalung (wie Anm. 129), 161-170.

183 Die Szene wurde mit einer Darstellung derselben Thematik übermalt. Im Mittelschiff und in den Seitenschiffen ist zudem mehrfach der stigmatisierte Heilige dargestellt.

184 Nach einem Dokument aus dem 18. Jahrhundert waren sie der unbefleckten Empfängnis, dem Erlöser, dem Hl. Sakrament, dem Hl. Kreuz und dem Hl. Franziskus geweiht. Zacchino, In umbilico (wie Anm. 125), 272. Zum Verständnis der Stigmatisierung als Martyrium vgl. z. B. Bonaventura de Balneoregio, Legenda maior sancti Francisci, in: Fontes franciscani. Ed. Enrico Menestò/Stefano Brufano. (Medioevo francescani, Testi, Bd. 2.) Assisi 1995, 777-961, bes. 862. 
niert, so tritt der die Wundmale am eigenen Körper nachempfindende , alter Christus $^{6}$ in seiner apokalyptischen Rolle in Kraft. Dass diese Kompetenzen nicht gegeneinander stehen, sondern miteinander verbunden, der Heilige und mit ihm sein Orden als Teil der Kirche und die Kirche als in sich franziskanisch begriffen werden, nimmt in der Papstfigur Gestalt an: sie ist mit einer dreifach geknoteten Kordel als Franziskaner ausgezeichnet. Mit dieser Veränderung der aus der Incoronata übernommenen ikonographischen Formel der triumphierenden Kirche werden verschiedene ,franziskanische" Bildmodelle in Erinnerung gerufen. Die Positionierung der Gestalt des Hl. Franziskus vor Christus ist bereits im so genannten Engelsfenster in der Oberkirche von S. Francesco in Assisi aus den 1270/80er Jahren gegeben, welches mit Hilfe einer Parallelisierung mit Maria und dem Christuskind sowie Kreuz und Stigmata die ,Christus-conformitas" des Ordensgründers glorifiziert und

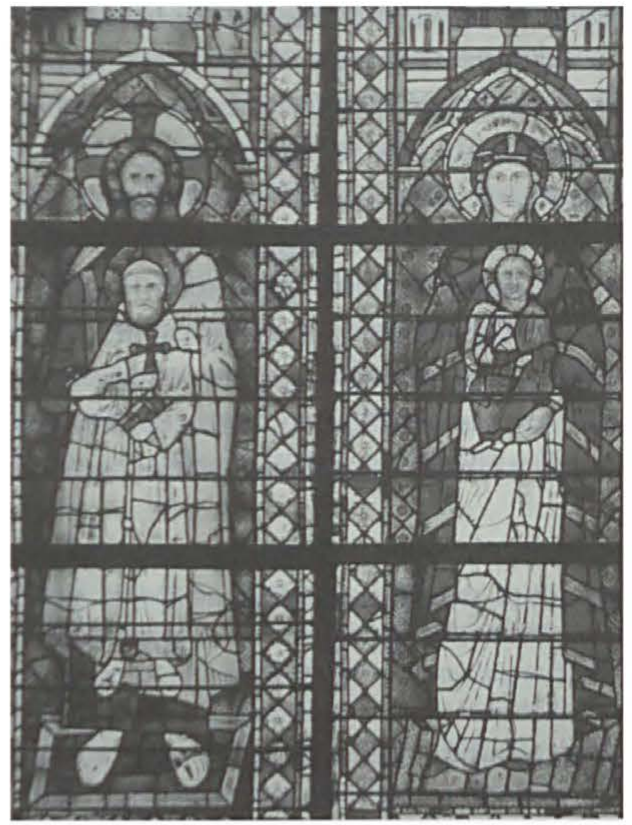

Abb. 37: Assisi, S. Francesco, Oberkirche, Südseite, sog. Engelsfenster, Christus und Franziskus bzw. Maria mit Christuskind (nach Martin, Die Glasmalereien von San Francesco in Assisi [wie Anm. 186], Abb. 194) ebenfalls als Bild für die Ecclesia triumphans gedeutet worden ist (Abb. 37). ${ }^{185} \mathrm{Mit}$ der Überreichung der Hl. Schrift wird in Galatina auch auf das Thema der Regelübergabe des $\mathrm{Hl}$. Franziskus an seine Orden rekurriert (vgl. Abb. 7). ${ }^{186}$ Gleichfalls positionieren sich die Fresken im Gewölbesegel von S. Caterina in der Verbindung mit Tugenden, dem apokalyptischen Geschehen und der Darstellung von Franziskus in der Tradition der Darstellungen der Vele in der Unterkirche von S. Francesco in Assisi über dem Grab des Heiligen, die den Ordensgründer als Zeichen eines neuen Zeitalters im escha-

185 So Belting, Oberkirche (wie Anm. 174), 47f. Vgl. William R. Cook, Images of St. Francis of Assisi. A Catalogue. (Italian Medieval and Renaissance Studies, Bd. 7.) Città di Castello 1999, 43f.; Frank Martin, Die Glasmalereien von San Francesco in Assisi. Regensburg 1997, 84-88, 288.

186 Dieses verbreitete sich in Apulien in Nachfolge der vermutlich ersten Darstellung im Konvent von S. Lorenzo Maggiore in Neapel. Zum Fresko im Konvent von S. Lorenzo Maggiore in Neapel aus dem 14. Jahrhundert und seiner Nachfolge in Apulien vgl. La Selva, Affresco (wie Anm. 77). 
tologischen Kontext feiern (Abb. 27) ${ }^{187}$ Jedoch werden in Galatina in Kombination verschiedener heilsgeschichtlicher Konzepte zur Bedeutung von Christus, Pontifex und Franziskus die Franziskaner an die Papstkirche gekoppelt und auf diese Weise der Führungsanspruch des Papsttums ebenfalls auf den Minoritenorden übertragen. In der Gestalt eines zeitgenössischen franziskanischen Papstes - Vergleichsbeispiele lassen vermuten, dass es sich um Alexander V. (1409-1410) handelt - konnte diese Verquickung am eindrucksvollsten zum Ausdruck kommen. ${ }^{188}$

Die übermächtige Papstfigur, der zwei mit Adlern bzw. Lilien dekorierte Königspaare $^{189}$ untergeordnet sind, musste aber ebenfalls im Interesse der Politik der Stifterfamilie sein, hielt diese doch auch nach dem Tod Raimondo Del Balzo Orsinis (17.1.1406) und der Heirat seiner Witwe Maria mit Ladislaus von Neapel an ihrer traditionell engen

187 Vgl. dazu Mary Ann Channell Dougan, The Franciscan Allegories in the Lower Church at San Francesco, Assisi: Form and Meaning. Magisterarbeit Univ. of Georgia 1997. Möglich wäre auch eine Anregung durch die ehemaligen, nur schriftlich überlieferten Apsisfresken der Unterkirche; vgl. ebd. 52-55.

188 Mehrere Darstellungen Alexanders V. zeigen eine Ähnlichkeit mit der Figur, so die Intarsiendarstellung im Chorgestühl von S. Francesco in Assisi von 1501 sowie ein Fresko in S. Francesco in Montefalco von Benozzo Gozzoli von 1451. Alexander V. galt nicht nur als berühmter franziskanischer Gelehrter, sondern er stärkte auch gezielt die Privilegien der Bettelorden. Er hatte sein Amt etwa ein Jahr lang inne, nämlich vom 26.6.1409-3.5.1410, womit ein terminus post quem für die Gewölbefresken des zweiten Jochs und somit, bei einem Fortschreiten der Arbeiten von Osten nach Westen, auch für die Fresken im ersten Joch festgelegt wäre. - Die Darstellung Alexanders V. könnte als Stellungnahme im Streit innerhalb der Kirche erfolgt sein. In diesem Sinne sind die Auseinandersetzungen zwischen dem Konvent und den Erzbischöfen von Otranto auf ihre Unterstützung unterschiedlicher päpstlicher Parteien zurückgeführt worden. Vgl. dazu Poso, Fondazione (wie Anm. 126), 219-221. Jedoch war generell in Apulien das Verhältnis zwischen den Bischöfen und den von den Päpsten geförderten Mendikanten häufig von Zwistigkeiten geprägt. Vgl. dazu Luigi Pellegrini, Vescovi e ordini mendicanti, in: Giuseppina De Sandre Gasparini, Antonio Rigon, Francesco Trolese, Gian Maria Varannini (Hrsg.), Vescovi e diocesi in Italia dal XIV alla metà del XVI secolo (Atti del VII convegno di Storia della Chiesa in Italia, Brescia, 21-25.9.1987). 2 Bde. Rom 1990. Bd. 1, 183-258. Eine entsprechende Parteinahme des Konvents ist jedenfalls nicht festzumachen. Die Situation in Apulien im Kirchenschisma ist in vielen Punkten offen und durch Uneinheitlichkeit geprägt. Ausschlaggebend mussten neben dem Orden auch die Del Balzo Orsini sein, die sich gerade durch die Flexibilität ihrer Anhängerschaft auszeichneten und durch deren Hilfe der Konvent seine Unabhängigkeit vom Bischof erlangte. Vermutlich bestimmte vor allem die Tatsache, dass es sich um einen Franziskaner handelte, die Darstellung dieses Papstes. Speziell zur Situation in Süditalien: Poso, Vescovi e potere (wie Anm. 130); Luigi Pellegrini, „Che sono queste novità?“ Le religiones novae in Italia meridionale (secoli XIII e XIV). Neapel 2005; Vitolo, Ordini mendicanti (wie Anm. 7).

189 Die Identität der beiden Königspaare hinter Petrus und Paulus bleibt dank ihrer generischen Gestaltung fraglich. Laut Presta handelt es sich bei dem linken Paar um den Staufer Friedrich II. und seine Gattin Jolande von Brienne, eine der Vorfahren von Maria d'Enghien. Das rechte Paar soll Ladislaus von Neapel und Maria d'Enghien darstellen. Presta, Basilica (wie Anm. 132), 81. Die äußerst allgemeine Kennzeichnung sowie die unvollständige Darstellung 
Verbindung zum Papsttum fest. ${ }^{190}$ Angesichts wechselnder politischer Koalitionen für oder gegen die jeweiligen Anwärter bzw. Inhaber des neapolitanischen Königstitels versuchten Raimondo und später sein Sohn durch eine anhaltende Nähe zum Hl. Stuhl ihre Machtansprüche in Apulien durchzusetzen. ${ }^{191}$ Somit war auch dem Kirchengründer und seinen Nachkommen an einer Demonstration päpstlicher Stärke gelegen, mit deren Hilfe sie ihre Ansprüche gegenüber den neapolitanischen Königen zur Geltung bringen konnten. Die mächtigen und finanzkräftigen Del Balzo Orsini hegten sogar Hoffnungen auf den Königsthron. Bereits Raimondo lag in jahrelanger Auseinandersetzung mit König Ladislaus von Neapel. Die Kampfeshandlungen hatten erst nach seinem Tod und nach der Heirat seiner Witwe Maria mit dem König ein Ende. Der Sohn von Raimondo und Maria, Giovanni Antonio del Balzo Orsini, wiederum starb bei einem Rebellions-

der Königin sprechen aber jedenfalls im zweiten Fall eher für eine bewusst generische Wiedergabe von Familienmitgliedern der Anjou. Auf diese Weise hätte die Auftraggeberin ihre königliche Abstammung sowie den Beistand der Königshäuser für die Kirche und die Franziskaner demonstrieren können. Um wen es sich auch immer handeln sollte, auf jeden Fall musste die Darstellung der beiden dem franziskanischen Papst untergeordneten Königspaare die Unterstützung des Kirchenoberhauptes durch die irdischen Ordnungsmächte einfordern und seinen Anspruch auf Oberhoheit untermauern.

190 Unklar bleibt, ob die Abbildung von Staufern und Anjou als Herrscher über Sizilien und Frankreich bzw. Neapel ebenfalls Bezug auf eine konkrete politische Streitfrage nimmt. Die kurze Amtszeit von Alexander V. war durch schwankende Machtverhältnisse in Süditalien und harte Auseinandersetzungen zwischen dem mit den französischen Anjou koalierenden Pontifex und dem neapolitanischen König im Kampf um Sizilien und Neapel geprägt. Der Papst suchte seine Macht mit Hilfe von Frankreich auszuweiten, von Neapel wurde er jedoch nicht anerkannt. Im Gegenteil, der Kirchenstaat befand sich zu dieser Zeit in den Händen von König Ladislaus von Neapel, den der Papst mit dem Bann belegte und gegen den er mit der Hilfe von Ludwig II. von Anjou militärisch vorging. Des Weiteren entzog er ihm den Anspruch auf den neapolitanischen Thron und wies das Königreich Ludwig II. zu. Dies geschah zu einem Zeitpunkt, als die Erbfolge des amtierenden, Papst Benedikt XIII. unterstützenden Königs Martin von Aragon, auf dessen Reich Ludwig II. von Anjou ebenfalls Anspruch erhob, durch den Tod seines Sohnes als Herrscher Siziliens gefährdet war und auf den Tod König Martins 1410 ein zweijähriges Interregnum folgen sollte. Die bildliche Glorifizierung des Papstes in dieser historischen Situation könnte darauf gezielt haben, den päpstlichen Anspruch auf die Machtverteilung im südlichen Italien zu propagieren. Zugleich hätte ein Anspruch Marias auf Sizilien und Neapel durch ihre Verwandtschaft mit Staufern wie Anjou angezeigt werden können. Die unklare Identität der gezeigten Könige sowie der Mangel an Informationen zur Stellung und zu Zielen von Maria d'Enghien am neapolitanischen Königshof während ihrer Ehe mit Ladislaus von Durazzo verhindern jedoch vorerst weitere Interpretationen. Die anhaltende Konkurrenz zu Neapel seitens der Feudalfamilie wie deren dauerhafte Unterstützung durch die Franziskaner des Konvents ließe eine gegen Ladislaus gerichtete Botschaft möglich erscheinen. Zur Haltung der Franziskaner vgl. Rosanna Alaggio, Il ruolo dei principi di Taranto nelle vicende del Regno di Napoli, in: Antonio Cassiano/Benedetto Vetere (Hrsg.), Dal giglio all'orso. I principi d'Angiò e Orsini del Balzo nel Salento. Galatina 2006, 117-133, bes. 132f.

191 Zur konfliktreichen Beziehung zwischen den Del Balzo Orsini und den Königen Neapels vgl. Andreas Kiesewetter, Problemi (wie Anm. 157); Alaggio, Ruolo (wie Anm. 190). 
versuch gegen die Krone. Unklar ist die Haltung Marias nach ihrer Eheschließung mit Ladislaus von Neapel.

Auf jeden Fall bezeichnend für die Feudalfamilie der Del Balzo Orsini ist ihre zwischen Konkurrenz und Anlehnung changierende Beziehung zum politischen und künstlerischen Zentrum Neapel, die auch für die Dekoration von S. Caterina prägend wurde und die Kirche zum Zeichen einer neuen Macht im südlichen Apulien werden ließ. So ist das Gebäude einerseits durch zahlreiche Wappen und Epitaphien ausdrücklich als Gotteshaus der Del Balzo Orsini gekennzeichnet und knüpft andererseits an die Kunst der neapolitanischen Königslinie an; zum Beispiel gilt dies für den Apokalypsezyklus, das Sakramentsgewölbe und die Auswahl bestimmter Heiliger.192 Zugleich steht der Marienzyklus gerade in der Familienkapelle ikonographisch in der östlich geprägten Lokaltradition und könnte somit für eine Verbindung der Herrschenden mit dem lokalen Erbe sprechen (Abb. 38). 193

Die gezielte Orientierung an unterschiedlichen ikonographischen und stilistischen Vorbildern und Traditionen mittelitalienischen, neapolitanischen und lokalen Ursprungs ist nicht nur mit der Anstellung verschiedener Künstler und Werkstätten zu begründen, sondern lässt auf ein bewusstes Vorgehen schließen, mit dem die sich im Kirchenprojekt von S. Caterina verquickenden glaubens- und machtpolitischen Interessen von Konvent, Stifterfamilie und Papstkirche

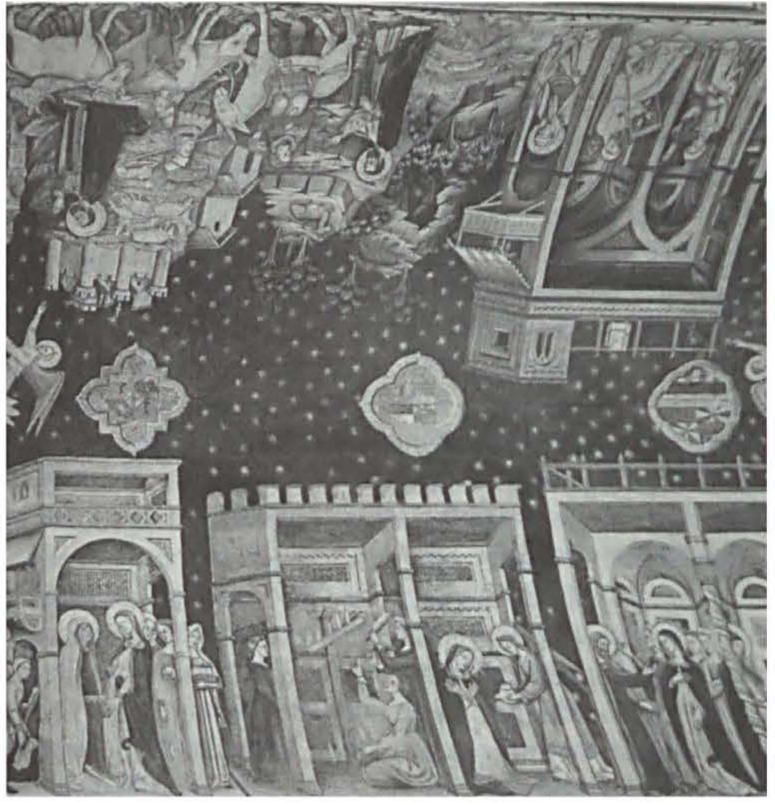

Abb. 38: Galatina, S. Caterina, Südseitenschiff, Familienkapelle, Szenen aus dem Marienleben und Familienwappen (Detail) (Foto: U. Ritzerfeld)

192 Vgl. dazu Zimdars, Ausmalung (wie Anm. 129), 111-139; Belli D'Elia, Principi (wie Anm. 103), 284-294.

193 Mit der Szene des Marientodes mit dem frevelnden Juden wird auf eine ursprünglich aus dem Osten stammende, aber mit der Zeit eingebürgerte Bildtradition zurückgegriffen; vgl. Anm. 89. Ein gewisser Bekanntheitsgrad ist auch für die Thematik weiterer, von orientalischen Apokryphentexten inspirierter Episoden des Zyklus der Familienkapelle in S. Caterina zu vermuten. So sind beispielsweise Szenen der Flucht nach Ägypten nach dem Pseudo-Matthäus bereits in einem Fenster in Chartres dargestellt. Zudem ist zu berücksichtigen, dass Apokryphentexte aus dem Osten vom 12. Jahrhundert an in westliche Legendensammlungen einflossen und über diese große Verbreitung fanden. Vgl. dazu Milella, Parola (wie Anm. 172), bes. 123-133. 
vertreten werden sollten. Das Programm entwickelt im Rückgriff auf franziskanisches Gedankengut ein Bild der Heilsgeschichte, wobei die für die Mönche des Konvents aktuelle missionarische Aufgabenstellung als Leitfaden dient und die Bedeutung des Minoritenordens und seines Gründers im zeitgenössischen und endzeitlichen Kampf gegen das Böse zelebriert wird. Für die bildliche Umsetzung dieser Inhalte zeigt sich vor allem die Orientierung der Del Balzo Orsini am neapolitanischen Königshof verantwortlich, während zusätzliche Elemente die gleichzeitige Konkurrenz zu diesen bezeugen und sie sich in der Familienkapelle in der apulischen Tradition verorten. Sichtbar wird der Anspruch der Familie auf eine Führungsrolle in Apulien und ihre Bedeutung als Förderer der Franziskaner sowie die Tätigkeit des Ordens für die Verbreitung des wahren Glaubens unter Führung bzw. als Führungskräfte der (Papst-)Kirche. ${ }^{194}$

\section{Schlussbetrachtung}

Die politische Dominanz zunächst durch Byzantiner und später durch Normannen und Anjou nahm mit Zuwanderern aus den jeweiligen Heimatgebieten und, besonders in letzterem Fall, aufgrund einer territorialen Reorganisation des Gebiets mit einer mächtig werdende Auftraggeberschicht Einfluss auf die religiöse wie auf die künstlerische Entwicklung in Apulien. Die aus Frankreich kommende Feudalaristokratie agierte in enger Kooperation mit den monastischen Orden, den Benediktinern und später vor allem den der Papstkirche eng verbundenen Franziskanern. Das potenzierte Zusammenwirken der aus den südwesteuropäischen Gebieten einwandernden politischen und religiösen Kräfte musste die apulische, durch ihre byzantinische Vergangenheit geprägte Kunstlandschaft grundlegend verändern. Dabei setzten Monumentalität und Modernität von Kirchenbau und Bildprogramm von S. Caterina in Galatina neue Maßstäbe, die in den folgenden Jahrzehnten für die Region bestimmend blieben. ${ }^{195}$ Die Entstehungsgeschichte und der Werdegang von Konvent und Kirche gibt ein exemplarisches Beispiel für die Interessengemeinschaft von Feudalfamilie, Franziskanerorden und Papsttum, die im Bilddekor des Gebäudes präsentiert wird. Gemeinsames Anliegen war die Stärkung der römischen Kirche und des Minoritenordens vor Ort, die Ausbreitung der katholischen Lehre auf dem Balkan sowie die Konsolidierung der Stellung der Feudalfamilie im Ringen um die religiöse und politische Vormachtstellung im südlichen Apulien. Letztendlich ausschlaggebende Kraft für die Entstehung von Kirche und Konvent und somit auch für Bau und Dekor des Komplexes in Galatina war die feudale

194 Belli D’Elia sieht dagegen eine Zäsur in der Dekoration. Sie nimmt an, dass nach dem Tod Raimondos die Franziskaner ausschlaggebend für die Wahl der Ikonographie wurden, und führt darauf das Erscheinen der Ordensheiligen zwischen erstem und zweitem Joch zurück. Das Erscheinen der Familienwappen in allen Jochen belegt jedoch die kontinuierliche Einflussnahme der Del Balzo ebenso wie das Bildprogramm die Einbringung franziskanischer Interessen belegt. Belli D'Elia, Principi (wie Anm. 103), 282f.

195 Traditionell wird die Kirche als Ausgangspunkt für die Kunstentwicklung der Folgezeit gewertet. Z. B. Matteucci, Affreschi (wie Anm. 125), 189. 
Stifterfamilie. Bauform und Ausstattung der Kirche wurde in ihrer Mischung mittelitalienischer, neapolitanischer, apulisch-normannischer und griechisch-byzantinischer Elemente in erster Linie den spezifischen Intentionen der Stifter dienlich gemacht. Deutlich wird die bewusste Kombination verschiedener kultureller Versatzstücke mit spezifischen ideologisch-politischen Aussagen. Bau und Bildprogramm lassen ein Bemühen der herrschenden Feudalfamilie um eine auf den Voraussetzungen des multikulturell geprägten Apuliens aufbauende eigene Identität sichtbar werden. Die aus Frankreich stammenden Del Balzo hatten sich als junge, ortsfremde Dynastie im Salento erst noch zu etablieren. Ihre Vorgehensweise bezeugt ihre autonome Stellung sowie die großflächige Einbeziehung und Verbindung der verschiedenen kulturellen Entitäten und geographischen Territorien. Sie verfolgten eine Reorganisation des Territoriums mit dem Aufbau eines Netzes von Befestigungsanlagen unter Nutzung alter Strukturen sowie der Förderung ekklesialer, monastischer und karitativer Strukturen. ${ }^{196}$ Die breite kulturelle Förderung beinhaltete die Verbreitung des Volgare ebenso wie die Förderung des Griechischen, ${ }^{197}$ die Unterstützung der Mendikanten wie orthodoxer Klöster, die Finanzierung von

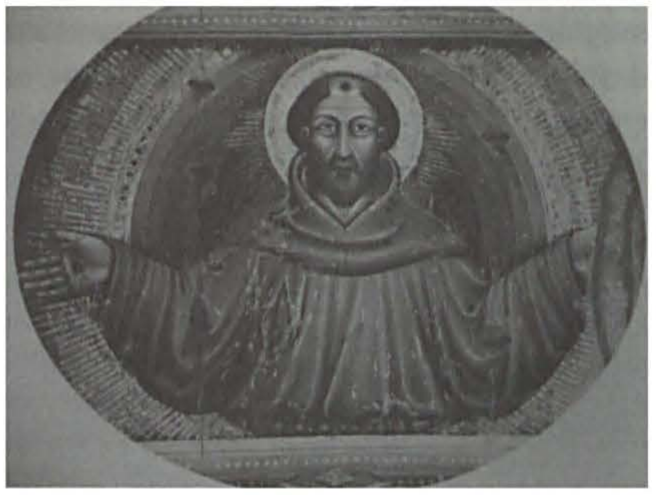

$A b b$. 39: Galatina, S. Caterina, Gurtbogen zwischen erstem und zweitem Mittelschiffsjoch, Hl. Franziskus (nach Cassiano/Vetere, Dal giglio all'orso [wie Anm. 103], 240) Kunstwerken in gotischer wie in lokaler Tradition. Im Zusammenfügen diverser künstlerischer und linguistischer Merkmale in $\mathrm{S}$. Caterina in Anlehnung an die normannische und byzantinisch-griechische Vergangenheit wie neapolitanische Gegenwart manifestiert sich die bewusste Kreation eines eigenen kulturellen, die unterschiedlichen Elemente kombinierenden Gepräges, wodurch sich das Fürstentum ein eigenes, vom neapolitanischen Königshof unabhängiges kulturelles Gesicht, eine eigene höfische Identität verleihen konnte.

Die Bestimmung der Kirche als Grablege der Stifter bedingte eine besonders intensive Einflussnahme der Stifterfamilie, wodurch sich das ,Templum Ursinianum '198 von anderen Mendikantenbauten der Region abhebt. Letztere demonstrierten in der Regel weniger die Einwirkung mächtiger Stifterpersönlichkeiten und orientierten sich in Bau und, soweit dies heute noch zu sagen ist, vermutlich auch im Bilddekor an den traditio-

196 Zur Organisation des Territoriums vgl. Cazzato, Imprese (wie Anm. 76).

197 Zur Verbreitung des Volgare vgl. Giancarlo Vallone, Autonomismo orsiniano e volgare salentino, in: Sallentum 4, 1981, 49-59; Coluccia, Lingua e religione (wie Anm. 22), 71-95.

198 So bezeichnete bereits Antonio de Ferraris die Kirche; Antonio de Ferraris detto il Galateo, De situ Japigiae. Basel 1558, 95. 
nellen Formen und Inhalten ihres Ordens, was jedoch die Verwendung einheimischer Motive ursprünglich ,östlicher` Herkunft durchaus nicht ausschloss. Die orthodoxen Klosterkirchen der Region wiederum zeigten sich wohl generell besonders der ursprünglich an der byzantinischen Kunst ausgerichteten lokalen Tradition verbunden, die jedoch mit der Zeit mit ,westlichen" Neuerungen durchsetzt wurde. Demnach sind durchaus spezifische künstlerische Präferenzen der konfessionell unterschiedlichen Auftraggebergruppen nachzuvollziehen. Jedoch handelte es sich dabei nicht um eine gezielte Verdrängung des ,Östlichen“ oder ,Westlichen“. Eine Profilierung mit Hilfe von Kunst ist nicht per se mit exkludierenden Maßnahmen gleichzusetzen. Der Kontakt mit dem religiös und kulturell Anderen mag eine Selbstdefinition vorangetrieben haben, die sich in Kunstwerken manifestieren konnte, was jedoch nicht per se als Protest oder gar als Konflikt angesehen werden kann. ${ }^{199}$ Zudem ist eine kulturelle und künstlerische Abgrenzung in Apulien nicht die Regel. Charakteristisch ist vielmehr eine im Laufe der Zeit verstärkt auftretende Annäherung, Vermischung und Vereinnahmung neuer Elemente unterschiedlichster Herkunft. Diese Tendenz zeigt sich gerade im Umfeld der Franziskaner, personifiziert in der Gestalt ihres Gründers. Dieser wurde nicht nur, wie in S. Caterina nachzuvollziehen ist, als zentraler Heilsvermittler innerhalb der katholischen Kirche angesehen. In der Person des Hl. Franziskus ergab sich (und besteht bis heute) darüber hinaus die Möglichkeit einer Überbrückung der konfessionellen Unterschiede.200 Die von Franziskus vertretene Mystik, sein Verständnis des Mönchstums und die Bedeutung des Gehorsams machten ihn zum ,einzigen katholischen authentisch orthodoxen" Heiligen.201 Dass diese Charakteristiken auch im Salento auf Gegenliebe stießen, zeigt sich im lokalen Festkalender. Obwohl Franziskus von der Ostkirche nicht offiziell als Heiliger anerkannt war, wurde sein Festtag dort in den liturgischen Kalender aufgenommen. ${ }^{202}$ Die auffällig zahlreichen Darstellungen des Ordensheiligen in den Höhlenkirchen Apuliens bestätigen seine allgemeine, über die Grenzen der katholischen Kirche hinausreichende und bis heute anhaltende Verehrung in Apulien, wo „(n)on v'è città che non lo ricordi (...)“ (vgl. Abb. 5, 7, 39, Ta-

199 Vgl. dazu die Situation im mittelalterlichen Griechenland. Hirschbichler, Monuments (wie Anm. 101), 206.

200 Zur Verehrung des Hl. Franziskus in der orthodoxen Kirche vgl. Yannis Spiteris, Francesco e l'Oriente cristiano, un confronto. Rom 1999; Marta Stetsko, L'impegno ecumenico dell'ordine dei frati minori: nell'opera di evangelizzazione dei territori dell'ex Unione Sovietica. Venedig 2003, 21-52.

201 So definiert in Spiteris, Francesco (wie Anm. 200), 27. Thaddée Matura, La visione teologica di Francesco d'Assisi e la sua affinità con la teologia ortodossa, in: San Francesco e la cultura russa (Tagung, Sankt Petersburg, 18.-19.9.1996). (Quaderni di Studi Ecumenici, Bd. 2.) Venedig 2001, 75-88.

202 Danieli, Rito Greco (wie Anm. 25), bes. 101. Zu dem wohl im 15. Jahrhundert in Galatone geschriebenen liturgischen Offizium zu Ehren des Heiligen zuletzt Anna Gaspari, Francesco d'Assisi: un santo venerato anche dalla chiesa bizantina? Il „caso“ del manoscritto Galat. 4, in: Archivum Francescanum Historicum 101, 2008, 155-180. 
fel VI 10) ${ }^{203}$ Gerade in der Person des Franziskus zeichnet sich eine Annäherung der unterschiedlichen Konfessionen und Sprachgemeinschaften im liturgischen und religiösen Leben, eine gewisse konfessionelle Osmose im alltäglichen Miteinander der Menschen ab. Die Popularität des Heiligen musste der Verbreitung und Einflussnahme seines Ordens förderlich sein. Seine Brückenfunktion eröffnete den Minoriten besondere Möglichkeiten im interreligiösen Miteinander Apuliens. Selbst wenn einige Quellen von Auseinandersetzungen zwischen Franziskanern und ,Griechen' berichten bzw. die religiös-kulturellen Gräben offiziell aus politischen Gründen gewollt zelebrieren - im religiösen Alltag musste eine friedliche Annäherung über die Gestalt des Ordensheiligen erfolgversprechender als jegliche Form der Konfrontation sein. Dass dieses Vorgehen erfolgreich war, zeigt die fast ausschließliche Verehrung mendikantischer, hauptsächlich franziskanischer, Mönche in Apulien im Quattrocento.204 Die Bettelorden und vor allem die Franziskaner veränderten grundlegend das religiöse Leben und auch die Sehkonventionen der Region.

203 So Saverio La Sorsa, Il culto di S. Francesco in Puglia, in: Lares 10, 1939, 102-126, hier 102. $\mathrm{Zu}$ Themen in der Malerei der Höhlenkirchen vgl. Klaus-Rainer Althaus, Die Apsidenmalereien der Höhlenkirchen in Apulien und in der Basilikata. Ikonographische Untersuchungen. Hamburg 1997.

204 Salvatore Palese, Geografia della santità pugliese nel XV secolo, in: Rivista di scienze religiose $6,1992,83-96$, bes. 90 . 
Tafel VI
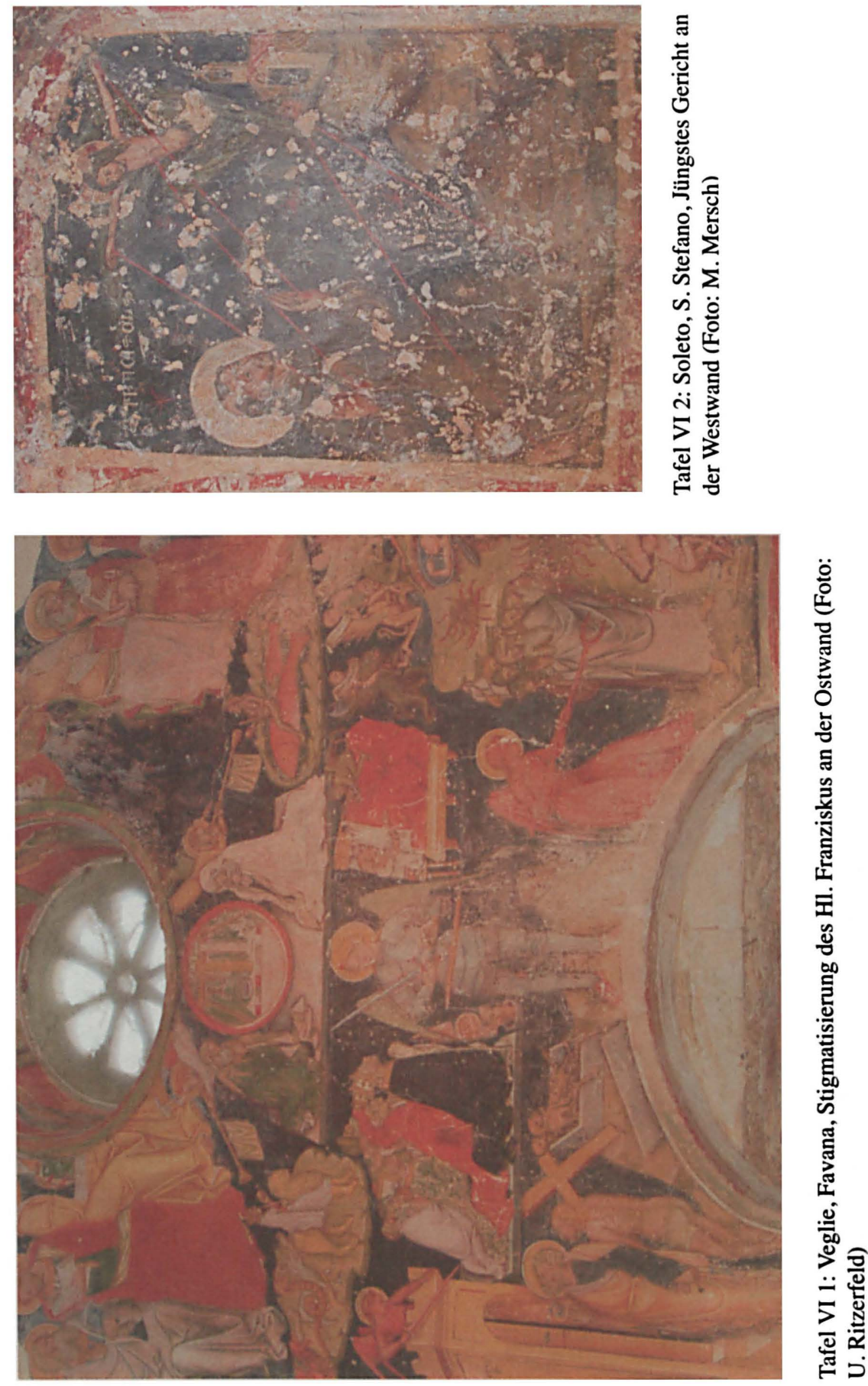
Tafel VI
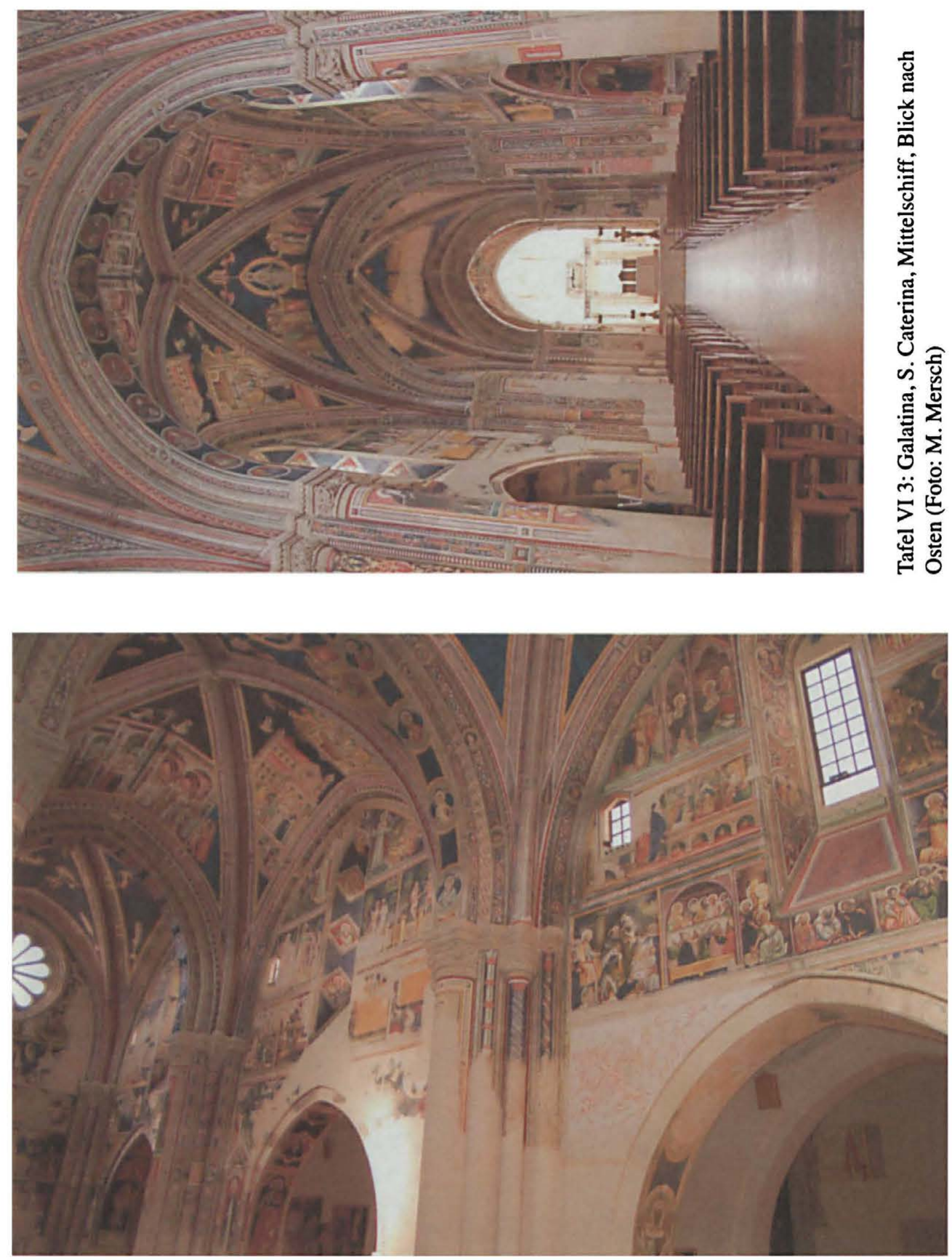

Tafel VI 4: Galatina, S. Caterina, Mittelschiff (Foto: M. Mersch) 
Tafel VI
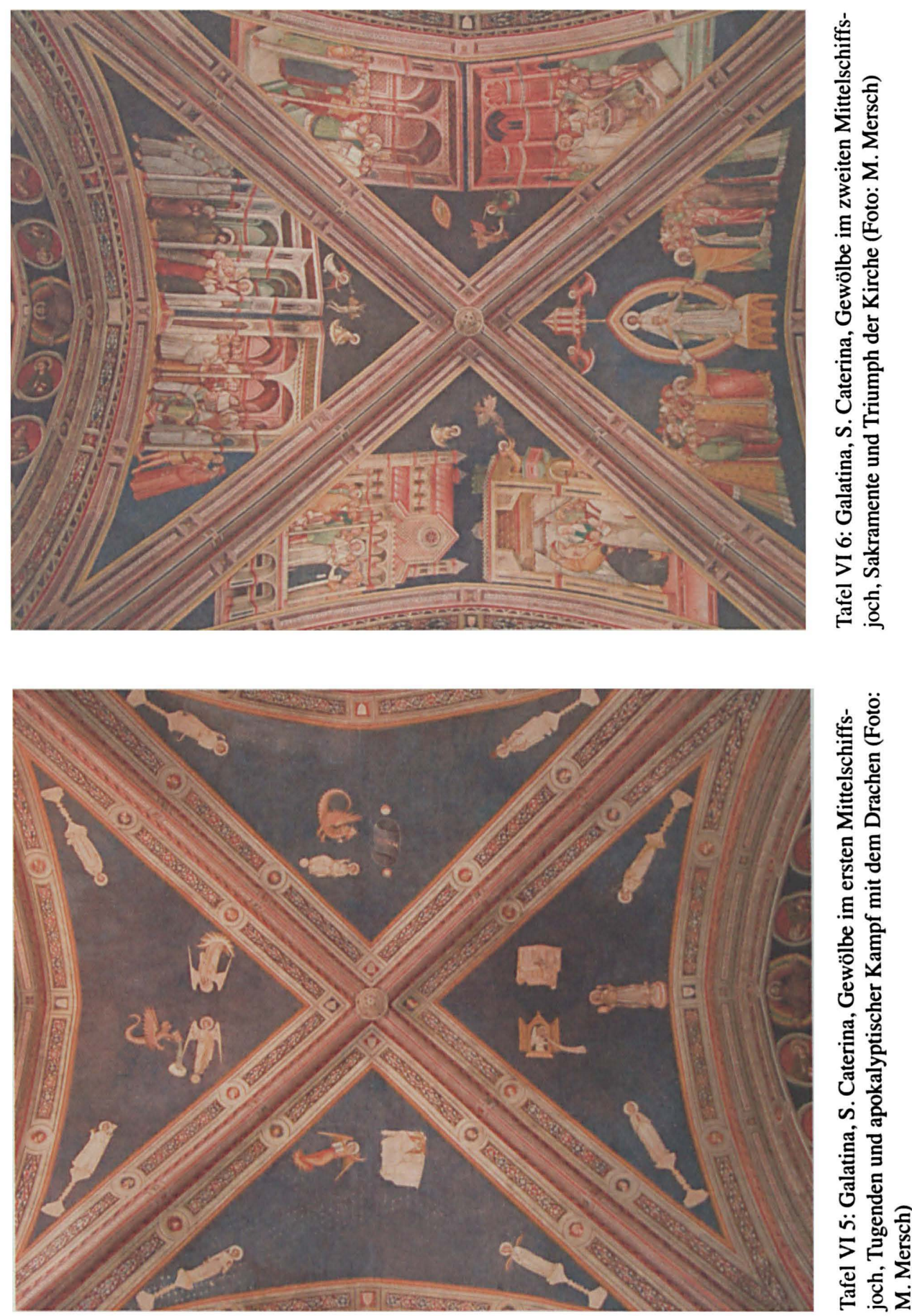
Tafel VI

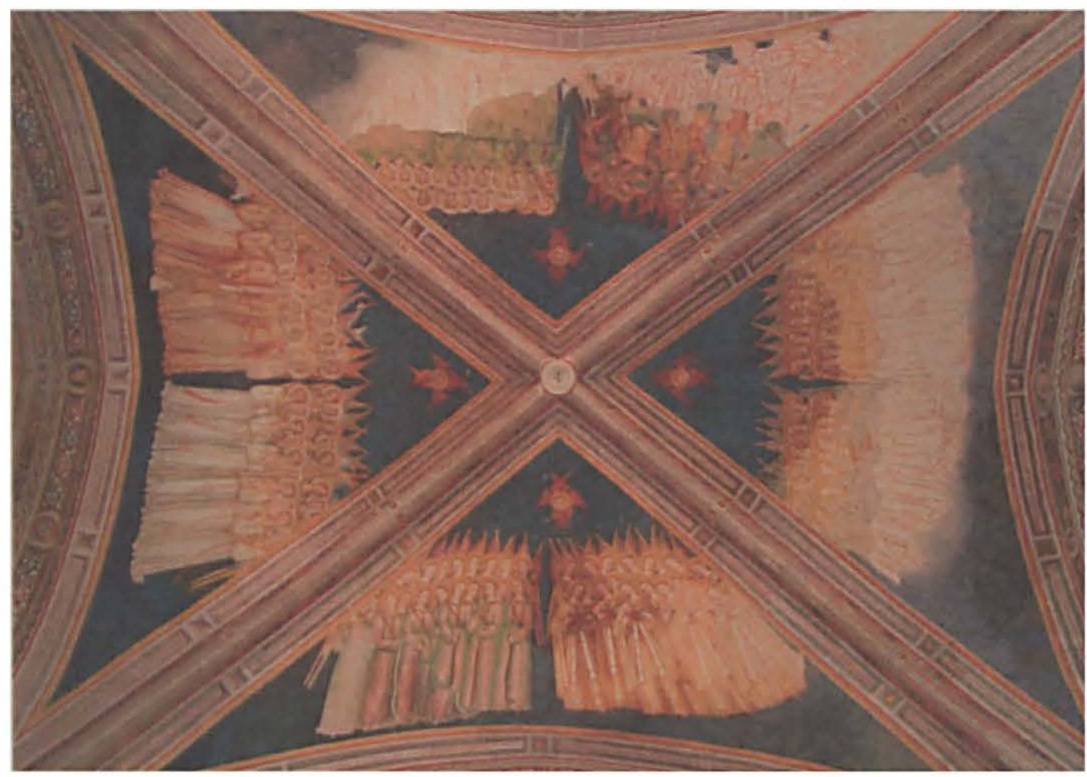

Tafel VI 7: Galatina, S. Caterina, Gewölbe im dritten Mittelschiffsjoch, Himmelshierarchien (Foto: M. Mersch)

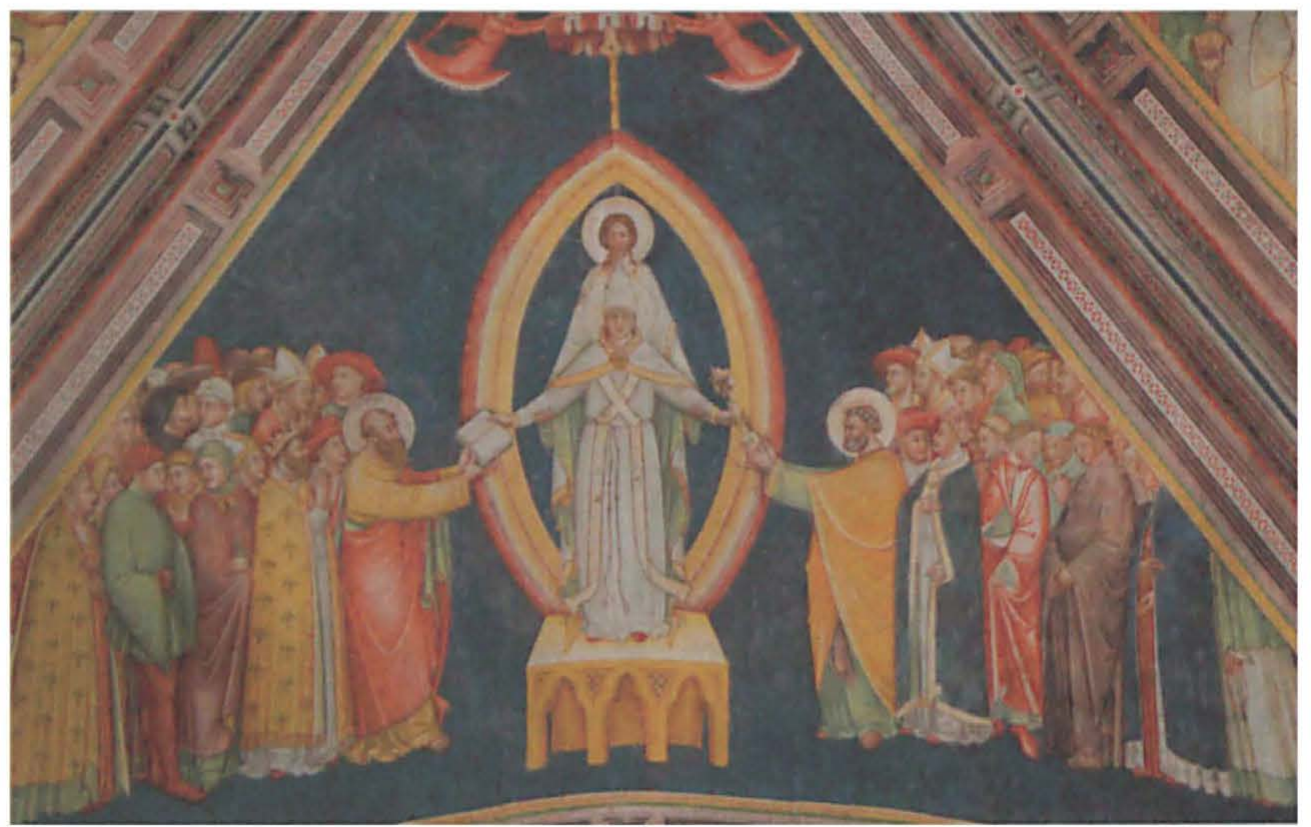

Tafel VI 8: Galatina, S. Caterina, Gewölbe im zweiten Mittelschiffsjoch, Triumph der Kirche (Foto: M. Mersch) 
Tafel VI
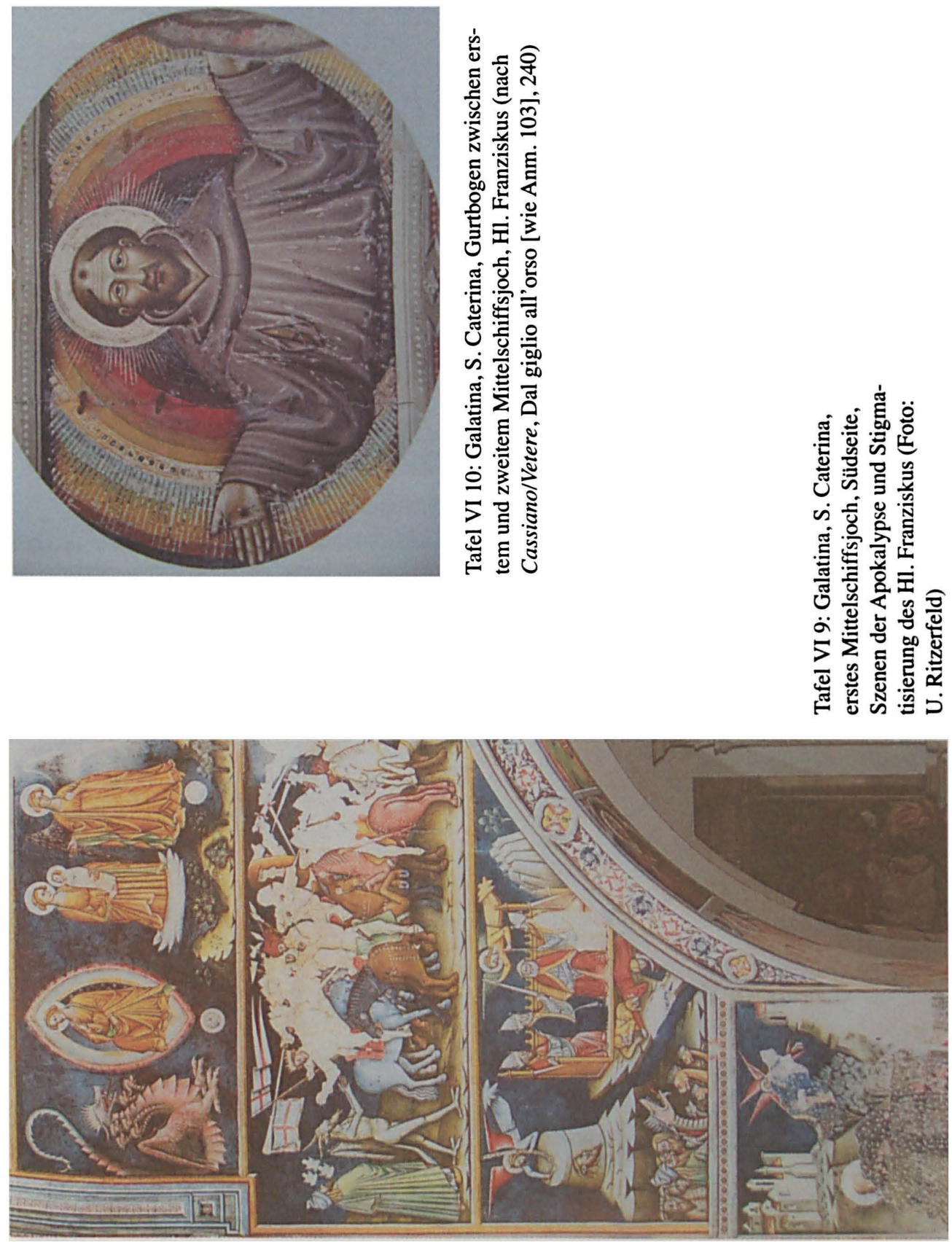